\title{
The microbial side of soil priming effects
}

\author{
Domenico Paolo Di Lonardo
}




\section{Thesis committee}

\section{Promotor}

Prof. Dr W. de Boer

Special Professor Microbial Soil Ecology, Wageningen University \& Research Netherlands Institute of Ecology, Wageningen

\section{Co-promotor}

Dr A. van der Wal

Project Leader

National Institute for Public Health and the Environment, Bilthoven

\section{Other members}

Prof. Dr W.H. van der Putten, Wageningen University \& Research

Prof. Dr G.A. Kowalchuk, Utrecht University

Dr J.T. Weedon, VU Amsterdam

Dr K.J. van Groenigen, University of Exeter, UK

This thesis was conducted under the auspices of the C.T. de Wit Graduate School for Production Ecology \& Resource Conservation (PE\&RC) 


\title{
The microbial side of soil priming effects
}

\author{
Domenico Paolo Di Lonardo
}

Thesis

submitted in fulfilment of the requirements for the degree of doctor at Wageningen University

by the authority of the Rector Magnificus,

Prof. Dr A.P.J. Mol, in the presence of the

Thesis Committee appointed by the Academic Board to be defended in public

on Friday 12 April 2019 at 11 a.m. in the Aula. 


\section{Domenico Paolo Di Lonardo}

The microbial side of soil priming effects

148 pages

PhD thesis, Wageningen University, Wageningen, the Netherlands (2019)

With references, with summary in English

ISBN: 978-94-6343-588-8

DOI: https://doi.org/10.18174/470122 
Cedit item retro, de terra quod fuit ante, in terras

(What once sprung from earth sinks back into the earth)

Lucretius - De Rerum Natura 


\section{Table of contents}

$\begin{array}{ll}\text { Abstract } & 9\end{array}$

Chapter 1

General introduction

Chapter 2 Priming of soil organic matter: chemical structure of added compounds is more important than the energy content

Chapter 3

Chapter 4

Chapter 5

Chapter 6

List of references

Summary

Acknowledgements

Relationship between home-field advantage of litter decomposition and priming of soil organic matter

Effect of the amount of organic trigger compounds and soil microbial biomass on the magnitude of priming of soil organic matter

Effect of nitrogen on fungal growth efficiency

General discussion

101

109

139

About the author 


\section{Abstract}

Priming effects (PEs) are defined as short-term changes in the turnover of soil organic matter (SOM) caused by the addition of easily degradable organic compounds. The direction (positive / negative) and magnitude of PEs in response to organic carbon additions are not easy to predict. Yet, PEs are considered to be large enough to influence ecosystem carbon fluxes. The main aim of this thesis is to increase the understanding of the mechanisms involved in soil PEs, with a particular focus on the role of the quantity and quality of added organic substrates, the size of the soil microbial biomass, the soil microbial community structure and mineral nitrogen availability.

The major conclusions are:

(1) The degree of resemblance of the chemical structure of the added organic compounds to SOM is an important factor in PEs.

(2) PEs are more influenced by trigger substrate concentrations than by the size of the microbial biomass.

(3) Triggering of PEs in soils by litter is not only influenced by litter quality but also by the ability of the soil microbial communities to decompose it (home field advantage for PEs).

(4) High nitrogen availability can stimulate fungal biomass production but has little effect on PEs.

The implications of these results for local and global $\mathrm{C}$ and $\mathrm{N}$ dynamics are discussed. 


\section{Chapter 1}

General introduction 
The decomposition of soil organic matter (SOM) is one of the most important processes influencing the global carbon $(\mathrm{C})$ cycle, the physico-chemical characteristics of soils, the mineralization of nutrients for plant growth and soil food webs. Recently, it was estimated that under the current climate change scenario a loss of on average 55 petagrams of $\mathrm{C}$ from the upper soil horizons would occur by 2050 (Crowther et al., 2016). Decomposition of SOM by soil organisms can be accelerated by warming, generating a positive feedback that could further increase global warming. Even though this estimate needs further investigation (van Gestel et al., 2018), it is clearly important to understand the turnover of organic matter in soils since it plays a crucial role in soil ecosystem functioning and climate change.

SOM is a mixture of partially decayed residues of plants, soil fauna and soil microorganisms and compounds, such as humic substances, which represent modified by-products of decomposition (Schmidt et al., 2011). Understanding the mechanisms that are involved in formation of stable SOM could help to formulate practices for proper soil management leading to enhanced carbon sequestration. Three major factors of SOM stabilization have been proposed: 1) physical stabilization, for instance formation of clayorganic matter aggregates, which hamper the accessibly of SOM by microbial decomposers, 2) chemical stabilization due to chemical modifications leading to poorly degradable compounds, such as polyaromatic substances and 3) structural inherent recalcitrance of certain organic materials, such as lignin, resistant to microbial degradation (Mikutta et al., 2006). In addition, a fourth mechanism was proposed, namely the scarcity of easily degradable energy sources (labile $\mathrm{C}$ ) which prevents microbial decomposition of the stable organic carbon pool, commonly indicated as the priming effect (PE) (Fontaine et al., 2007). Priming effects could also play a role during decomposition of lignin-rich plant residues as it has been shown that decomposition of such residues only occurred when easily decomposable carbon sources were available (Klotzbücher et al., 2011). Hence, it appears that the availability of "labile C" is an important factor in the decomposition or stabilization of SOM.

\section{Definition of priming effects}

Priming effects (PEs) are defined as short-term changes in the turnover of SOM caused by the addition of easily degradable organic carbon (e.g. plant residues, root exudates, excretes of soil animals) to the soil (Blagodatskaya et al., 2007; Hamer and Marschner, 2002; Kuzyakov et al., 2007; Wu et al., 1993). PEs are known for a long time (Löhnis, 1926) and are considered large enough to influence ecosystem carbon balances since they can suppress or stimulate up to $50 \%$ and $400 \%$ of SOM decomposition, respectively (Broadbent and Norman, 1947; Wieder et al., 2013; Zhu et al., 2014). Kowalchuk (2012) suggested that PEs could be taken into account as a strategy for the degradation of 
organic pollutants, as the stimulation of microbes by the addition of easily degradable organic material can lead to increased pollutant degradation (Megharaj et al., 2011). In addition, studies on mechanisms of PEs are suggested to be important for the evaluation of strategies promoting $\mathrm{C}$ sequestration in soils, in order to mitigate the atmospheric $\mathrm{CO}_{2}$ levels (Guenet et al., 2018).

PEs affecting $\mathrm{C}$ and $\mathrm{N}$ cycling are categorized into four classes (Kuzyakov et al., 2000): positive real, negative real, positive apparent, and negative apparent. The distinction between positive and negative PEs refers to induced acceleration or retardation of SOM decomposition, respectively. The distinction between real and apparent PEs is based on the origin of the extra respired $\mathrm{CO}_{2}$ released from the soil when an easily degradable compound is added. In apparent PE the increased $\mathrm{CO}_{2}$ originates from the turnover of microbial biomass, (in particular intracellular storage materials), and in real PE it is due to the decomposition of SOM (Blagodatskaya and Kuzyakov, 2008).

Mainly two approaches to measure PEs are followed (Kuzyakov and Bol, 2006):

1) Without the use of added labeled $\mathrm{C}$, a comparison is made of $\mathrm{SOM}$-derived $\mathrm{CO}_{2}$ from soil with plants or plant residues with that of unplanted or unamended soil (equal to the SOM-derived $\mathrm{CO}_{2}$ ). In this case PE quantifications are based on the natural differences in the ${ }^{13} \mathrm{C}$ to ${ }^{12} \mathrm{C}$ ratios $\left(\delta^{13} \mathrm{C}\right.$ values) between plants with a $\mathrm{C} 3$ photosynthetic pathway and plants with a C4 pathway (Cheng, 1996). Likewise, there are different $\delta^{13} \mathrm{C}$ values between SOM-derived $\mathrm{CO}_{2}$ from the two types of plants. Hence, when C3 plants are grown in a C4-derived soil, the rhizodeposits have a different $\delta^{13} \mathrm{C}$ value than the $\delta^{13} \mathrm{C}$ value of the soil. In other studies rootcontaining and root-free soils were used to estimate root-derived $\mathrm{CO}_{2}$ as the difference between the two (e.g., Saar et al., 2016; Subke et al., 2004). This approach is frequently called the root exclusion technique.

2) The use of added labeled $C\left({ }^{13} \mathrm{C},{ }^{14} \mathrm{C}\right)$ gives the possibility to study PEs by monitoring the release of labeled and unlabeled $\mathrm{CO}_{2}$ which reveals whether the respired $\mathrm{CO}_{2}$ is originating from the added, labeled $\mathrm{PE}$ trigger substrate or from the unlabeled SOM. The amount of ${ }^{12} \mathrm{C}$ and ${ }^{13} \mathrm{C}$ or ${ }^{14} \mathrm{C}$ respired allows to disentangle the decomposition rates of "older" soil organic matter $\left({ }^{12} \mathrm{C}\right)$ from "fresh" substrate $\left({ }^{13} \mathrm{C}\right.$ or $\left.{ }^{14} \mathrm{C}\right)$, respectively (Paterson et al., 2008).

A distinction of the organic carbon inputs can be based on their levels of decomposability and availability in time. Occasional (or pulse) inputs are occurring during the breakdown of microbial, root and animal cells, decomposition of above-ground litter with subsequent leaching of dissolved organic matter (DOM), and root exudation. Because of the easy accessibility to microbes, such inputs produce hotspots of microbial activity in which the turnover rates are much higher than they are outside these zones (Kuzyakov and Blagodatskaya, 2015). Slow decomposition of dead roots, leaf and shoot residues, and 
some rhizodeposits can be considered as continuous sources for microbial activity. In these cases, the substrates are less easily accessible and metabolizable and, therefore, utilized slowly and over longer periods. Because of the recalcitrance of these organic sources, it is likely that the range of extracellular enzymes generated to degrade these organic residues may be more efficient in decomposing SOM than the intracellular enzymes that are used to breakdown the easily available substrates (Fontaine et al., 2003; Mau et al., 2018).

Most studies conducted up to now have investigated PEs with a single addition into soils of different labile trigger substrates, like glucose, malic acid, glycine or cellulose (e.g., Chowdhury et al., 2014; Fontaine et al., 2011; Liu et al., 2018; Whitaker et al., 2014) or have investigated the effect of incorporation of plant residues (e.g., Li et al., 2018; Razanamalala et al., 2018; Sauvadet et al., 2018). In addition, effects of mixtures of labile C and crop residues on PEs have been examined (Shahbaz et al., 2018). The latter represent a situation that is naturally occurring, namely when root exudates are released in soil in combination with an input of dead plant material, such as litter.

\section{Factors controlling priming effects}

The direction (acceleration or retardation of SOM decomposition) and magnitude of priming in response to organic carbon additions are not easy to predict. Several environmental factors are involved, such as the amount and quality of added substrates, the inorganic nutrient availability, soil microbial biomass and soil microbial community composition.

\section{$\underline{\text { Quality of added substrate }}$}

The quality of added substrates, defined by chemical structure complexity and stoichiometry, can have different effects on PE (Guenet et al., 2010; Whitaker et al., 2014). It has been suggested that a high degree of physicochemical similarity between added compounds and SOM fractions will result in a positive priming effect, provided that indigenous soil microbes adapted to decompose SOM are well represented (van der Wal and de Boer, 2017). Since plant litter provides the primary source of SOM formation, it is likely that SOM-degrading microbes are, to some extent, specialized on their substrate. This idea relates to the phenomenon of home-field advantage (HFA), which refers to the fact that plant litter decomposes more rapidly in its own environment than in a foreign environment (Ayres et al., 2009; Gholz et al., 2000).

Moreover, the added compounds differ with respect to the amount of energy that can be used for microbial growth. For instance, the increase of soil microbial biomass has been found to be much higher for glucose than for equimolar amounts of oxalate and phenol 
(Brant et al., 2006). Hence, the quality of the added substrates can also be expressed in terms of the energy that can be used for microbial growth and growth-supporting functions. Limitation in energy for growth-supporting functions (e.g. production of extracellular enzymes) may be constraining microbial decomposers to break down more complex components of SOM (Wild et al., 2014). Therefore, it can be expected that addition of more energy-rich compounds will result in higher positive priming effects.

\section{$\underline{\text { Inorganic nutrient availability }}$}

Positive and negative PEs have also been linked to inorganic nutrient availability, in particular of mineral nitrogen (Cheng et al., 2012; Fontaine et al., 2011). When mineral nitrogen availability is low, a positive PE is expected as soil microbes start mining the SOM to fulfill their nitrogen demand (Dijkstra et al., 2013). Conversely, high nitrogen availability ( $\mathrm{N}$ deposition, symbiotic fixation, fertilization) is expected to coincide with negative a PE as there is no need to invest energy in production of SOM-decomposing enzymes. These mechanisms are known as the "nitrogen mining theory" (Craine et al., 2007; Moorhead and Sinsabaugh, 2006). In contrast, it has been proposed that decomposition of SOM is driven by the stoichiometry of substrates and the microbial demands for energy resources. This is known as the "stoichiometric decomposition theory" (Craine et al., 2007), where microbial activity, and therefore also SOM decomposition, is highest when the $\mathrm{C}: \mathrm{N}$ ratio of the substrate matches the microbial demands (Hessen et al., 2004). Many studies on PEs have included the addition of both $\mathrm{C}$ and $\mathrm{N}$ and they have shown that inclusion of $\mathrm{N}$ can increase (Chowdhury et al., 2014; Koranda et al., 2013; Tian et al., 2016; Wild et al., 2014) or decrease PEs (Chowdhury et al., 2014; Garcia-Pausas and Paterson, 2011; Koranda et al., 2013; Murphy et al., 2015; Tian et al., 2016; Wild et al., 2017). Based on these results it is not possible to indicate which of the two theories is correct. It has been suggested that depending on the availability of soil $\mathrm{C}$ and mineral $\mathrm{N}$ (at different spatial and temporal scales) these two contrasting hypotheses on organic matter decomposition can coexist in the same system and influence the strength and size of PEs (Chen et al., 2014). Furthermore, the $\mathrm{N}$ mining theory was recently challenged (Mason-Jones et al., 2018) since in its current form it cannot represent a universal explanation for PEs.

\section{Soil microbial biomass}

The quantity of soil microbial biomass appears to affect the intensity and direction of PEs (Blagodatskaya and Kuzyakov, 2008; Li et al., 2018; Liu et al., 2017). In a meta-analysis by Blagodatskaya and Kuzyakov (2008), it was shown that the magnitude and direction of priming effects are dependent on the relation between the amount of added trigger 
substrate and the size of the microbial biomass. Their analysis revealed a linear increase in priming with increasing amount of trigger compounds as long as the added $\mathrm{C}$ substrate was less than $15 \%$ of the size of the microbial biomass in the soil. In contrast, when the amount of trigger compounds is increasing from $50 \%$ of the size of the soil microbial biomass an exponential decrease in priming was observed. This decrease in priming with high amount of trigger compounds was suggested to be due to the so called preferential microbial substrate utilization (Cheng and Kuzyakov, 2005; Kuzyakov, 2002), where soil microbes switch to utilize added easily degradable $\mathrm{C}$ sources instead of native soil C. Yet, the aforementioned relationship between microbial biomass and amount of added substrate is not always seen. In fact, different studies reporting positive PEs have used an amount of trigger substrate that was at least $45 \%$ of the soil microbial biomass (MasonJones et al., 2018; Sullivan and Hart, 2013; Whitaker et al., 2014).

\section{The role of soil microorganisms in priming effects}

Microorganisms involved in SOM decomposition have different life strategies reflected in their ability to metabolize different substrates (Ho et al., 2017). These metabolic abilities can play a role in PEs. Several studies have shown that different microbial groups (e.g. fungi, Gram-positive and Gram-negative bacteria) take part in priming (Blagodatskaya et al., 2014; Creamer et al., 2015; Perveen et al., 2014; Whitaker et al., 2014; Xiao et al., 2015). Bacteria show a wide metabolic diversity and often an opportunistic strategy that allow them to rapidly absorb soluble substrates (Fierer et al., 2007). Many filamentous fungi, on the other hand, have generally more oligotrophic features (Blagodatskaya et al., 2014, 2007; de Vries and Shade, 2013; Dungait et al., 2013; Garcia-Pausas and Paterson, 2011; Koranda et al., 2014; Shahzad et al., 2014; Whitaker et al., 2014). Fungi are able to connect sources of easily-available carbon with stable SOM via transport through their hyphae (Boberg et al., 2011). They can also produce a wide range of enzymes (e.g. lignindegrading peroxidases) allowing the degradation of recalcitrant compounds such as those present in SOM. Because of these properties, fungi are thought to be more important in PEs than bacteria (Fontaine et al., 2011). Moreover, as fungi are strongly linked with plant residue decomposition (van der Wal et al., 2013), it is expected that their contribution to PEs induced in the detritusphere is higher than in the rhizosphere (Kuzyakov, 2010). Yet, the importance of fungi in metabolizing rhizodeposits has received attention (Buée et al., 2009). Several studies have shown that soil fungi can receive substantial quantities of plant-derived carbon in the form of root exduates (Butler et al., 2003; Lu et al., 2004) and can quickly respond to these inputs (Broeckling et al., 2008; de Graaff et al., 2010; Hannula et al., 2012). Even though the biomass of saprotrophic fungi in highly managed arable soils is very low (van der Wal et al., 2006), fungi can have an important role in the decomposition of rhizodeposits of crops (Hannula et al., 2012, 2010). 
Microbial enzyme responses to substrate additions may be important to clarify the mechanisms of PE. The enzymes that are produced by the microbial community in order to decompose the added carbon substrates can also be involved in degrading soil organic matter, which can be referred to as co-metabolism (Fontaine et al., 2004b). The higher the chemical diversity of the added carbon sources, the higher will be the diversity of the produced enzymes and the probability that positive PEs will occur (Mason-Jones et al., 2018). Furthermore, the analysis of SOM-degrading enzyme activities has been used to differentiate real and apparent priming (Wild et al., 2017). Carbon inputs that induce PEs can activate the microbial synthesis of intracellular and extracellular enzymes (Marinari et al., 2000). The increase of intracellular enzyme activity without any increase in extracellular enzyme activities may be involved in apparent PE caused by the activation of the internal microbial metabolism. Hence, measurements of the type of enzymes activated after adding the trigger substrate might be important to distinguish apparent from real PEs. Soil enzyme activities associated with fungal activity (cellulase, hemi-cellulase, peroxidases and laccase) can occur during real PEs caused by fungal growth. An increase in lignin degrading oxidase and peroxidase activity may indicate real PEs, since lignin is an important component of SOM. Monitoring the intracellular trehalase (glycoside hydrolase enzyme) can help to distinguish apparent PE from real PE. This enzyme is related to the activation of the internal microbial metabolism as trehalose (a non-reducing disaccharide), together with glycogen, is one of the main energy storage compounds of fungi (Deacon, 2006). Likewise, the monitoring of polyhydroxybutyrate (PHB) can be used for bacteria, being a common storage compound for this group of microorganisms (Dijkstra et al., 2015).

Microbial carbon use efficiency (CUE), defined as the ratio of $\mathrm{C}$ invested in growth and total C uptake (Sinsabaugh et al., 2013), is relevant to predict which proportion of the utilized organic $\mathrm{C}$ will be lost via microbial respiration and which proportion potentially persists in soils as organic matter (Bradford et al., 2013; Hagerty et al., 2014). Many of the ecological studies report their results as the mean responses of soil microbial communities (e.g., Dijkstra et al., 2015; Geyer et al., 2018; Koranda et al., 2014; Mooshammer et al., 2014), while only a few have been conducted on individual species (e.g. Allison et al., 2009; Boberg et al., 2008; Lashermes et al., 2016; Song et al., 2012). However, in soil microbial communities many interactions occur, such as competition and predation, making it difficult to have a basic understanding of the relationships between added carbon, microbial biomass production and microbial respiration. In addition, a higher microbial CUE may coincide with a higher or a more diverse production of extracellular enzymes, possibly affecting PEs (Liu et al., 2018; Manzoni et al., 2012). Therefore, a better understanding of microbial CUE in soils is important for a greater comprehension of SOM decomposition as well as in PEs. 


\section{Aim, research questions and outline of the thesis}

The main aim of my thesis research is to increase the understanding of the mechanisms involved in the priming of soil organic matter, with a particular focus on the role of the quantity and quality of added organic substrates, the quantity of soil microbial biomass, the soil microbial community structure and mineral nitrogen availability.

The three general research questions addressed in this thesis are:

1. Are PEs mainly related to mining for nitrogen or availability of energy?

2. Do PEs depend on the resemblance of the physicochemical characteristics of the added organic compounds with those of SOM fractions?

3. How do soil microbial biomass and community structure influence PE?

To address these research questions, different studies were performed that are described in four experimental chapters of this thesis.

Chapter 2 describes the results of a study on the effect of two characteristics of added trigger compounds on PE, namely the metabolic usable energy for microbes and the resemblance to recalcitrant fractions of SOM. Furthermore, in this chapter the response of the microbial community to $\mathrm{C}$ additions as well as the effect of the addition of mineral $\mathrm{N}$ concurrently with $\mathrm{C}$ substrates have been studied.

Chapter 3 reports on the role of physicochemical similarity between added organic compounds and that of soil organic matter fractions in PEs. More specifically, the relationship between home-field advantage of litter decomposition and priming of soil organic matter was investigated. Moreover, in this chapter the addition of mineral $\mathrm{N}$ was used to test the effect on PE, HFA and their relationships.

Chapter 4 investigates the importance of the ratio between amount of added substrate and soil microbial biomass for the magnitude and direction of PEs. This was tested by adding three different amounts of a simple organic trigger compound with or without addition of mineral $\mathrm{N}$ to soils collected from arable lands, grasslands and forests that differ in terms of amount of soil microbial biomass, soil microbial community composition and soil organic matter quality.

Chapter 5 reports on the influence of different concentrations of mineral $\mathrm{N}$ on the growth efficiency of two common soil fungi, Trichoderma harzanium and Mucor hiemalis in a soillike environment.

In chapter 6 I discuss the results obtained in this thesis and place them in a broader context, integrating existing knowledge on PEs with findings of my thesis research. The chapter ends with an outlook on future research directions, including possible implication 
of the results obtained in this research for development of sustainable agricultural management strategies. 


\section{Chapter 2}

Priming of soil organic matter: chemical structure of added compounds is more important than the energy content

D.P. Di Lonardo, W. de Boer, P.J.A. Klein Gunnewiek, S.E. Hannula \& A. van der Wal

Soil Biology and Biochemistry 108 (2017): 41-54

DOI: 10.1016/j.soilbio.2017.01.017 


\begin{abstract}
The addition of easily degradable compounds to soil (e.g. root exudates, plant residues) can result in priming effects (PEs), a short-term change in the turnover of soil organic matter (SOM). Although PEs are recognized to be large enough to be taken into account into the ecosystem carbon balance, the exact mechanisms are still unknown. Here, we examined the effect of two characteristics of added compounds on PEs, namely metabolic usable energy for microbes and resemblance to recalcitrant fractions of soil organic matter (SOM). For this purpose, glucose, cellobiose (energy rich compounds, low resemblance with recalcitrant SOM) and vanillic acid (energy-poor compound, higher resemblance with recalcitrant SOM) were selected. In addition the effect of mineral nitrogen (N) on PEs was tested. ${ }^{13} \mathrm{C}$ labelled compounds were mixed with sandy soil from an ex-arable site. To separate the effect of energy content from that of resemblance to SOM, the amount of carbon and the amount of energy content of added compounds was kept constant in treatments, respectively. The community structure of microbes that were able to use added compounds was evaluated using stable isotope probing (DNA-SIP) combined with qPCR and Illumina sequencing.
\end{abstract}

When corrected for energy content, vanilic acid induced the highest $\mathrm{CO}_{2}$ respiration and PE. DNA-SIP revealed that bacterial classes like $\beta$ - and $\gamma$-Proteobacteria, that are known to harbour many opportunistic bacteria, responded quickly $(5 \mathrm{~h})$ with incorporation of ${ }^{13} \mathrm{C}$ from added substrates, whereas classes like Acidobacteria and Actinobacteria responded over a longer incubation time. In treatments where the energy-level of added compounds was kept constant, vanillic acid caused an increase in DNA copy numbers of bacteria and fungi using native SOM after prolonged incubation. The contribution of fungi to PEs was minor, reflecting the low $\mathrm{F}: \mathrm{B}$ ratio of the soil used for the experiment. Different substrates resulted in different PEs but appeared to stimulate the growth of similar bacterial groups. This suggests that the added compounds stimulate different enzyme systems within similar bacterial taxa. Although combined addition of mineral nitrogen (ammonium nitrate) and organic compounds caused a slightly extra increase in PEs in most treatments, this might be an artefact as addition of mineral $\mathrm{N}$ only decreased respiration. Overall our results indicate that the effect of chemical structure of added compounds on PE is much larger than the effect of energy-content. 


\section{Introduction}

The addition of easily degradable compounds (e.g. root exudates, plant residues) to soil can result in priming effects (PEs), defined as a short-term change in turnover of soil organic matter (SOM) (Blagodatskaya et al., 2007; Hamer and Marschner, 2002; Kuzyakov et al., 2007; Wu et al., 1993). PEs can be positive (acceleration of SOM decomposition) but also negative (retardation of SOM decomposition) (Kuzyakov et al., 2000). PEs can be classified as real or apparent, and the distinction is based on the origin of the extra $\mathrm{CO}_{2}$ released from the soil. In apparent PEs the increased $\mathrm{CO}_{2}$ originates from the turnover of microbial compounds such as reserve materials, whereas in real PEs it is due to the decomposition of SOM (Kuzyakov et al., 2000). This process is considered large enough to influence ecosystem carbon balance as PEs generated by living roots can suppress or stimulate up to $50 \%$ and $400 \%$ of SOM decomposition, respectively (Wieder et al., 2013; Zhu et al., 2014).

The amount and quality of added substrates can influence the direction and magnitude of PEs. It has been suggested that the added compounds can trigger the microbial production of extracellular enzymes which decompose fractions of SOM, especially when the added substrate resembles compounds present in SOM (Fontaine and Barot, 2005). It has also been suggested that a limited inorganic nitrogen $(\mathrm{N})$ availability can influence PEs by stimulating microbes to mine for N in SOM (Dijkstra et al., 2013). According to the latter theory, addition of substrates with high $\mathrm{C}: \mathrm{N}$ ratio will stimulate positive PEs. Furthermore, both microbial biomass and microbial community structure appear to affect the intensity and direction of PEs (Blagodatskaya and Kuzyakov, 2008). Differences in capabilities of microbial species to decompose different fractions of SOM are suggested as possible explanation for this effect (Fontaine et al., 2011, 2003).

Recently it was suggested how two competing hypotheses on organic matter decomposition, namely "microbial stoichiometric theory" (Craine et al., 2007; Hessen et al., 2004) and "nitrogen mining theory" (Craine et al., 2007; Moorhead and Sinsabaugh, 2006), can coexist in the same system and influence the strength and size of PE (Chen et al., 2014). Chen et al. (2014) propose that the contribution of microorganisms to SOM decomposition is controlled by mineral $\mathrm{N}$ availability and their growth strategies: under low-N availability K-strategists were predominant (nutrient mining theory), whereas $\mathrm{r}$ strategists played a more important role with high- $\mathrm{N}$ availability (stoichiometry theory).

SOM is a mixture of partially decayed plant residues, soil microorganisms and soil fauna, by-products of decomposition and humic substances (Schmidt et al., 2011). Three major factors of SOM stabilization have been proposed: 1) physical stabilization, 2) chemical stabilization and 3) structural inherent recalcitrance of specific organic molecules (Mikutta et al., 2006). In addition, a fourth mechanism was proposed, namely the scarcity of "fresh 
C" which prevents microbial decomposition of the stable organic carbon pool, representing PE (Fontaine et al., 2007). Recently it has also been shown that decomposition of recalcitrant, lignin-rich plant residues only occurs when easily decomposable carbon sources are available (Klotzbücher et al., 2011). Taken together, it is clear that decomposition of SOM is highly controlled by the availability of "fresh C".

During the biological breakdown (oxidation) of SOM, small water-soluble compounds are released and these are energy sources for the growth of microorganisms. Compounds differ with respect to the amount of energy that can be used for growth. For instance, the increase of soil microbial biomass has been found to be much higher for glucose than for equimolar amounts of oxalate and phenol (Brant et al., 2006). Hence, the quality of the added substrate can also be expressed in terms of the energy that can be used for microbial growth and growth-supporting functions. Limitation in energy for growthsupporting functions (e.g. production of extracellular enzymes) may be constraining microbial decomposers to break down more complex components of SOM (Wild et al., 2014). Therefore, it can be expected that more energy-rich added compounds would result in higher positive priming effects.

Several studies have shown that different microbial groups (e.g. fungi, Gram-positive and Gram-negative bacteria) take part in PEs (Blagodatskaya et al., 2014; Creamer et al., 2015; Perveen et al., 2014; Xiao et al., 2015). Bacteria show a wide metabolic diversity and often an opportunistic strategy that allow them to rapidly absorb soluble substrates. Fungi, on the other hand, are able to connect sources of easily-available carbon with stable SOM via transport through their hyphae (Boberg et al., 2011). They can also produce a wide range of enzymes (e.g. lignin-degrading peroxidases) allowing the degradation of recalcitrant compounds such as those present in SOM. Because of these properties fungi are thought to be more important in PEs than bacteria (Fontaine et al., 2011).

In the present study we will address the following hypotheses: 1) a positive PE increases when the availability of energy for microbial growth increases 2) positive PE will also increase with increasing availability of the added compounds that resemble fractions of recalcitrant SOM, 3) fungi are more important than bacteria in causing PEs and 4) addition of mineral $\mathrm{N}$ will negatively affect PEs. To test these hypotheses, three ${ }^{13} \mathrm{C}$-labelled substrates, namely glucose, cellobiose and vanillic acid, were added to natural grassland soil in a mesocosm approach. Glucose and cellobiose represent energy rich compounds with low resemblance to recalcitrant SOM, whereas vanillic acid represents an energypoor compound with higher resemblance to recalcitrant SOM. We measured soil respiration and changes in the microbial community to provide a better understanding of the underlying mechanisms of PE and the role played by the microbes. 


\section{Materials \& Methods}

\section{Soil sampling and processing}

In March 2014 soil $(0-10 \mathrm{~cm})$ was collected in Dennenkamp, a former arable site that has developed into a natural grassland (van der Wal et al., 2006). The site is located in the central part of the Netherlands ( $52^{\circ} 01^{\prime} 43^{\prime \prime}$, E $\left.005^{\circ} 48^{\prime} 2 "\right)$. The soil is a sandy soil with a disturbed profile due to former agricultural activities and can be classified as a Typic Haplorthod (US soil taxonomy) (van der Wal et al., 2007). The fungal: bacterial ratio is 0.06 (based on PLFA analysis) and C:N ratio of 19.90 (Table 1). In the laboratory, fresh soil was sieved $(4 \mathrm{~mm})$ and homogenized, removing fine roots and other plant debris. Field-moist soil was then stored at $4{ }^{\circ} \mathrm{C}$ until further use.

Table 1: Edaphic and biological properties of the soil $(0-10 \mathrm{~cm})$. Edaphic properties are from Van der Wal et al. 2006, while biological data are from two different sampling times 2003 (van der Wal et al., 2006) and 2012 (Morriën et al., 2017). Values from the different years are separated by a slash. Bacterial biomass was calculated using the average of the PLFA data converted in $\mathrm{mg} \mathrm{C} / \mathrm{g}$ soil according to the conversion factors reported in

\begin{tabular}{|c|c|c|c|c|c|c|c|c|c|c|c|}
\hline $\begin{array}{l}\text { Abandoned } \\
\text { from } \\
\text { agriculture }\end{array}$ & $\begin{array}{c}\text { Former } \\
\text { crop }\end{array}$ & $\mathrm{pH}$ & $\underset{(\mathrm{g} / \mathrm{kg})}{\mathrm{C}}$ & $\begin{array}{l}\mathrm{C}: \mathrm{N} \\
\text { ratio }\end{array}$ & $\begin{array}{c}\% \\
\text { Sand } \\
>53 \\
\mu \mathrm{m}\end{array}$ & $\begin{array}{c}\text { Soil } \\
\text { texture }\end{array}$ & $\begin{array}{c}\text { Bacterial } \\
\text { PLFA } \\
\text { (nmol/g } \\
\text { soil) }\end{array}$ & $\begin{array}{c}\text { fungal } \\
\text { PLFA } \\
\text { (nmol/g } \\
\text { soil) }\end{array}$ & fungal/bacterial & $\begin{array}{c}\text { Ergosterol } \\
\text { content } \\
(\mathrm{mg} / \mathrm{kg})\end{array}$ & $\begin{array}{c}\text { Microbial } \\
\text { biomass } \\
\text { (mg C/g } \\
\text { soil) }\end{array}$ \\
\hline 1982 & $\begin{array}{c}\text { Rye, } \\
\text { potatoes, } \\
\text { asparagus }\end{array}$ & 5.60 & 34.30 & 19.90 & 86.2 & $\begin{array}{c}\text { Sand / } \\
\text { coarse } \\
\text { sand }\end{array}$ & $\begin{array}{c}39.84 / \\
42.09\end{array}$ & $\begin{array}{c}2.56 / \\
2.38\end{array}$ & $0.064 / 0.057$ & $1.36 / 1.03$ & 0.235 \\
\hline
\end{tabular}

\section{Estimation of microbial usable energy released by the priming substrates}

For the purpose of our study it is important to know how much of the available energy in substrates is actually converted into microbial biomass. This means that also loss of energy, such as due to maintenance costs, has to be included. Therefore, we determined microbial biomass yield for the three selected substrates (glucose, cellobiose and vanillic acid) and used that as a proxy for microbial usable energy instead of theoretical energy availability such as given by Gibbs free energy or possible ATP production based on catabolic pathways. Glucose is a common component in dissolved organic carbon and root exudates (Strickland et al., 2012), cellobiose is the structural unit that is repeated in cellulose, the most abundant polymer in plants (Martínez et al., 2005) and vanillic acid is a lignin-related phenolic compound (Milstein et al., 1983).

Five saprotophic fungi (Mucor hiemalis, Trichoderma harzianum, Aspergillus niger, Hypholoma fasciculare, Marasmius androsaceus) belonging to different phyla and functional groups were selected to estimate the amount of energy available for biomass production. Fungal strains were grown on $2 \%$ malt extract agar. A plug of agar $(6 \mathrm{~mm}$ diameter) was added to a liquid medium used for biomass production tests.

Bacterial species were extracted from the same soil as used for the mesocosm experiments. The soil suspension was prepared by dispersing $10 \mathrm{~g}$ of fresh soil in $100 \mathrm{ml}$ 
of sterile demi water, shaking it for 1 hour. Next, the solid particles were allowed to settle for two hours and the supernatant was collected and filtered through Whatman filters papers with pore diameter $3 \mu \mathrm{m}$ to remove suspended soil particles and most fungal hyphae (Rudnick et al., 2015).

The liquid medium used for biomass production tests was composed as follows $\left(\mathrm{g} \mathrm{L}^{-1}\right)$ : $\mathrm{KH}_{2} \mathrm{PO}_{4} 0.10$, yeast extract $0.01,\left(\mathrm{NH}_{4}\right)_{2} \mathrm{SO}_{4} 0.20$, the buffering compound MES (2-(Nmorpholino) ethanesulfonic acid) 1.952 and carbon source (glucose, cellobiose or vanillic acid) $0.5 \mathrm{~g}$. The $\mathrm{pH}$ was adjusted to 6 before autoclaving. For both bacterial and fungal tests 5 replicates for each treatment were prepared.

We measured the biomass production after two weeks of incubations as no further increase of biomass was observed. Fungal hyphae were filtered on pre-cleaned (with demi water) glass fiber filters (WhatmanTM GF/F, UK) and dried at $60^{\circ} \mathrm{C}$ overnight and the fungal biomass was determined by weighing the dried fungal hyphae. The growth of bacterial biomass was determined via optical density (OD) measurements at $600 \mathrm{~nm}$.

\section{Mesocosm set-up}

$80 \mathrm{~g}$ of fresh weight soil was put into $500 \mathrm{ml}$ glass bottles. The moisture content was adjusted to $60 \%$ of the water holding capacity, and the soil was pre-incubated for an acclimatization period ( 15 days in the dark at $20^{\circ} \mathrm{C}$ ). Soil $\mathrm{CO}_{2}$ efflux rates were regularly checked to confirm stabilization of the soil microbial activity.

The first set of soil samples was treated with the addition of uniformly labeled 99 atom\% ${ }^{13} \mathrm{C}$-glucose (Campro Scientific $\mathrm{GmbH}$ ), ${ }^{13} \mathrm{C}$-cellobiose (Omicrom Biochemicals, Inc.) and ${ }^{13} \mathrm{C}$-vanillic acid (Cambridge Isotope Laboratories, Inc) in a quantity of C equal to $45 \%$ of the microbial biomass carbon (Table 1) (Sullivan and Hart, 2013). We refer to these treatments as "same amount of C" (Table 2). The second set of soil samples was treated with the addition of the same carbon sources but the amount of microbial usable energy was kept constant among treatments (Table 2). Based on the results of the previous growth experiment, a higher amount of vanillic acid than cellobiose and glucose had to be added to the soil to keep the amount of energy available for microbial growth constant between treatments (Table 2). We refer to these treatments as "same amount of energy". Using this approach, we were able to test the effect of differences in energy level between added compounds on PE. For example, vanillic acid may hardly stimulate SOM decomposition compared to glucose in the "same amount of C" treatments, but taken into account the lower energy that is provided by vanillic acid for microbial growth, it may yield similar SOM decomposition compared to glucose in the "same amount of energy" treatments. In that case, we would conclude that the energy-level of trigger compounds is the most important factor explaining the magnitude of PE. 
The third set of soil samples received, besides the carbon sources (treatments included "same amount of C" and "same amount of energy"), also $\mathrm{NH}_{4} \mathrm{NO}_{3}$ amendment. The solution was prepared to give a final C-substrate: $\mathrm{N}$ ratio of 15:1 (Fontaine et al., 2011). Controls were treated in the same way as the substrate-amended soils and consisted of soils without the addition of any carbon source with nitrogen, and soils receiving neither carbon nor nitrogen. Each treatment was replicated 5 times. Soils were incubated at $20^{\circ} \mathrm{C}$ in the dark for 30 days. After 0.2 ( 5 hours), 3 and 13 days (time periods based on the development of total $\mathrm{CO}_{2}$ respiration) of incubation, soil was sampled from each treatment using an ethanol-cleaned tweezer to minimize the disturbance. The samples were frozen prior to DNA extractions.

Table 2: Amount of substrates added to the soil.

\begin{tabular}{lccc}
\hline & \multicolumn{3}{c}{$\mathrm{mg}$ of C-substrate / $\mathrm{g}$ soil } \\
\cline { 2 - 4 } & Glucose & Cellobiose & Vanillic Acid \\
\cline { 2 - 4 } Same amount of carbon & 0.11 & 0.11 & 0.11 \\
Same amount of energy & 0.13 & 0.11 & 0.84 \\
\hline
\end{tabular}

\section{$\mathrm{CO}_{2}$ measurements}

Headspace $\mathrm{CO}_{2}$ was sampled through the lid septa and injected into $5.9 \mathrm{~mL}$ evacuated Exetainer vials (Labco Ltd., Buckinghamshire, UK). An aliquot of the gas samples (20 $\mu$ l for each vial) was directly measured using Ultra GC gas chromatograph (Interscience, The Netherlands) equipped with a flame ionization detector (FID) and at Rt-QBOND (30 $\mathrm{m}, 0.32 \mathrm{~mm}$, ID) capillary column. We used helium as a carrier gas and set oven temperature at $50{ }^{\circ} \mathrm{C}$. While the rest of the samples were sent to the Stable Isotope Facility at the University of California, Davis, where samples were measured for ${ }^{13} \mathrm{C}-\mathrm{CO}_{2}$ using a ThermoScientific GasBench system interfaced to a ThermoScientific Delta V Plus isotope ratio mass spectrometer (ThermoScientific, Bremen, Germany). Samples were taken at $0,0.2$ (5 hours), 1, 2, 3, 4, 5, 7, 9, 11, 13, 17, 19, 21, 25, 30 days of incubation (16 sampling times in total). After each $\mathrm{CO}_{2}$ sampling, the bottles were opened for aeration for 15 minutes.

\section{Priming effect calculations}

The percentage of respired $\mathrm{CO}_{2}$ derived from ${ }^{13} \mathrm{C}$ substrate was calculated for all treatments and sampling times according to the formula:

$$
\% \mathrm{C}_{\text {substrate derived }}=\left[\left(\delta_{\mathrm{C}}-\delta_{\mathrm{T}}\right) /\left(\delta_{\mathrm{C}}-\delta_{\mathrm{L}}\right)\right] \times 100
$$

Where $\delta_{\mathrm{C}}$ is the $\delta^{13} \mathrm{C}$ value of the respired $\mathrm{CO}_{2}$ from control soils, $\delta_{\mathrm{T}}$ is the $\delta^{13} \mathrm{C}$ value in respired $\mathrm{CO}_{2}$ from treated soils and $\delta_{\mathrm{L}}$ is the $\delta^{13} \mathrm{C}$ value of the labelled substrate (Nottingham et al., 2012). Data were expressed in $\mu \mathrm{g} \mathrm{C} \mathrm{g}^{-1}$ soil. Priming effect was then 
calculated as the total respiration in treated soils minus control respiration minus the substrate-derived respiration and expressed in $\mu \mathrm{g} \mathrm{C} \mathrm{g}^{-1}$ soil (Qiao et al., 2016):

$$
\text { Primed } \mathrm{C}=\mathrm{C}_{\text {total }}-\mathrm{C}_{\text {substrate }}-\mathrm{C}_{\text {control }}
$$

\section{DNA extraction and gradient fractionation}

DNA was extracted from soils using the PowerSoil ${ }^{\circledR}$ DNA Isolation Kit (MOBIO Laboratories, Carlsbad, California, USA) according to the manufacturer's instruction with some modifications: after adding solution $\mathrm{C} 1$ (causing cell lysis), samples were incubated at $60{ }^{\circ} \mathrm{C}$ for $30 \mathrm{~min}$; after adding solution $\mathrm{C} 6$ (releasing DNA from spin filter), samples were incubated at $30^{\circ} \mathrm{C}$ for $10 \mathrm{~min}$. Total DNA was quantified using a NanoDrop ND-1000 Spectrophotometer (Bio-Rad Laboratories Inc.).

From 3 replicates per treatment, ${ }^{13} \mathrm{C}$-enriched DNA was separated from non-labelled DNA by density-gradient centrifugation. The gradient buffer was composed of $\mathrm{CsCl}$ (Sigma Aldrich Inc., St. Louis, MO, USA) with an average density of $1.80 \mathrm{~g} \mathrm{~mL}^{-1}$ dissolved in a buffer (0.1 M Tris-HCl, pH 8; $0.1 \mathrm{M} \mathrm{KCl}$ and $1 \mathrm{mM}$ EDTA) (Lueders et al., 2004). $1 \mu \mathrm{g}$ of DNA was used per sample and centrifugation was carried out in $1.8 \mathrm{~mL}$ polyallomer quick seal tubes in a micro ultracentrifuge Sorvall discovery m120 SE (S120-VT vertical rotor). Centrifugations were done $60,000 \mathrm{rpm}$ at $20^{\circ} \mathrm{C}$ for $72 \mathrm{~h}$. Per sample, 18 fractions (of 100 $\mu \mathrm{l})$ of the developed density gradient were collected. The density of each fraction was determined by weighing the fractions and by using an AR200 digital refractometer (Reichert Inc., Depew, NY, USA). Absence of fungal and bacterial DNA in ${ }^{13} \mathrm{C}$-enriched fractions in control samples was confirmed using PCR. The fractionated DNA was combined into samples called 'heavy' (densities $>1.77 \mathrm{~g} \mathrm{ml}^{-1}$ ) and 'light' (densities $<1.75$ $\mathrm{g} \mathrm{ml}^{-1}$ ) fractions, the first containing mainly ${ }^{13} \mathrm{C}$-enriched DNA and the latter containing mainly unlabelled ${ }^{12} \mathrm{C}$ DNA (Neufeld et al., 2007).

\section{Quantitative PCRs}

Briefly, each qPCR reaction for bacterial quantification (total volume $15 \mu \mathrm{l}$ ) consisted of $7.5 \mu$ l of Sybergreen (iTaq ${ }^{\text {TM }}$ Universal SYBR ${ }^{\circledR}$ Green Supermix), $0.6 \mu$ l of forward primer (Eub 338, $10 \mathrm{pmol}^{-1} \mathrm{l}^{-1}$ ) (Amann et al., 1990), $0.6 \mu \mathrm{l}$ of reverse primer (Eub 518, $10 \mathrm{pmol}$ $\mu^{-1}$ ) (Muyzer $\mathrm{G}$ et al., 1993), $4.3 \mu \mathrm{l}$ Nucleic acid free water (Sigma) and $2 \mu$ l of DNA (5 ng $\mu^{-1}$ ). Plasmid Ter331 (Collimonas 16S) was used as a standard for the quantification. The PCR program consisted of an initial denaturation step at $95{ }^{\circ} \mathrm{C}$ for $2 \mathrm{~min}$, followed by 40 cycles of $95{ }^{\circ} \mathrm{C}$ for $10 \mathrm{sec}, 53^{\circ} \mathrm{C}$ for $10 \mathrm{sec}$ and $72{ }^{\circ} \mathrm{C}$ for $25 \mathrm{sec}$. For the quantification of fungi each qPCR reaction (total volume $15 \mu \mathrm{l}$ ) consisted of $7.5 \mu \mathrm{l}$ of Sybergreen

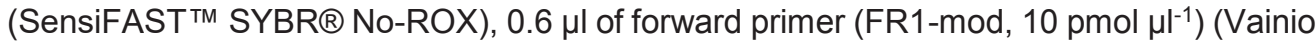
and Hantula, 2000), $0.6 \mu \mathrm{l}$ of reverse primer (FF390-mod, $10 \mathrm{pmol}^{\mathrm{l}} \mathrm{l}^{-1}$ ) (Vainio and 
Hantula, 2000), $4.3 \mu \mathrm{l}$ of Sigma water and $2 \mu \mathrm{l}$ of DNA $\left(5 \mathrm{ng} \mathrm{\mu l}^{-1}\right)$. Plasmid F1 (Hypholoma, Basidiomycete EF4-ITS4) was used as a standard for the quantification. The PCR program consisted of an initial denaturation step at $95^{\circ} \mathrm{C}$ for $2 \mathrm{~min}$, followed by 45 cycles of $95{ }^{\circ} \mathrm{C}$ for $10 \mathrm{sec}, 55^{\circ} \mathrm{C}$ for $10 \mathrm{sec}$ and $72{ }^{\circ} \mathrm{C}$ for $25 \mathrm{sec}$. The qPCRs were performed with a Rotor-Gene RG-3000 (Corbett research). For each template DNA, for both for bacteria and fungi, we analysed three biological replicates in duplicate. The final results are expressed in [DNA copy numbers $/ \mathrm{g}$ of soil] and the conversion was based on the standard curves of the plasmid inserts and the amount of dry weight of soil from which the DNA was extracted.

\section{Sequencing of the bacterial community}

The 16S rRNA region was amplified using the bacterial-specific primer pair $515 \mathrm{f}$ and $806 \mathrm{r}$ (Vos et al., 2012). The first PCR reactions were performed using the pair of primers without tags for 30 cycles (this was necessary since the amount of DNA was not enough to amplify directly with tagged pair of primers). Then $1 \mu \mathrm{l}$ of this PCR-product was used as DNAinsert for a second PCR reaction with 10-12 cycles performed with tagged pair of primers as recommended by Illumina as well as 12-bp tags specific for each sample. PCR reactions were performed in $25 \mu \mathrm{l}$ reaction mixtures and contained $200 \mu \mathrm{M}$ of each dNTP,0.04 U of FastStart Expand High Fidelity polymerase (Roche Applied Sciences, Indianapolis, IN), $2.5 \mu \mathrm{l} 10 \times \mathrm{PCR}$ buffer with $\mathrm{MgCl}_{2}, 0.3 \mu \mathrm{l}(10 \mathrm{pmol} \mu \mathrm{l}-1)$ of each of the two primers, $2.5 \mu \mathrm{l} \mathrm{BSA}\left(4 \mathrm{mg} \mathrm{ml}^{-1}\right)$ and $1 \mu \mathrm{l}$ DNA. The temperature cycling of PCR conditions were: denaturation at $94^{\circ} \mathrm{C}$ for $5 \mathrm{~min}$, followed by 30 or $10-12$ cycles of $94^{\circ} \mathrm{C}$ for $40 \mathrm{~s}, 50^{\circ} \mathrm{C}$ for $60 \mathrm{~s}$ and $72^{\circ} \mathrm{C}$ for $1.30 \mathrm{~min}$. The final extension step was $72^{\circ} \mathrm{C}$ for 10 $\min$.

The presence of PCR products of expected sizes was verified by agarose-gel electrophoresis. PCR products were then pooled from 4 reactions per sample and purified using Agencourt AMPure XP reagent. Amount of DNA in samples was quantified on a Fragment Analyzer instrument (Advanced Analytical) and each PCR sample was normalized to $100 \mathrm{ng}$ and pooled together for multiplex sequencing. The samples were sequenced on an Illumina MiSeq instrument (BGI-Europe).

\section{Bioinformatics}

The RDP extension to PANDASeq (Masella et al., 2012) named Assembler (Cole et al., 2014) was used to merge paired-end reads with a minimum overlap of $10 \mathrm{bp}$ and at least a PHRED score of 25.

Primer sequences were removed per sample. FASTQ files and sequences were converted to FASTA format and concatenated into a single file. 
All reads were clustered into OTUs using the UPARSE strategy by dereplication, sorting by abundance with at least two sequences and clustering using the UCLUST smallmem algorithm (Edgar, 2010). These steps were performed with VSEARCH version 1.0.10.

Next, chimeric sequences were detected using the UCHIME algorithm (Edgar et al., 2011) implemented in VSEARCH. All reads before the dereplication step were mapped to OTUs using the usearch_global method implemented in VSEARCH to create an OTU table and converted to BIOM-Format 1.3.1 (McDonald et al., 2012).

Finally, taxonomic information for each OTU was added to the BIOM file by using the RDP Classifier version 2.10 (Cole et al., 2014) and by aligning the sequences to the SILVA database (release 123) (Quast et al., 2013) using SINA (Pruesse et al., 2012). All steps were implemented in a Snakemake workflow (Koster and Rahmann, 2012).

The MiSeq sequencing files are deposited in the European nucleotide Archive (http://www.ebi.ac.uk/ena/data/view/PRJEB15393).

\section{Statistical analysis}

To test for differences in priming effects between treatments One-way ANOVA, followed by post-hoc Tukey's test, was performed using IBM SPSS Statistics 22. In case of unequal variances among treatments, statistical comparisons were performed by Tamhane's test. Soils with and without nitrogen amendments were compared pairwise (independent t-test), based on the carbon source addition that they received (e.g. Glucose_C VS Glucose C+N, etc.).

All ordination analyses were performed in Canoco version 5.03 (Smilauer and Lepš, 2014). Analyses were performed with the dataset including the most abundant OTUs (more than $1 \%$ of the total number of sequences per sample). Detrended correspondance analysis (DCA) was used to visualize differences between bacterial communities collected from the different soil treatments. Canonical Correspondence Analysis (CCA) was used to test whether the composition of the bacterial community was related to carbon source, sampling time or fraction type $\left({ }^{13} \mathrm{C}\right.$ or $\left.{ }^{12} \mathrm{C} \mathrm{DNA}\right)$. Carbon sources with different amount or energy levels were grouped. Significance of canonical axes was assessed by the forward approach using Monte Carlo permutation tests under the reduced model. This test generates a F-ratio that has a similar meaning as the F-value in ANOVA of the regression model, and the Monte Carlo permutation test is used in an analogous way (Smilauer and Lepš, 2014). 


\section{Results}

Estimation of microbial usable energy released by the priming substrates

We observed significant differences in the amount of produced fungal biomass (all fungal species analyzed together) in liquid cultures between different substrates (Fig. S1A). The results for vanillic acid are based on the average biomass production of two species ( $A$. niger and $H$. fasciculare) since the other three species ( $M$. hiemalis, $T$. harzianum and $M$. androsaceus) did not grow on this substrate. Fungal biomass production was stimulated by carbon sources in the order: cellobiose $>$ glucose $>$ vanillic acid $(P<0.05)$. Similar results were observed for bacteria (Fig. S1B). Bacterial biomass production was equally stimulated by glucose and cellobiose and much less by vanillic acid. Our third hypothesis is related to the importance of the fungal taxa in $\mathrm{PE}$, thus we used the data obtained from the fungal cultures to correct for differences in microbial usable energy content between the trigger compounds (Table 2). However, as can be seen from Fig. S1, the correction would have been almost the same when based on bacterial biomass production.

\section{Effect of different substrates on PEs}

In general, the supply of substrates induced an increase in total soil respiration as compared to the control treatments (Fig. S2). The highest $\mathrm{CO}_{2}$ levels were observed in the treatments amended with vanillic acid in the "same amount of energy" treatments (both in presence or absence of external supply of ammonium nitrate) $(P<0.05)$. In contrast, the lowest levels of $\mathrm{CO}_{2}$ evolution were observed in treatments amended with vanillic acid in the "same amount of C" treatments. Soils treated with cellobiose and glucose showed similar patterns in $\mathrm{CO}_{2}$ evolution, independently of the amount of energy or carbon $(P>0.05)$. This is not a surprising result, since the amounts added were (almost) the same for the carbon and energy treatment.

This general $\mathrm{CO}_{2}$ evolution pattern was mirrored by an increase in the rates of substrate mineralization (respiration of labeled C) (Fig.S3) and in PEs (respiration of unlabeled C) (Fig. 1). Substrate mineralization rates and PEs were highest in soils amended with vanillic acid in the "same amount of energy" treatments $(P<0.01)$ (Fig. S3B and Fig. $1 A$ and $B$ ) and there were no significant differences between the added compounds in the "same amount of C" treatment ( $P>0.05$ ) (Fig. S3A Fig. 1C and D). The responses of the soil to the other two substrates, glucose and cellobiose, were not significantly different in magnitude from each other in both treatments $(P>0.05)$.

In general, addition of $\mathrm{N}$ stimulated PEs in almost all the treatments (Fig. 1). PE was significantly higher $(P<0.05)$ in soils where extra $N$ was added in treatments with glucose 
and vanillic acid, but not in the treatments with cellobiose. PE was calculated for each time period (0-0.2 d; 0.2-3 d; 3d-13 d) to indicate the highest peak in PE (Fig. S4). Addition of $\mathrm{N}$ caused a positive priming effect during the first 5 hours for all treatments, after which $\mathrm{PE}$ gradually decreased. In contrast, in treatments with no $\mathrm{N}$ addition, PE was negative during the first 5 hours. After that time period, PE showed a positive peak, and gradually decreased during the last time period.
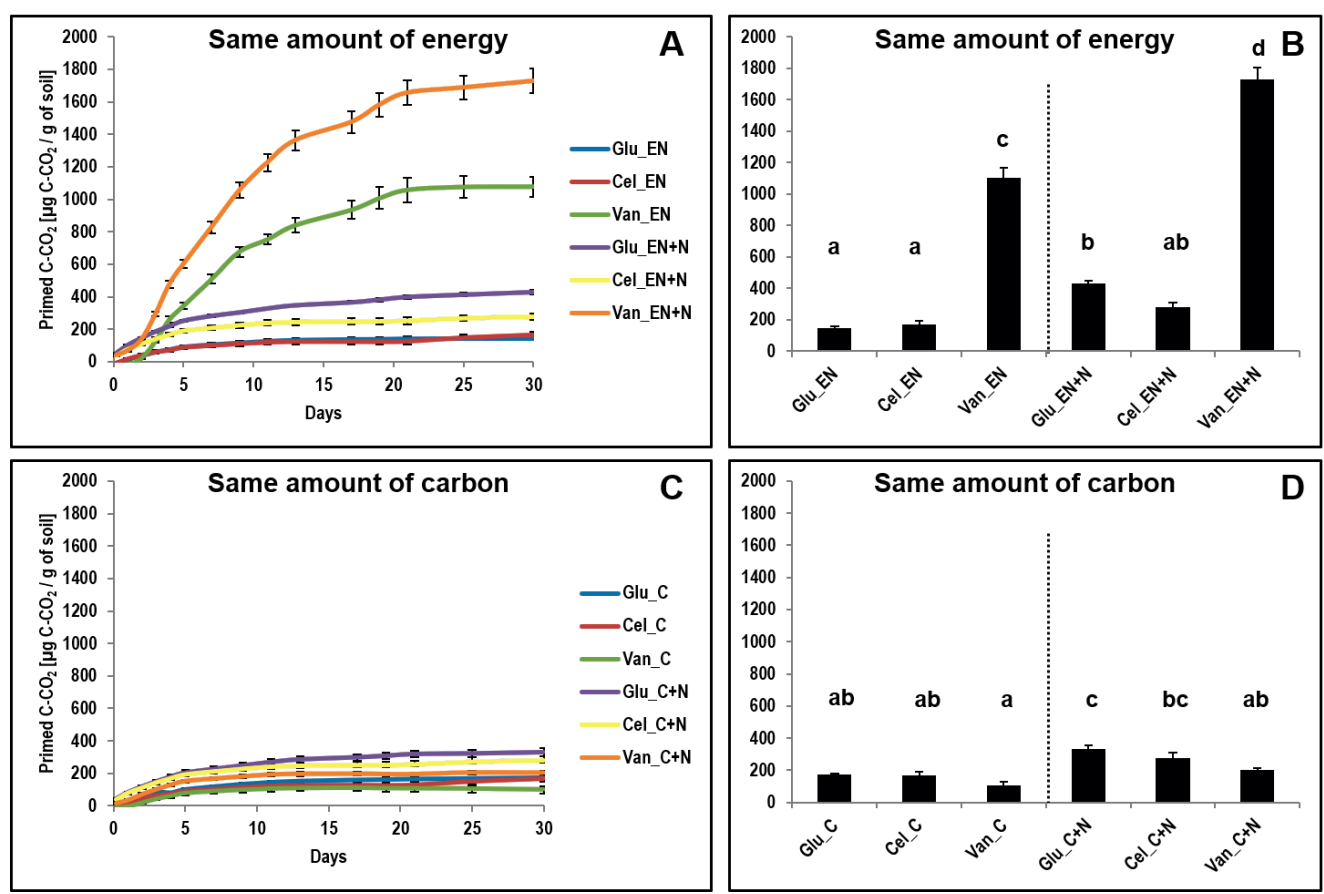

Fig. 1: Priming effect [ $\mu \mathrm{g} \mathrm{C-CO} / \mathrm{g}$ of soil] induced by three different substrates: glucose, cellobiose and vanillic acid. A) and C) show the dynamic of cumulative primed $\mathrm{CO}_{2}$ after 30 days of incubation. $\mathrm{B}$ ) and D) show primed $\mathrm{CO}_{2}$ level after 30 days of incubation. Statistically significant differences $(p<0.05)$ in primed $\mathrm{CO}_{2}$ are marked with different letters. C: substrates added with the same carbon content; EN: substrates added with the same energy released; $+\mathrm{N}$ : addition of $\mathrm{NH}_{4} \mathrm{NO}_{3}$. Vertical bars represent standard errors.

\section{Effect of different substrates on the microbial communities}

The DNA-SIP technique in combination with qPCR allowed us to track which groups of micro-organisms (fungi and/or bacteria) were using added labeled carbon substrates and which groups were using non-labeled carbon from SOM for growth (measured as increase in 16S rRNA gene copy numbers and 18SrDNA copy numbers, for bacteria and fungi respectively, per $\mathrm{g}$ of soil). In general, fungi and bacteria showed similar dynamics in abundance in treatments with "same amount of energy" and "same amount of C", both in presence and in absence of $\mathrm{N}$ (Fig. 2 and 3). Overall, the microbial community responded quickly to the substrate addition with an increase in DNA copy numbers in both ${ }^{13} \mathrm{C}$ and 
${ }^{12} \mathrm{C}$ fractions after 5 hours and 3 days of incubation, and a subsequent drop after 13 days of incubation (Fig. 2 and 3). This indicates that both added carbon as well as SOM were used for growth. However, the microbial response was somewhat different in treatments with the same amount of energy where vanilic acid was added. After 13 days of incubation, an increase in DNA copy numbers was found in the ${ }^{12} \mathrm{C}$ fraction for both bacteria and fungi, especially in treatments that received ammonium nitrate $(P<0.05)$ (Fig. $2 \mathrm{~B}$ and $3 \mathrm{~B}$ ). The ratio of DNA copy numbers between ${ }^{12} \mathrm{C}$ and ${ }^{13} \mathrm{C}$ fractions was more or less equal for fungi and bacteria $\left({ }^{12} \mathrm{C}:{ }^{13} \mathrm{C}, 16.8\right.$ for bacteria and 17.8 for fungi). It should be noted that some of the samples did not react. We believe that this is due to the low amount of DNA in those samples.
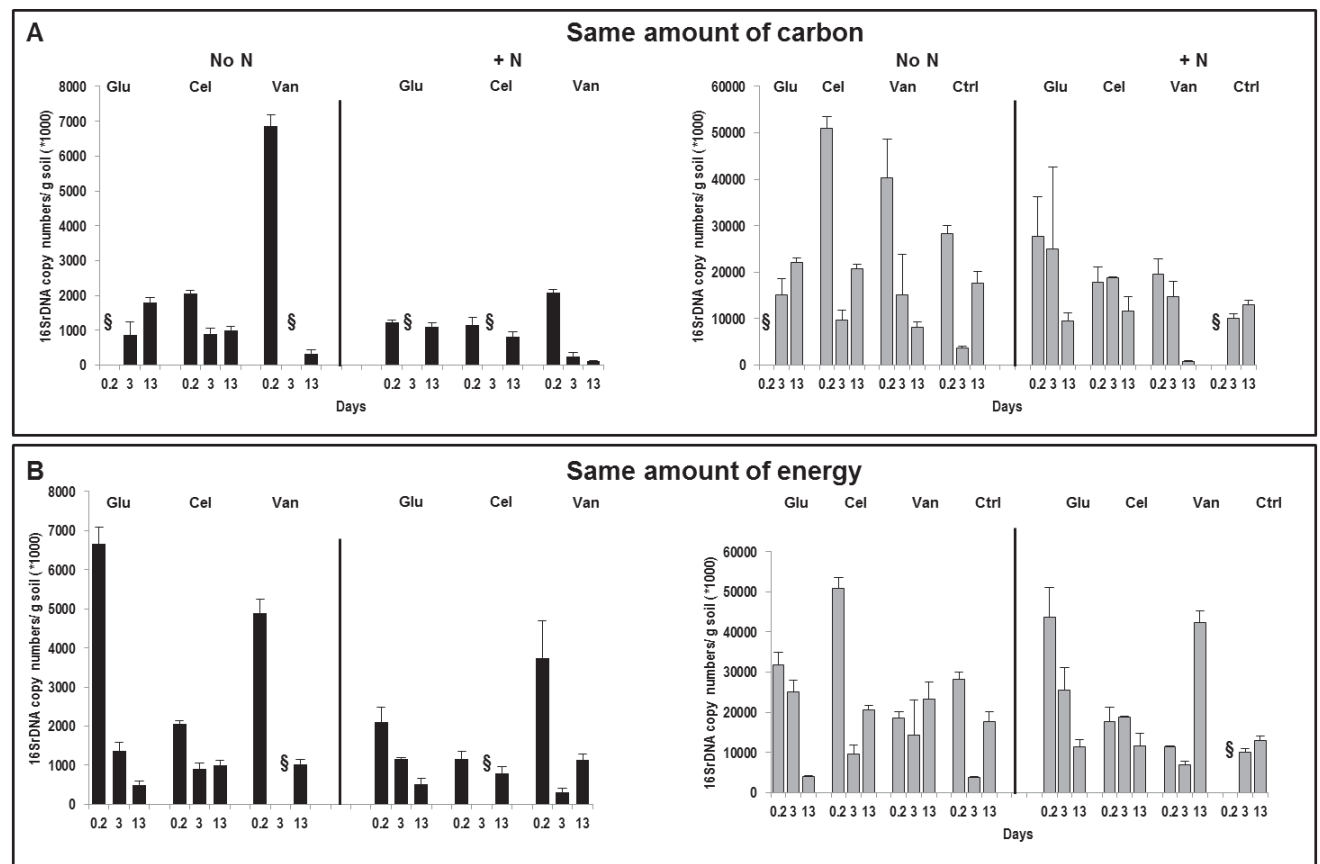

Fig. 2: Changes in bacterial numbers during the priming effect induced by three different substrates. A: substrates added with the same carbon content; B: substrates added with the same energy released; Black bars

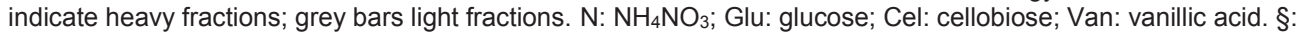
no PCR products were obtained. Vertical bars represent standard errors. 

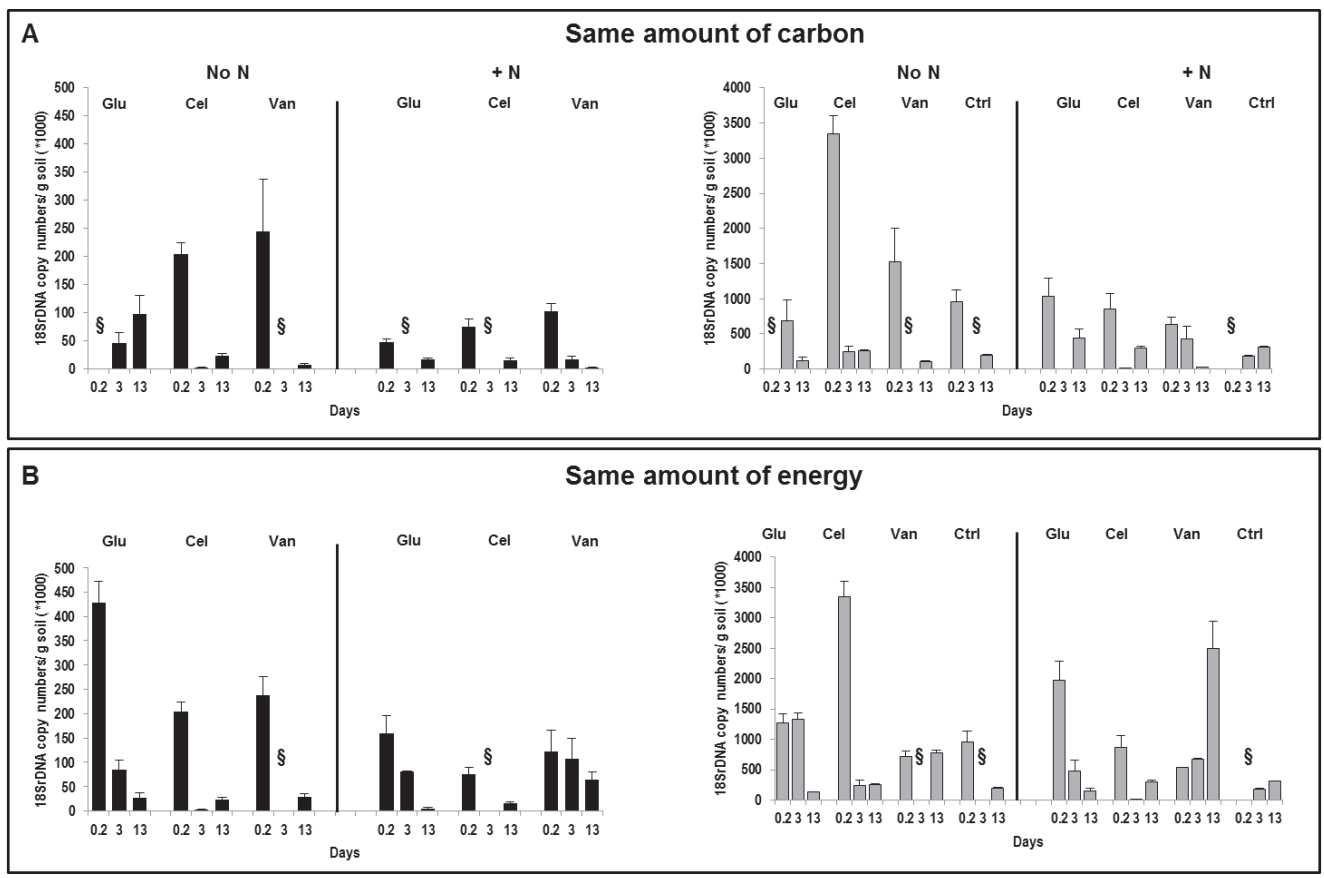

Fig. 3: Changes in fungal numbers during the priming effect induced by three different substrates. A: substrates added with the same carbon content; B: substrates added with the same energy released; Black bars indicate

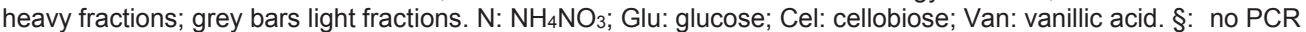
products were obtained. Vertical bars represent standard errors.

\section{Bacterial diversity}

In total we identified 9126 bacterial OTUs of which only 86 OTUs were more abundant than $1 \%$ of the total number of sequences per sample, indicating a high amount of rare species. These most abundant OTUs were distributed across five known bacterial phyla (Acidobacteria, Actinobacteria, Bacteroidetes, Firmicutes, Proteobacteria) and one unclassified phylum, 9 known bacterial classes (Acidobacteria, Actinobacteria, $\alpha$ Proteobacteria, Bacilli, $\beta$-Proteobacteria, $\delta$-Proteobacteria, Flavobacteriia, $\gamma$ Proteobacteria, Sphingobacteriia) and two unclassified classes. After 5 hours, a clear differentiation in bacterial community composition between ${ }^{13} \mathrm{C}$ and ${ }^{12} \mathrm{C}$ fractions of DNA could be observed for all samples (Fig S5): ${ }^{13} \mathrm{C}$ fractions grouped together on the upper left side of the DCA biplot, whereas ${ }^{12} \mathrm{C}$ fractions clustered at the bottom right. Indeed, forward selection in CCA showed that bacterial community composition significantly correlated with sampling time and fraction $\left({ }^{12} \mathrm{C}\right.$ or $\left.{ }^{13} \mathrm{C}\right)$ type $(\mathrm{P}<0.01$ in both cases), explaining $5.7 \%$ and $3.8 \%$ of the total variance in species composition respectively. After 3 and 13 days, these differences disappeared and dominant bacterial OTUs in ${ }^{13} \mathrm{C}$ fractions resembled those in ${ }^{12} \mathrm{C}$ fractions (Fig. 5 and 6). Overall, bacterial community composition was significantly related to the added substrates $(P<0.01)$, but this pattern was only clear for samples amended with vanillic acid after 3 days of incubation (Fig. S5, 
squares in the middle cluster together). OTUs that were exclusively found in these treatments were assigned to unclassified Acidobacteria, unclassified $\alpha$-Proteobacteria, unclassified Burkholderiales, Rhizobiales and Sphingobacteriales, and were found in both ${ }^{13} \mathrm{C}$ and ${ }^{12} \mathrm{C}$ fractions.

Both ${ }^{13} \mathrm{C}$ and ${ }^{12} \mathrm{C}$ fractions in all samples were dominated by Acidobacteria and $\alpha$ Proteobacteria. $\beta$-Proteobacteria, Sphingobacteriia, and $\gamma$-Proteobacteria responded quickly ( 5 hours) after the addition of the substrates. Surprisingly, no clear differences in dominant bacterial OTUs were found between the different substrates after 5 hours of incubation.

Although qPCRs worked, data on fungal diversity are not available since the PCR reactions for sequencing did not work. This is possibly due to the low amount of fungal biomass present in the samples.
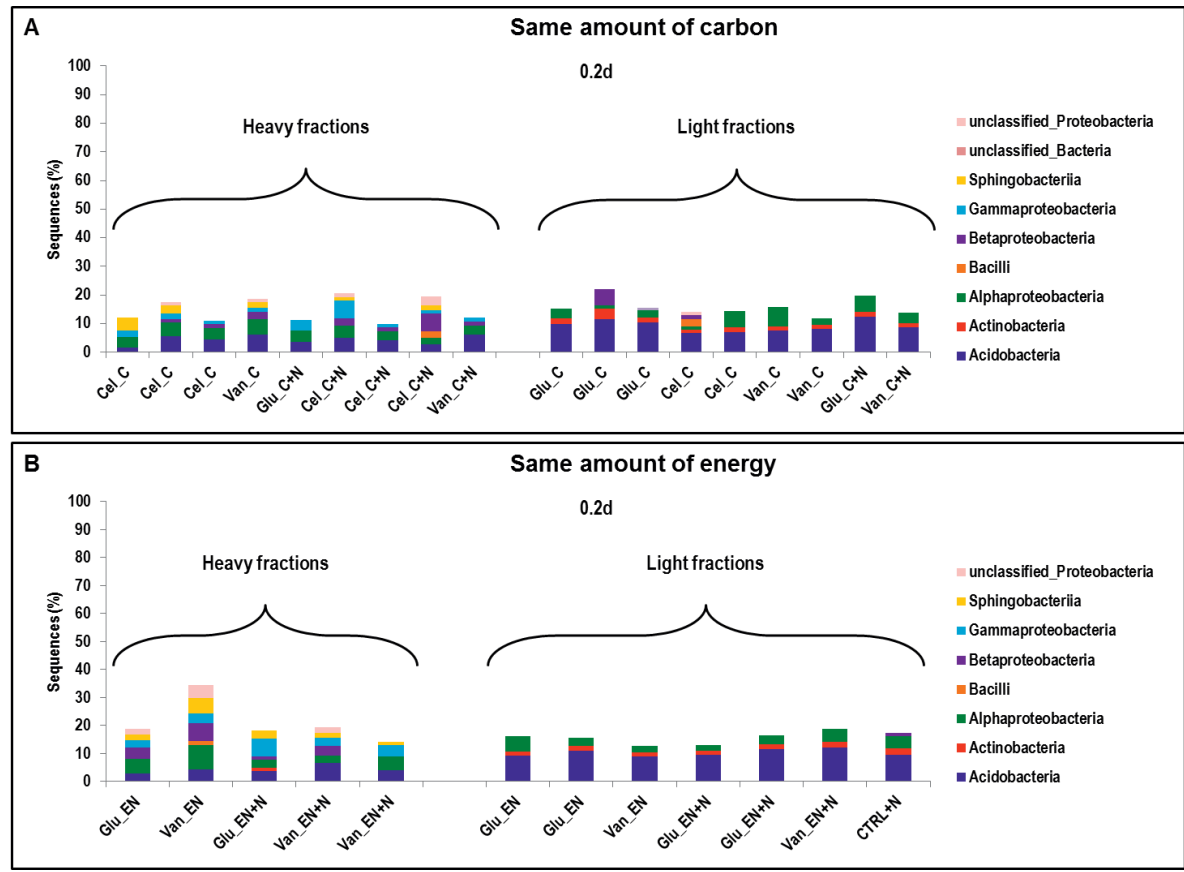

Fig. 4: Percentage of most abundant operational taxonomic units (OTUs) in soil samples collected after 5 hours of incubation. A: substrates added with the same carbon content; B: substrates added with the same energy released. Glu: glucose; Cel: cellobiose; Van: vanillic acid; C: substrates added with the same carbon content; EN: substrates added with the same energy released; $+\mathrm{N}$ : addition of $\mathrm{NH}_{4} \mathrm{NO}_{3}$. 

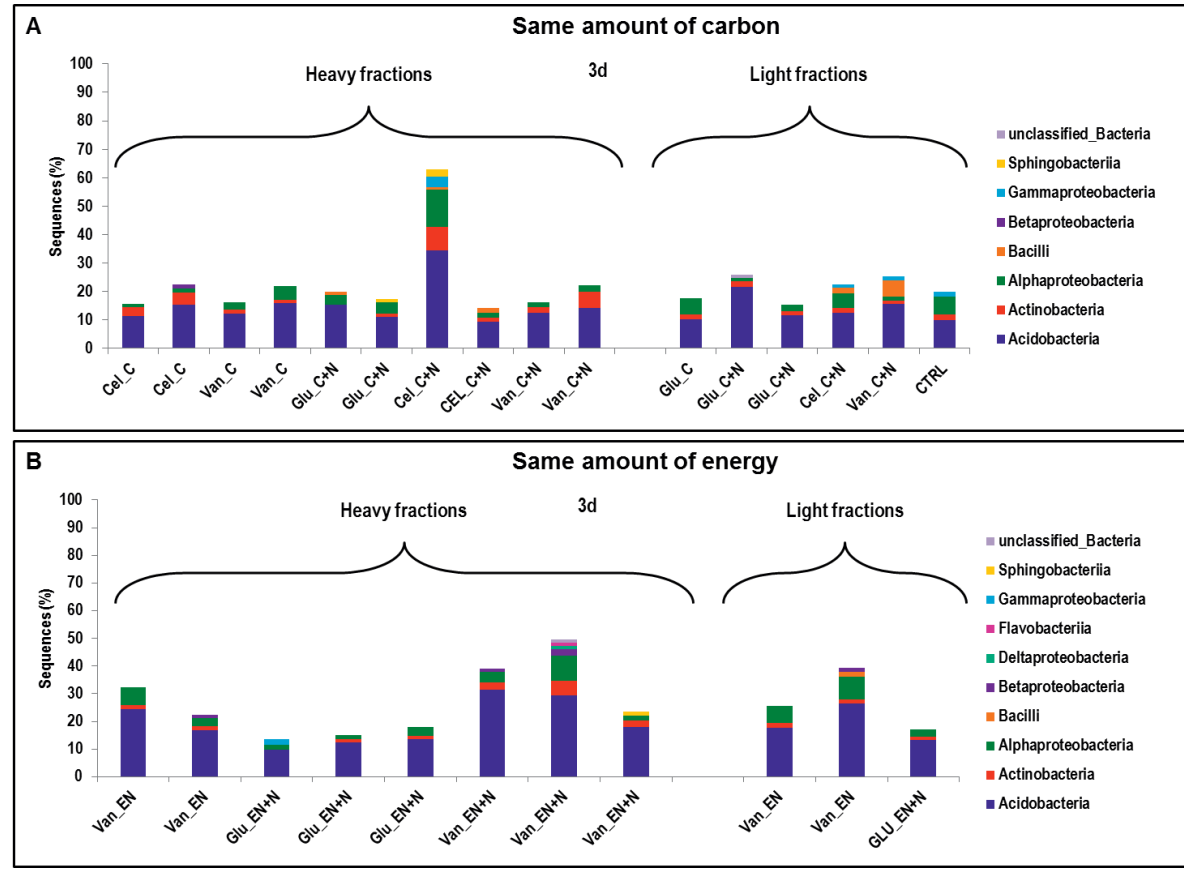

Fig. 5: Percentage of most abundant operational taxonomic units (OTUs) in soil samples collected after 3 days of incubation. A: substrates added with the same carbon content; B: substrates added with the same energy released. Glu: glucose; Cel: cellobiose; Van: vanillic acid; C: substrates added with the same carbon content; EN: substrates added with the same energy released; $+\mathrm{N}$ : addition of $\mathrm{NH}_{4} \mathrm{NO}_{3}$.
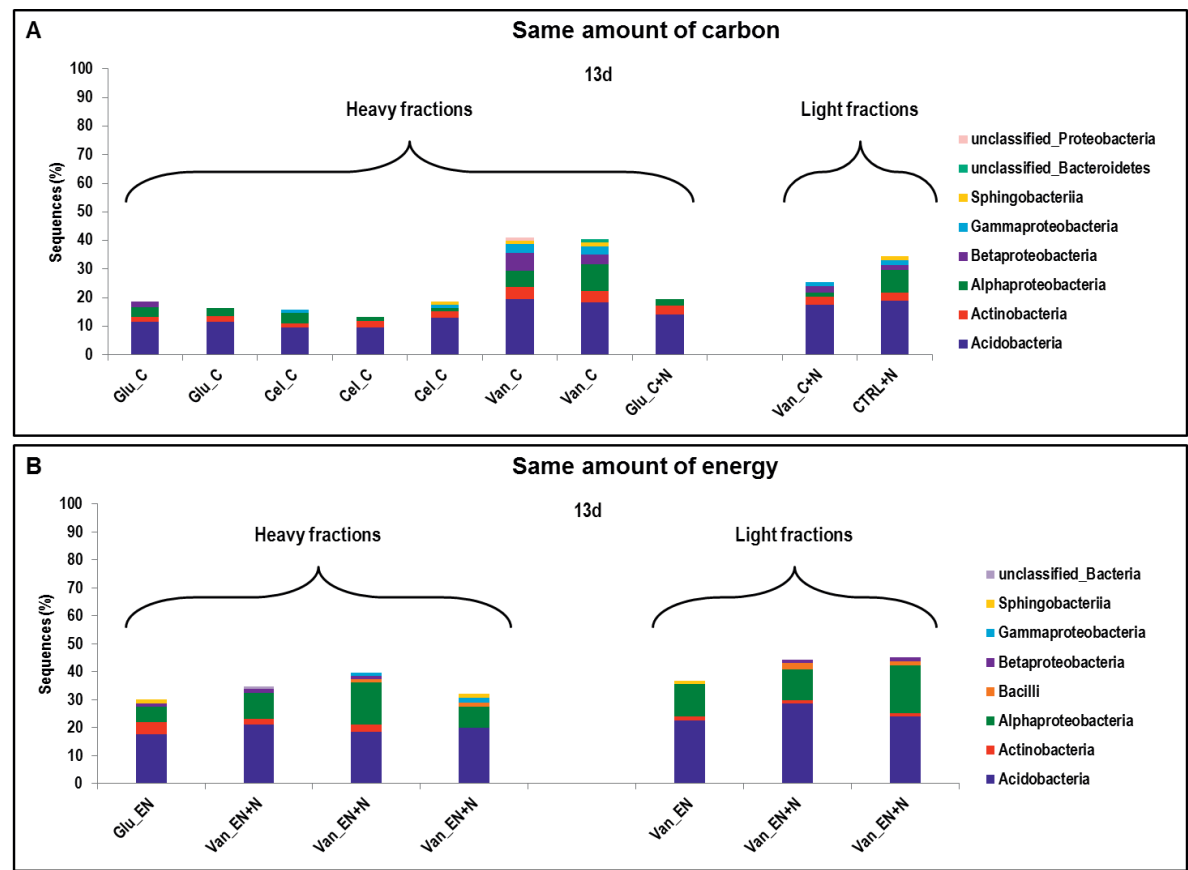

Fig. 6: Percentage of most abundant operational taxonomic units (OTUs) in soil samples collected after 13 days of incubation. A: substrates added with the same carbon content; B: substrates added with the same energy released. Glu: glucose; Cel: cellobiose; Van: vanillic acid; C: substrates added with the same carbon content; EN: substrates added with the same energy released; $+\mathrm{N}$ : addition of $\mathrm{NH}_{4} \mathrm{NO}_{3}$. 


\section{Discussion}

\section{Energy-rich versus energy-poor, complex compounds}

To test the effect of energy content of compounds on PEs, the amount of added carbon of the priming compounds was kept constant among treatments. This allowed us to test the first hypothesis. All substrates given at equal amounts of carbon induced PEs. The addition of the energy-rich compounds glucose and cellobiose caused a slightly higher total $\mathrm{CO}_{2}$ respiration (Fig. $2 \mathrm{~S}$ ) and a two times higher $\mathrm{PE}$ as compared to the energy-poor compound vanillic acid (Fig. 1C and 1D). Fresh available substrates can serve as energy source stimulating the soil microbial community, causing the production of extracellular enzymes with the subsequent increase in the decomposition of SOM (Blagodatskaya and Kuzyakov, 2008; Schimel and Weintraub, 2003). In fact, enzyme production requires an energetic investment and enzymes are only beneficial if their substrates are available in high enough concentration to offset these costs (Allison et al., 2014). In this study, the microbial community appeared to be partially limited by energy to break-down recalcitrant SOM, which is in agreement with the findings of previous studies (De Nobili et al., 2001; Fontaine et al., 2004a).

To test the effect of structural similarity of trigger compounds with SOM on PEs (second hypothesis), the amount of energy was kept constant among treatments. Microbial biomass yield for the three selected substrates (glucose, cellobiose and vanillic acid) was used to determine microbial usable energy instead of theoretical energy availability such as given by Gibbs free energy. Glucose, cellobiose and vanillic acid have different values of Gibbs free energy $(\Delta \mathrm{G}=-686 \mathrm{kcal} / \mathrm{mol}$; $1355 \mathrm{kcal} / \mathrm{mol}$ and $-819 \mathrm{kcal} / \mathrm{mol}$, respectively). Thus, theoretically, cellobiose contains the highest amount of energy, followed by vanillic acid and glucose. However, this is not observed with microbial biomass yields, as we found that bacterial and fungal biomass production was much less on vanillic acid than on cellobiose and glucose. This discrepancy is due to the fact that the actual amount of energy that can be used for biomass production is determined by the catabolic pathways coupled to ATP production and the losses of energy due to maintenance costs. Therefore, we think that microbial biomass yield is the best choice as proxy for of energy availability for PEs.

Under conditions of similar energy addition vanillic acid induced the highest total $\mathrm{CO}_{2}$ respiration, substrate mineralization and PE (Fig. S2, S3 and $1 \mathrm{~A}$ ), with PE being more than 7 times higher than in treatments with glucose and cellobiose. Structural complex compounds can increase PEs (Brant et al., 2006) by production of broad variety of enzymes, thereby possibly co-metabolizing SOM fractions (Fontaine et al., 2003; Schimel and Weintraub, 2003). Microbial enzyme responses to substrate addition may be important to clarify the mechanisms of PEs. An increase in extracellular enzymes degrading cellulose and lignin was considered to be the cause of PEs because these 
enzymes are also involved in SOM decomposition (Blagodatskaya and Kuzyakov, 2008; Fontaine and Barot, 2005). Therefore, if the added compounds reflect the chemical composition of the SOM, the production of enzymes by microorganisms may be induced that will also decompose fractions of SOM (van der Wal and de Boer, 2017).

The two mechanisms proposed, namely the availability of energy and the chemical similarity between SOM and the added compounds, do not exclude each other and can coexist. Indeed, the direction and magnitude of PEs can depend on the quality and quantity of the added compounds.

\section{Fungi versus bacteria in priming effects}

To test if fungi were more important than bacteria in priming effects, we investigated how different substrates affected the microbial community. Both bacteria and fungi were able to use the added substrates, as the heavy fractions of DNA copy numbers increased for both groups (Fig. 2 and 3). In addition, both fungi and bacteria were growing on SOM as indicated by an increase in DNA copy numbers in light fractions. The increase in light DNA copy numbers of fungi and bacteria as compared to control samples, after 5 hours of incubation (Fig. 2 and 3) might be due to the activation of the internal microbial metabolism. Adding carbon to the soil, independently of the amount of available substrate in the soil, may trigger microbes to switch from a dormant to an active state (Blagodatskaya and Kuzyakov, 2008). The increase in the energy requirements might be sustained by the use of intracellular reserves (Blagodatskaya et al., 2007; Blagodatskaya and Kuzyakov, 2008). Furthermore, we observed a temporary decrease in the decomposition of SOM after 5 hours of incubation (negative PE) (Fig. S4, treatments with no $\mathrm{N}$ addition). This may be explained by preferential substrate utilization where opportunistic microbes decompose the added labile $\mathrm{C}$ which may negatively affect the microbes that decompose SOM via production of inhibitors or uptake of inorganic nutrients resulting in a negative apparent PE (Blagodatskaya and Kuzyakov, 2008; Bradford et al., 2008; Rousk et al., 2016).

We hypothesized that the contribution of fungi in PEs was more important because of their hyphal growth and SOM-degrading enzyme production (Fontaine et al., 2011). However, copy numbers of $18 \mathrm{~S}$ (fungi) and $16 \mathrm{~S}$ (bacteria) rDNA fragments indicated that the contribution of fungi to $\mathrm{PE}$ was quite low as compared to bacteria, reflecting the low $\mathrm{F}: \mathrm{B}$ ratio of the ex-arable soil used for the experiment (Table 1). Based on the first growth experiment, both fungi and bacteria were equally able to grow on the added vanillic acid (Fig. S1). This may explain why, in contrast to our expectation, fungi were not specifically stimulated by addition of vanillic acid to soils. Yet, the ratio of DNA copy numbers between light and heavy fractions for fungi and bacteria was similar, suggesting that fungi were proportionally equally important for PEs. However, the numerical dominance of bacteria 
over fungi in the soil that we have been using has been shown for other grassland ecosystems as well (Bird et al., 2011).

Comparison of different soils and trigger compounds indicates that several microbial groups can take the lead in PEs (e.g., Dungait et al., 2013; Garcia-Pausas and Paterson, 2011; Sullivan and Hart, 2013; Whitaker et al., 2014) and this can change over time (Blagodatskaya et al., 2014). Low fungal DNA copy numbers that were found for all treatments suggest that the fungi have a minor role in PEs in the ex-arable soil. For ecosystems where the contribution of fungi in the decomposition of SOM is more important such as forest soils, it is likely that their role in PE is also more important (Terrer et al., 2016).

\section{Bacterial diversity}

In this study, we observed a clear differentiation between ${ }^{13} \mathrm{C}$ and ${ }^{12} \mathrm{C}$ fractions shortly $(5$ h) after addition of the compounds (Fig. 4 and S5), where $\beta$-Proteobacteria, Sphingobacteriia, and $\gamma$-Proteobacteria were mostly present in the ${ }^{13} \mathrm{C}$ fractions, and Acidobacteria, $\alpha$-Proteobacteria were dominantly present in both ${ }^{13} \mathrm{C}$ and ${ }^{12} \mathrm{C}$ fractions. After prolonged incubation ( 3 and 13 days) these differences disappeared (Fig. 5 and 6), and the bacterial community (in the ${ }^{13} \mathrm{C}$ as well in the ${ }^{12} \mathrm{C}$ fractions) was dominated by Acidobacteria, Actinobacteria and $\alpha$-Proteobacteria in all samples. This indicates that added substrates were first consumed by bacterial species from the classes $\beta$ Proteobacteria, Sphingobacteriia, $\gamma$-Proteobacteria, Acidobacteria and $\alpha$-Proteobacteria. After 3 days and 13 days bacteria from the classes Acidobacteria and $\alpha$-Proteobacteria were still ${ }^{13} \mathrm{C}$-labeled, and ${ }^{13} \mathrm{C}$-labeled Actinobacteria were increasing. The rapidly responding classes $\beta$-Proteobacteria, Sphingobacteriia, and $\gamma$-Proteobacteria did only consume the trigger compounds but did not contribute to PE. Other microbial taxa, i.e. Acidobacteria, $\alpha$-Proteobacteria, were decomposing the added $\mathrm{C}$ as well as SOM, indicating direct co-metabolism of SOM (Fontaine et al., 2004b). These groups probably also contributed to $\mathrm{PE}$ via decomposition of the necromass of the pioneer microbial groups (Kuzyakov, 2010). A similar pattern was previously observed (Bernard et al., 2007; Pascault et al., 2013). Phylogenetic bacterial groups like Acidobacteria and $\alpha$ Proteobacteria, that are well known to harbor oligotrophic species, where retrieved in both DNA heavy and light fractions in soils treated with ${ }^{13} \mathrm{C}$-labelled plant residues.

In general, bacterial species from the classes $\beta$ - and $\gamma$-Proteobacteria are known as opportunistic bacteria, fast growers, with a rapid turnover. They can be considered copiotrophs that are stimulated by high substrate availability (Aneja et al., 2006; Bernard et al., 2007; Fierer et al., 2007; Jenkins et al., 2010; Pascault et al., 2013). For example, within the class $\mathrm{y}$-Proteobacteria, we found Pseudomonas spp. that have high metabolic versatility and they have previously been reported as ecological opportunists 
(Padmanabhan et al., 2003). On the other hand, $\alpha$-Proteobacteria are far more abundant than the other proteobacterial classes in environments characterized by recalcitrant carbon (Kielak et al., 2016b), thus they may be considered as decomposer specialists (sensu Moorhead and Sinsabaugh, 2006).

Actinobacteria were increasing in the ${ }^{13} \mathrm{C}$ fractions after three days of incubation. Members of this phylum (e.g. Actinomycetales) are known for their ability to decompose complex carbon compounds (Barder and Crawford, 1981). Moreover, Actinomycetes can compete with fungi during degradation of plant polymers (De Boer et al., 2005) and Mycobacteria are able to degrade polycyclic aromatic hydrocarbon (Uyttebroek et al., 2006).

Acidobacteria is a cosmopolitan soil bacterial phylum (Barns et al., 1999; Youssef and Elshahed, 2009), that generally consist of oligotrophic organisms (Fierer et al., 2007; Pascault et al., 2013). The wide physiological capabilities among taxa of this group (Kielak et al., 2016a) point out that they can utilize complex carbon substrates that are also likely to be present in the native SOM (Pascault et al., 2013). ${ }^{13} \mathrm{C}$-labeled Acidobacteria were already found after 5 hours of incubation in this experiment, indicating that they either may be able to compete with the fast-growing Proteobacteria for labile C (R. T. Jones et al., 2009; Kielak et al., 2016a) or they might start with the consumption of lysed cells of opportunistic bacteria.

In most samples we observed similar bacterial communities after adding different carbon substrates. Hence, in general, different substrates did not stimulate the growth of different bacterial groups, although we found differences in PEs among the treatments. Differences in PEs can thus not be explained by the stimulation of different microbial groups with different capabilities to degrade SOM. Instead, it could be due to stimulation of different enzyme systems within similar bacterial taxa.

\section{Effect of nitrogen on PE}

In treatments where ammonium nitrate was added, we found a decrease in total $\mathrm{CO}_{2}$ production in the control treatment with $\mathrm{N}$ (Fig. S2), a slight increase in PEs (Fig. 1) and no effect of $\mathrm{N}$ on microbial dynamics (Fig. 2 and 3). A decrease in respiration after addition of mineral $\mathrm{N}$ to soils has been observed before (Ramirez et al., 2012; Schimel and Weintraub, 2003) and it was explained as a consequence of the reallocation of $C$ from "waste respiration" to microbial growth and a general depression of soil microbial activity. Nitrogen addition can cause a suppression of the activity of several extracellular enzymes (Carreiro et al., 2000; Frey et al., 2004; Ramirez et al., 2012; Sinsabaugh et al., 2005). The increase in PEs is in contrast to our last hypothesis, where we expected that the addition of $\mathrm{N}$ would have negatively influenced $\mathrm{PEs}$ since microbes are not stimulated to mine for $\mathrm{N}$ in SOM. Our system is dominated by bacteria (Table 1 ) and mining for $\mathrm{N}$ was 
found to be an important process in ecosystems that are dominated by fungi (Rousk et al., 2016; Terrer et al., 2016), since they are capable of adjusting the decomposition activity to the nutrient availability (Boberg et al., 2008) and by their ability to connect easilyavailable carbon with stable SOM (Fontaine et al., 2011). Another possible explanation is the limitation of $\mathrm{N}$ for microbial growth. According to the stoichiometric decomposition theory (Craine et al., 2007), microbial activity is highest when C:N ratio of the substrate matches with the microbial demands (Hessen et al., 2004). In two recent studies (Chen et al., 2014; Drake et al., 2013) it was shown that simultaneous amendments of $\mathrm{N}$ and $\mathrm{C}$ alleviated the stoichiometric constraint in soils and that allowed an increase in enzyme production (as $\beta$-glucosidase and cellobiohydrolase) and PE. Therefore, adding $\mathrm{N}$ and $\mathrm{C}$ to the soil mesocosms might better match the $\mathrm{N}$ demands necessary for microbial growth and PEs. Yet, it should be noted that we may have overestimated PE in the treatments that received nitrogen amendments because of the low respiration in the "control + N" soil.

\section{Conclusions}

In this study we compared the PEs induced by energy-rich, simple compounds with that of an energy-poor compound resembling fractions of recalcitrant SOM. We observed that the PE stimulated by the compound resembling SOM was much larger than the effect of the microbial useable energy of added compounds. To our knowledge, this study is the first to indicate the relative effect of energy versus structure of added compounds on PEs. This indicates that PEs can be better understood by including both the energy- and the structure of trigger compounds. We suggest that future studies should focus on the structural complexity of added compounds and the enzymes that are needed to breakdown the added compounds as well as SOM. Focusing on the enzymes involved seems to be essential to understand PEs. In this study differences in PEs could not be explained by the stimulation of different functional microbial groups. Instead, differences in PEs appeared to be due to the stimulation of different enzyme systems within similar phylogenetic bacterial communities. Finally, we showed that adding $\mathrm{N}$ and $\mathrm{C}$ to soils caused a slightly higher effect on PEs. It should be noted though that the increase in PEs might be an artefact caused by the reduced respiration levels in the control soil. Nonetheless, supplementing added compounds with $\mathrm{N}$ addition might better match the $\mathrm{N}$ demands necessary for microbial growth and PE which is in line with the stoichiometric decomposition theory but not with the mining for $\mathrm{N}$ theory.

\section{Acknowledgments}

We thank Machiel Bosch of Natuurmonumenten for permission to sample the ex-arable field and Mattias de Hollander for providing help with bioinformatics issues. This is 
publication number 6244 of the NIOO-KNAW Netherlands Institute of Ecology. Raw data are available on: https://dataverse.nl/dvn/dv/nioo-me. 


\section{Supplementary information}
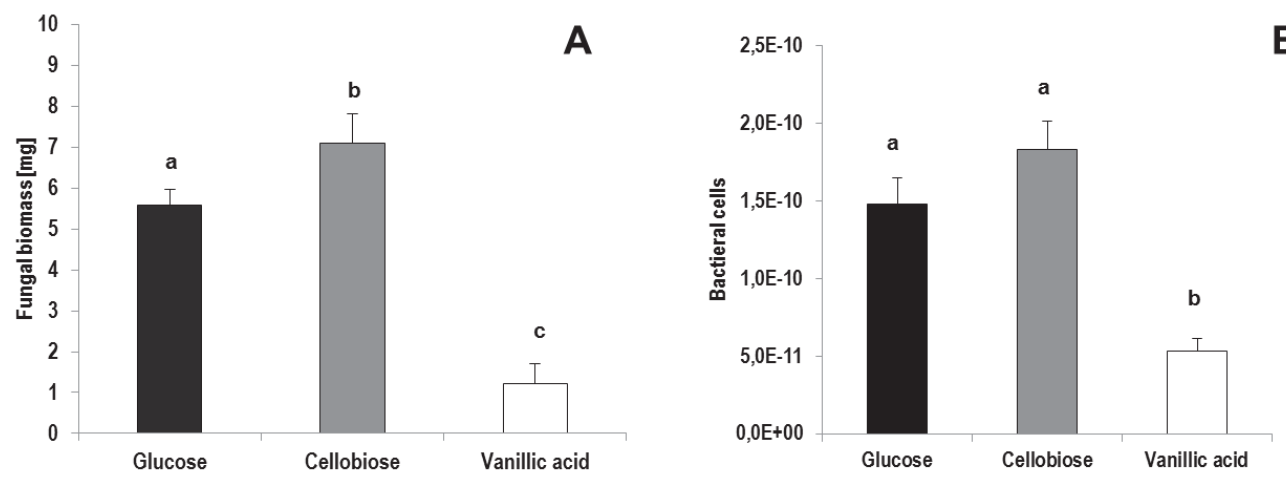

$\mathbf{B}$

Fig. S1: Estimation of the energy released by the priming substrates $(0.5 \mathrm{~g} / \mathrm{L})$ calculated as the amount of produced fungal $(A)$ and bacterial $(B)$ biomass. Statistically significant differences $(p<0.05)$ in biomass yield are marked with different letters. Vertical bars represent standard errors.

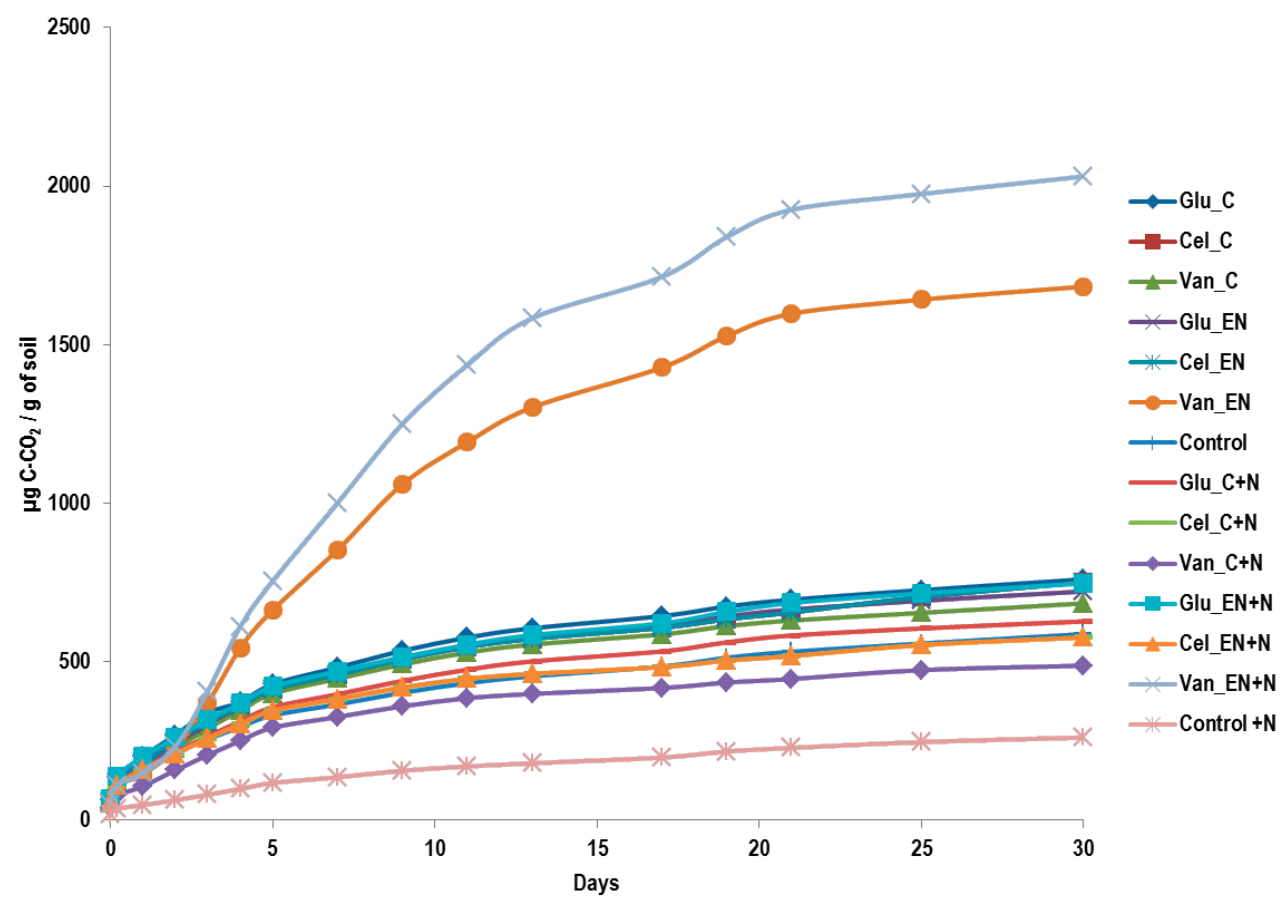

Fig. S2: Cumulative $\mathrm{CO}_{2}$ release during 30 days of incubation. Glu: glucose; Cel: cellobiose; Van: vanillic acid; C: substrates added with the same carbon content; EN: substrates added with the same energy released; $+\mathrm{N}$ : addition of $\mathrm{NH}_{4} \mathrm{NO}_{3}$. 

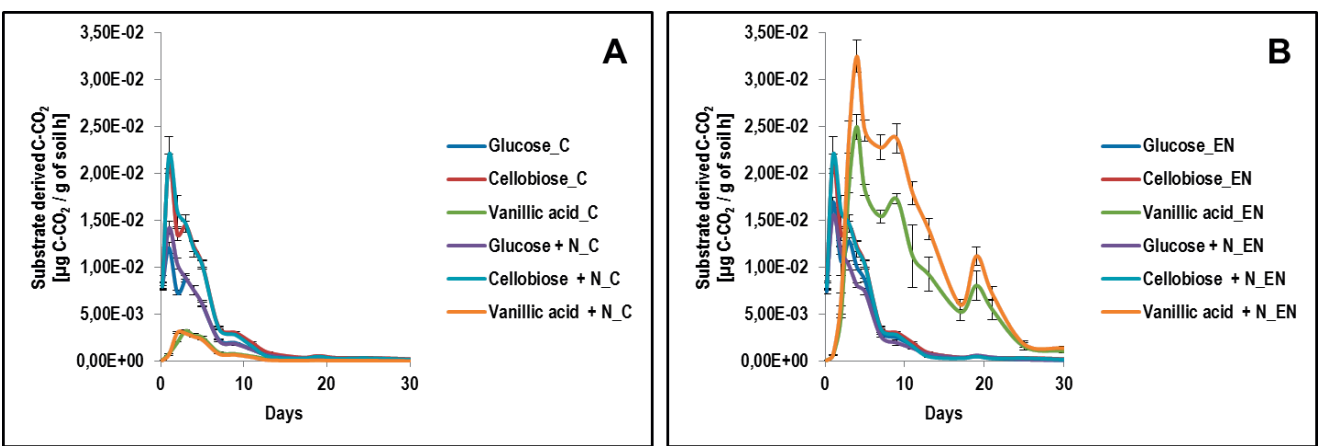

Fig. S3: Substrate derived $\mathrm{CO}_{2}\left[\mu \mathrm{g} \mathrm{C}-\mathrm{CO}_{2} / \mathrm{g}\right.$ of soil $\left.{ }^{*} \mathrm{~h}\right]$ induced by three different substrates: glucose, cellobiose and vanillic acid. A) Substrate derived $\mathrm{CO}_{2}$ in treatments where substrates were added with same amount of $\mathrm{C}$.

B) Substrate derived $\mathrm{CO}_{2}$ in treatments where substrates were added with the same energy released. $\mathrm{C}$ :

substrates added with the same carbon content; EN: substrates added with the same energy released; $+\mathrm{N}$ : addition of $\mathrm{NH}_{4} \mathrm{NO}_{3}$. Vertical bars represent standard errors.
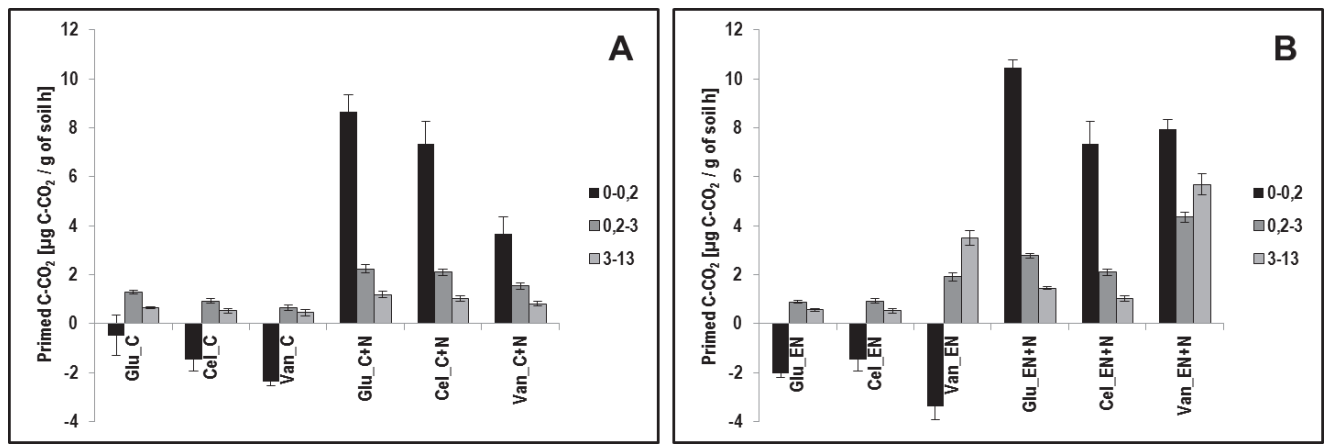

Fig. S4: Priming effect [ $\mu \mathrm{g} \mathrm{C}-\mathrm{CO}_{2} / \mathrm{g}$ of soil * $\left.\mathrm{h}\right]$ induced by three different substrates: glucose, cellobiose and vanillic acid. A) primed $\mathrm{CO}_{2}$ after $0.2,3$ and 13 days of incubation in treatments where substrates were added with same amount of $\mathrm{C}$. B) Primed $\mathrm{CO}_{2}$ after $0.2,3$ and 13 days of incubation in treatments where substrates were added with the same energy released. C: substrates added with the same carbon content; EN: substrates added with the same energy released; $+\mathrm{N}$ : addition of $\mathrm{NH}_{4} \mathrm{NO}_{3}$. Vertical bars represent standard errors. 


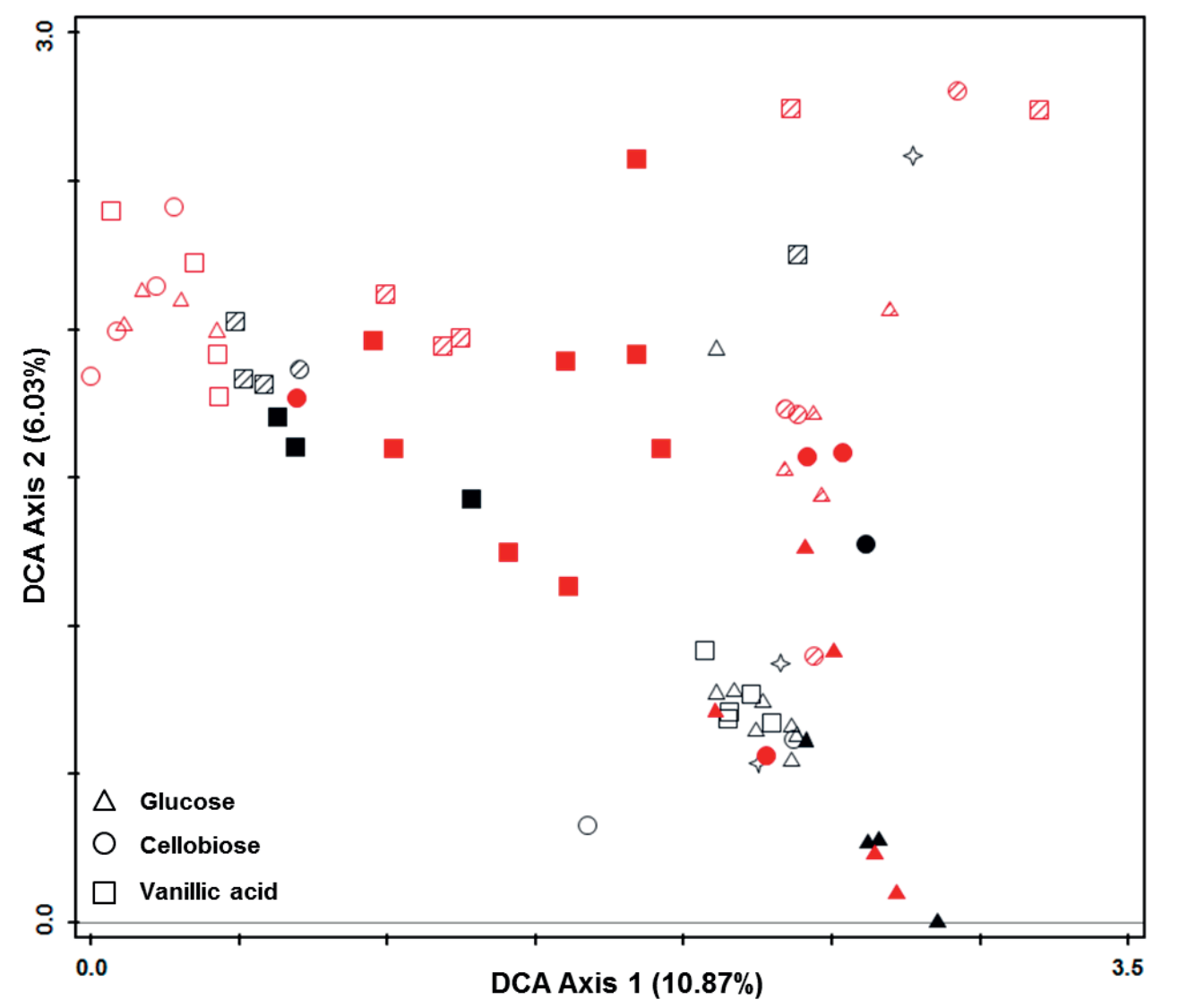

Fig. S5: Detrended correspondence analysis (DCA) biplot showing the variation of the bacterial community composition between the treatments. Triangles are samples amended with glucose; circles are samples amended with cellobiose; squares are samples amended with vanillic acid. Open symbols are samples collected at 0,2 days of incubation; solid symbols are samples collected at 3 days of incubation; diagonal hatch symbols are samples collected at 13 days of incubation. Red symbol are samples representing the DNA heavy fraction; black symbols are samples representing the DNA light fraction. Samples closer together have more similar bacterial communities. 


\title{
Chapter 3
}

\section{Relationship between home-field advantage of litter decomposition and priming of soil organic matter}

\author{
D.P. Di Lonardo ${ }^{1}$, M. Manrubia ${ }^{1}$, W. de Boer, H. Zweers, G.F. Veen ${ }^{2}$ \& A. van der Wal ${ }^{2}$
}

Soil Biology and Biochemistry 126 (2018): 49-56

DOI: 10.1016/j.soilbio.2018.07.025

${ }^{1}$ These authors contributed equally to this work.

${ }^{2}$ These authors are both senior authors for this work. 


\section{Abstract}

Home field advantage (HFA; acceleration of plant litter decomposition in soils that receive their indigenous litter) and priming effects (PEs; short-term changes in the turnover of soil organic matter caused by the addition of fresh organic carbon) are two aspects of decomposition processes that are driven by the composition and functioning of soil decomposer communities. Physicochemical similarity between added organic compounds and soil organic matter fractions has been indicated as an important steering factor of PEs. It is unknown whether PEs, like litter decomposition, experience HFA, i.e., whether PEs are higher than expected in soils receiving their own litter due to specialization of the decomposer community. Here we studied both HFA and PEs by measuring litter- and SOM-derived carbon $(\mathrm{C})$ fluxes after the addition of fresh plant litter. We reciprocally incubated three ${ }^{13} \mathrm{C}$ labelled litter types (maize, bent and beech) in soils from ecosystems where these litters are abundantly produced (e.g., arable sites, grasslands and forests), with and without the addition of mineral nitrogen $(\mathrm{N})$. Generally, respiration of both litterderived and SOM-derived $\mathrm{C}$ were lowest when beech litter was added, and were lower in forest soils than in arable or grassland soils. $\mathrm{N}$ addition generally slightly increased the respiration of litter-derived $\mathrm{C}$, but had no effect on SOM-derived C. All litter types induced a positive PE in all soils. HFA effects were not significantly different from zero, but were significantly higher in grasslands than in maize fields amended with nitrogen. We found a positive relationship between litter and priming HFA, indicating that the rates of both litter decomposition and PE may be affected in the same manner by home combinations of plant and litter versus away combinations. This positive relationship disappeared when $\mathrm{N}$ was added. Our results provide a first indication that the extent to which indigenous soil microbes are specialized to breakdown home litter, not only accelerates or decelerates the decomposition of litter, but affects the breakdown of SOM in the same way. This could imply that a specialized litter decomposer community driving HFA can further accelerate soil C mineralization via enhanced induction of PEs. Therefore, the impact of specialized decomposer communities on the dynamics of soil $\mathrm{C}$ pools may be bigger than expected from HFA of litter decomposition alone. 


\section{Introduction}

Global carbon (C) cycling plays a key role in climate regulation (Crowther et al., 2016). The main source of $\mathrm{C}-\mathrm{CO}_{2}$ from the soil to the atmosphere is the decomposition of soil organic matter (SOM) and fresh plant litter (Schlesinger, 1997). Besides controlling carbon cycling, SOM and plant litter decomposition are crucial processes for nutrient cycling and maintaining soil fertility (Schmidt et al., 2011; Swift et al., 1979). Traditionally, the main factors assumed to control decomposition rates in different ecosystems are climatic conditions and chemical complexity of the organic material (Aerts, 1997). However, over the last decade evidence is growing that decomposer community composition may also influence decomposition processes at local scales (e.g., Bradford et al., 2017; van der Wal et al., 2015) in particular when soil (decomposer) communities differ in their capacity to decompose different substrates (Ayres et al., 2009; Keiser et al., 2011). In light of global change, it is important to understand the role of litter and SOM-degrading abilities of microbial communities in soil carbon dynamics.

Home-field advantage (HFA) and priming effects (PEs) are two aspects of decomposition processes that are driven by the composition and functioning of soil decomposer communities. HFA is the phenomenon by which plant litter decomposition is accelerated in soils where the litter originates from (i.e., at home) compared to other soils (i.e., away) (Ayres et al., 2009; Gholz et al., 2000). This may be due to specialization of decomposer communities in the home soil compared to the away soil. PEs are short-term changes, often increases, in the turnover of SOM caused by the addition of fresh organic carbon (e.g. root exudates, plant litter) to the soil (Kuzyakov et al., 2000). PEs may occur when the addition of organic compounds triggers microbial production of extracellular enzymes which decompose fractions of SOM (Fontaine and Barot, 2005) or when the lack of inorganic nitrogen $(\mathrm{N})$ availability in the soil stimulates microbes to mine for $\mathrm{N}$ in SOM (Dijkstra et al., 2013). It has been hypothesized that positive PEs are stimulated when the physicochemical composition of added compounds (e.g. fresh litter) and SOM fractions are similar, because soil microbes may be specialized to decompose both added litter as well as SOM fractions (van der Wal and de Boer, 2017). This suggests, that in line with HFA for litter decomposition, PEs might be accelerated in home soils (own litter and SOM combination) than in away soils, but we have no evidence for this yet.

The breakdown of plant litter and SOM is affected by the availability of nitrogen $(\mathrm{N})$ in the soil (Craine et al., 2007; Knorr et al., 2005). Therefore, increased $\mathrm{N}$ availability may induce changes in HFA and PEs. Generally, addition of N increases decomposition of high quality litters, whereas the reverse is seen for low quality litters (Knorr et al., 2005). How this affects HFA is not yet well examined, but some studies revealed that HFA effects for litter decomposition can increase with $\mathrm{N}$ addition ( $\mathrm{Li}$ et al., 2017; Yu et al., 2015). The magnitude of PEs may also be influenced by the availability of $N$ (Dijkstra et al., 2013). According to the "microbial nitrogen mining" hypothesis microbes use labile C as an 
energy source to decompose recalcitrant organic matter and acquire $\mathrm{N}$ (Moorhead and Sinsabaugh, 2006). Hence, $\mathrm{N}$ addition may reduce mining for $\mathrm{N}$ and, consequently, SOM decomposition (Chen et al., 2014). However, it remains unclear how $\mathrm{N}$ addition changes PEs in soil receiving their own or foreign litter, and therefore how HFA for litter decomposition and $\mathrm{PE}$ are related.

In this study we aim to understand how litter breakdown in home and away soils (litter HFA) is related to SOM decomposition in home and away soils (priming HFA). We hypothesized that (1) there is a positive relationship between litter HFA and priming HFA, i.e., in soils where litter decomposition is accelerated by the addition of home litter, PEs will also be accelerated and vice versa, and that (2) $\mathrm{N}$ addition will modify the relationship between PEs and HFA. To test our hypotheses we performed a microcosm experiment under controlled laboratory conditions. We incubated maize, common bent and beech ${ }^{13} \mathrm{C}$ labelled litter in soils from arable maize fields, natural grasslands dominated by common bent and beech forests according to a full-factorial reciprocal design. We measured the amount of ${ }^{12} \mathrm{C}$ and ${ }^{13} \mathrm{C}$ respired from the microcosms, which allowed us to disentangle the decomposition rates of "older" soil organic matter $\left({ }^{12} \mathrm{C}\right)$ from "fresh" litter $\left({ }^{13} \mathrm{C}\right)$, respectively (Paterson et al., 2008). We examined litter decomposition and PEs in soils receiving "home" or "away" litter, with or without the addition of mineral nitrogen.

\section{Materials \& Methods}

Soil sampling and processing

In August 2015, soil $(0-10 \mathrm{~cm}$, after removing the litter layer) was collected in three different types of ecosystems in the central part of the Netherlands (Table S1), i.e. arable fields, deciduous forests and natural grasslands developed on abandoned arable fields (Table 1). The arable fields were planted with maize (Zea mays L.), the dominant plant species in the forests was beech (Fagus sys/vatica L.). The natural grasslands were dominated by grasses such as common bent (Agrostis capillaris L.), tufted grass (Holcus lanatus L.) and forbs such as narrow-leave plantain (Plantago lanceolata L.) (Table S1) (Morriën et al., 2017). For each ecosystem type, we collected soils from four separate sites that were about $1 \mathrm{~km}$ apart, representing four independent biological replicates for each ecosystem type (Table S1). Fresh soil was sieved $(4 \mathrm{~mm})$ and homogenized, removing fine roots and other plant debris, but keeping representative sized soil microand meso-fauna in our experimental soil incubations (Chapin et al., 2011). Field-moist soil was then stored at $4^{\circ} \mathrm{C}$ until further use. 


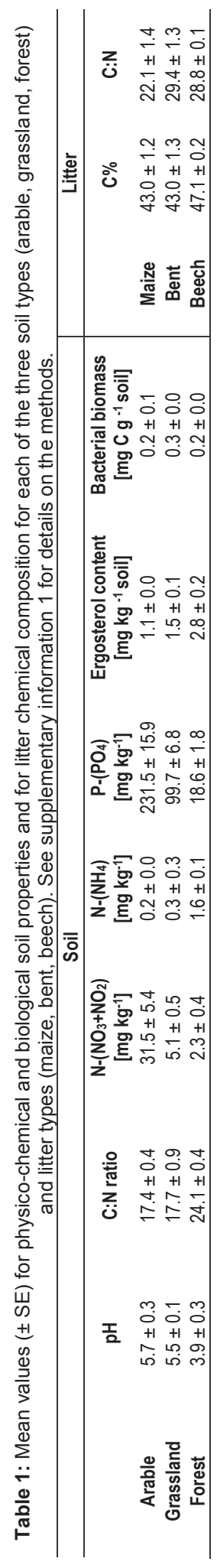


Measurement biotic and abiotic soil and litter properties

From each of our soil samples we collected a random subsample to determine biotic and abiotic soil conditions. In addition, for each of the litter types we determined $\mathrm{C}$ and $\mathrm{N}$ content.

\section{Soil and litter chemical properties}

Soil pH (soil: $\mathrm{H}_{2} \mathrm{O}, 1: 2 \mathrm{w}: \mathrm{v}$ ), gravimetric moisture content (dried at $105^{\circ} \mathrm{C}$, to constant mass) and maximum water holding capacity $(\mathrm{WHC})$ was measured in fresh soil samples. Total $\mathrm{C}$ and $\mathrm{N}$ in all soil samples and litters were measured by a combustion method using an elemental analyser (Thermo flash EA 1112, Thermo Fisher Scientific Inc.). Mineral N was extracted by shaking $10 \mathrm{~g}$ dry weight soil with $50 \mathrm{ml} 1 \mathrm{M} \mathrm{KCl}$ for two hours. Concentration of $\mathrm{N}_{-} \mathrm{NH}_{4}{ }^{+}$and $\mathrm{N}-\mathrm{NO}_{3}{ }^{-}$in the $\mathrm{KCl}$ extract were determined using an AutoAnalyzer (SEAL QuAAtro Segmented Flow Analysis system). The orthophosphate fraction from the soils was extracted in a 1:20 (w/v) ratio with a 0.5 molar solution of $\mathrm{NaHCO}_{3}$ at $\mathrm{pH}$ 8.5. Concentration of $\mathrm{P}-\left(\mathrm{PO}_{4}\right)$ in the extracts was determined by an AutoAnalyzer (SEAL QuAAtro Segmented Flow Analysis system). Soil characteristics of the soils are listed in Table 1.

\section{DNA extraction and quantitative PCRs}

To determine bacterial biomass we extracted DNA from soils using the PowerSoil ${ }^{\circledR}$ DNA Isolation Kit (MOBIO Laboratories, Carlsbad, California, USA) according to the manufacturer's instruction with some modifications: after adding solution $\mathrm{C} 1$ (causing cell lysis), samples were incubated at $60{ }^{\circ} \mathrm{C}$ for $30 \mathrm{~min}$; after adding solution $\mathrm{C} 6$ (releasing DNA from spin filter), samples were incubated at $30{ }^{\circ} \mathrm{C}$ for $10 \mathrm{~min}$. Total DNA was quantified using a NanoDrop ND-1000 Spectrophotometer (Bio-Rad Laboratories Inc.).

Briefly, each qPCR reaction for bacterial quantification (total volume $15 \mu \mathrm{l}$ ) consisted of $7.5 \mu \mathrm{l}$ of Sybergreen (iTaq ${ }^{\mathrm{TM}}$ Universal SYBR® Green Supermix), $0.6 \mu \mathrm{l}$ of forward primer

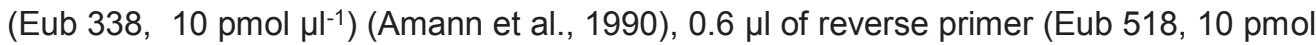
$\mu^{-1}$ ) (Muyzer et al. 1993), $3.3 \mu$ l Nucleic acid free water (Sigma) and $3 \mu$ of DNA. Plasmid Ter331 (Collimonas 16S) was used as a standard for the quantification. The PCR program consisted of an initial denaturation step at $95^{\circ} \mathrm{C}$ for $2 \mathrm{~min}$, followed by 40 cycles of $95{ }^{\circ} \mathrm{C}$ for $10 \mathrm{sec}, 53{ }^{\circ} \mathrm{C}$ for $10 \mathrm{sec}$ and $72{ }^{\circ} \mathrm{C}$ for $25 \mathrm{sec}$. The qPCRs were performed with a Rotor-Gene RG-3000 (Corbett research). For each template DNA we analysed four biological replicates in duplicate. The results obtained, expressed as 16S rRNA gene copy numbers/g of dw soil, were used to calculate the bacterial biomass using a conversion factor of 4.1 copies per cell (Santelli et al., 2008) to estimate the bacterial cell densities 
and then a conversion factor of $320 \mathrm{fg} \mathrm{C} \mathrm{mm}^{3}$ to estimate the carbon content per cell (Bloem et al., 1995).

\section{Fungal biomass}

Ergosterol, a sterol found in fungal membranes, was used as a biomarker for fungal biomass. We used the protocol described by de Ridder-Duine et al. (2006). Briefly, $4 \mathrm{~g}$ of moist soil was shaken with $6 \mathrm{ml}$ of methanol in the presence of glass beads, to disrupt the fungal mycelium and to release the ergosterol into the extractant. After centrifugation and filtration, ergosterol was measured on a 1260 Bio-inert LC coupled with a $6460 \mathrm{QQQ}$ (Agilent, Santa Clara, USA).

\section{Microcosm set-up}

Falcon tubes $(50 \mathrm{ml})$ were filled with $5 \mathrm{~g}$ of dry weight equivalent of moist soil. The lids of the Falcon tubes contained butyl rubber stoppers and o-rings (Rubber BV, Den Haag, The Netherlands), allowing to sample the headspace of the tubes while maintaining airtightness. Moisture content was adjusted to $60 \%$ of the water holding capacity, and the soil was pre-incubated for an acclimatization period ( 7 days in the dark at $20^{\circ} \mathrm{C}$ ). The acclimatization period was based on the results of a previous pilot experiment (data not shown), where soil $\mathrm{CO}_{2}$ efflux rates were regularly checked to confirm stabilization of the soil microbial activity.

We used a reciprocal transplant design, namely each litter type was incubated in all of the soil types. Uniformly labelled 97 atom $\%{ }^{13} \mathrm{C}$-maize litter, 97 atom\% ${ }^{13} \mathrm{C}$-beech litter and 97 atom $\%{ }^{13} \mathrm{C}$-common bent litter (Table S2) (IsoLife BV, Wageningen, The Netherlands) were added at a rate of $5 \mathrm{mg} \mathrm{C} \mathrm{g}^{-1}$ dry weight soil (Bernard et al., 2007; Lee et al., 2011; Pascault et al., 2013). Leaf litter was first cut in small pieces $(0.2 \mathrm{~cm}$ by $0.2 \mathrm{~cm})$ for homogenization, and then added on top of the soil to mimic litter fall (Ball et al., 2008; Bradford et al., 2002). Besides the addition of labelled litter, half of the microcosms also received an aqueous solution of $\mathrm{NH}_{4} \mathrm{NO}_{3}$ to establish a final C-substrate: $\mathrm{N}$ ratio of 15:1 (Fontaine et al., 2011). Controls consisted of soils without litter addition and with and without nitrogen addition. Each treatment was replicated four times. Soils were incubated at $20^{\circ} \mathrm{C}$ in the dark for 30 days. We maintained soil moisture constant throughout the incubation period by weighing the microcosms once a week and watering with deionized water when needed. 
$\mathrm{CO}_{2}$ measurements

For $\mathrm{CO}_{2}$ efflux measurements, microcosms were sealed tightly and the headspace was flushed with $\mathrm{CO}_{2}$-free air (Westfalen Gassen Nederland BV, The Netherlands). After $5 \mathrm{~h}$ of incubation, $6 \mathrm{ml}$ of headspace gas was sampled through the lid septum using a syringe and injected into $5.9 \mathrm{ml}$ evacuated Exetainer vials (Labco Ltd., Buckinghamshire, UK). To measure the total amount of $\mathrm{CO}_{2}$ in the headspace, an aliquot of the gas samples $(150 \mu \mathrm{l}$ for each vial) was injected using an auto-sampler in the Ultra GC gas chromatograph (Interscience, The Netherlands) equipped with a flame ionization detector (FID) and a RtQBOND (30 m, $0.32 \mathrm{~mm}$, ID) capillary column. Helium was used as carrier gas and the oven temperature was kept at $50{ }^{\circ} \mathrm{C}$ with a flow of $5 \mathrm{ml}$. For the analysis of the ${ }^{13} \mathrm{C}-\mathrm{CO}_{2}$ we used a ThermoScientific gaschromatograph with combustion interface (Conflo II) system connected to a ThermoScientific Delta V Plus isotope ratio mass spectrometer (ThermoScientific, Bremen, Germany). Gas samples $(250 \mu \mathrm{l})$ were injected into the split injector (split ratio 1:10), and eluted with helium (5 ml/min) on Rt-QBOND (30 m, $0.32 \mathrm{~mm}$, ID) capillary column at $31^{\circ} \mathrm{C}$. The reference gas was calibrated with Methane $\delta \mathrm{C}$ (VPDB) -38.25 (Arndt Schimmelmann, Indiana University, Bloomington, USA).

Samples were collected at 1, 2, 3, 4, 5, 6, 7, 9, 11, 13, 16, 19, 22, 26, 30 days after the start of the experiment (15 sampling times in total). $\mathrm{CO}_{2}$ concentrations of the 15 sampling times were used to calculate the cumulative respiration for the whole incubation period. Cumulative fluxes were calculated by linear interpolation between measuring times.

\section{Priming effect calculations}

The percentage of respired $\mathrm{CO}_{2}$ derived from ${ }^{13} \mathrm{C}$ substrate was calculated for all treatments and sampling times according to the formula:

$$
\% \mathrm{C}_{\text {substrate derived }}=[(\delta \mathrm{C}-\delta \mathrm{T}) /(\delta \mathrm{C}-\delta \mathrm{L})] \times 100
$$

Where $\delta \mathrm{C}$ is the $\delta^{13} \mathrm{C}$ value of the respired $\mathrm{CO}_{2}$ from control soils, $\delta \mathrm{T}$ is the $\delta^{13} \mathrm{C}$ value in respired $\mathrm{CO}_{2}$ from treated soils and $\delta \mathrm{L}$ is the $\delta^{13} \mathrm{C}$ value of the labelled substrate (Nottingham et al., 2012). Data were expressed in $\mu \mathrm{g} \mathrm{C} \mathrm{g}^{-1}$ soil. Priming effect was then calculated as the total respired $\mathrm{CO}_{2}$ in treated soils minus the substrate-derived $\mathrm{CO}_{2}$ and minus the respired $\mathrm{CO}_{2}$ in the control and expressed in $\mu \mathrm{g} \mathrm{C} \mathrm{g}^{-1}$ soil (Qiao et al., 2016):

$$
\text { Primed } \mathrm{C}=\mathrm{C}_{\text {total }}-\mathrm{C}_{\text {substrate }}-\mathrm{C}_{\text {control }}
$$




\section{Home field advantage calculations}

Litter-derived carbon and PE data $\left({ }^{13} \mathrm{C}-\mathrm{CO}_{2}\right.$ and ${ }^{12} \mathrm{C}-\mathrm{CO}_{2}$, respectively) were used to calculate HFA effects on litter (subsequently referred to as litter HFA) and SOM decomposition (subsequently referred to as priming HFA), respectively, using the procedure described by Gießelmann et al. (2011). This method consists of comparing litter derived carbon rate (or the SOM derived carbon rate in the case of priming HFA) of a particular litter type observed in the soil type from which it was originated (home) with the litter (or SOM) derived $\mathrm{C}$ rate observed in a different soil type (away). Multiple site comparison indices (HFAi) can be measured using the following four equations:

$$
\begin{aligned}
& \mathrm{HFAi}_{\mathrm{a}}=\left(\mathrm{HDD}_{\mathrm{a}}-\mathrm{ADD}_{\mathrm{a}}-H\right) /(n-2) \\
& \mathrm{HDD}_{\mathrm{a}}=\left(\mathrm{SR}_{\mathrm{aA}}-\mathrm{SR}_{\mathrm{bA}}\right)+\left(\mathrm{SR}_{\mathrm{aA}}-\mathrm{SR}_{\mathrm{cA}}\right) \\
& \mathrm{ADD}_{\mathrm{a}}=\left(\mathrm{SR}_{\mathrm{aB}}-\mathrm{SR}_{\mathrm{bB}}\right)+\left(\mathrm{SR}_{\mathrm{aC}}-\mathrm{SR}_{\mathrm{cC}}\right) \\
& \mathrm{H}=\Sigma \mathrm{HDD} /(n-1)
\end{aligned}
$$

Where $\mathrm{HFAi}_{\mathrm{a}}$ represents the additional decomposition at home for litter type a. A, B and $\mathrm{C}$ are the home soils for litter type $\mathrm{a}, \mathrm{b}$ and $\mathrm{c}$, respectively. Thus, for example, $\mathrm{SR}_{\mathrm{aA}}$ is the substrate derived (litter or SOM derived) respiration of litter type a in soil A (home). HDD and ADD represent at home decomposition difference and away from home decomposition difference, respectively. $H$ is the sum of all HDD divided by $n-1$. $n$ represents the number of litter types (in our case three).

\section{Statistical analysis}

To test how soil type, litter type, nitrogen amendment and their interactions affected litterderived $\mathrm{CO}_{2}, \mathrm{PE}$, litter HFA and priming HFA, we used three-way ANOVA, followed by post-hoc Tukey's test. We used one-sample T-tests to test if litter HFA and priming HFA indices (obtained with the procedure of Gießelmann et al. 2011) were different from zero. Data of litter HFA and priming HFA were compared pairwise using an independent sample t-test within $\mathrm{N}$ fertilized and non-fertilized treatments (e.g. Beech vs. Beech+N. etc.). We used one-way ANOVA to test for differences in HFA between treatments, followed by posthoc Tukey's test. Finally, we used regression analyses to test for the relationships between litter derived $\mathrm{CO}_{2}$ and PE, and between litter HFA and priming HFA. All the statistical analyses were performed using IBM SPSS Statistics 22. 


\section{Results}

\section{Litter decomposition and priming effects}

The $\mathrm{CO}_{2}$ production levelled off in all soil types within the first 10 days of the experiment (Fig. S1). This indicates that during our incubation experiment most litter decomposition was taking place during the first 10 days.

Litter type, soil type and their interaction affected the release of litter-derived $\mathrm{CO}_{2}\left({ }^{13} \mathrm{C}\right)$ (Table 2). Generally, the lowest amounts of litter-derived $\mathrm{C}$ were observed for beech litter, while maize and bent litters resulted in higher $\mathrm{CO} 2$ efflux in all soils (Fig. 1A-C and Table 2). The amounts of litter-derived $C$ were lower in forest soils, than in arable and grassland soils, particularly for bent litter as indicated by the interaction. Indeed, bent litter decomposes less in forest soil than in the other soils. Furthermore, beech litter decomposes more in arable soil than in the other soils. Nitrogen addition slightly increased litter respiration $\left(F_{1,54}=5.682, P=0.021\right)$, but this was not picked up by post-hoc testing (Fig 1A-C).

Table 2: ANOVA results testing the effect of soil type (arable, forest and grassland), litter type (maize, beech and bent), nitrogen addition and their interactions on the amount of litter-derived $\mathrm{C}\left(\mu \mathrm{g} \mathrm{C}-\mathrm{CO}_{2} \mathrm{~g} \mathrm{soil}^{-1}\right)$, primed $\mathrm{C}(\mu \mathrm{g}$ $\mathrm{C}-\mathrm{CO}_{2} \mathrm{~g} \mathrm{soil}^{-1}$ ) and their ratio. df represents the numerator, denominator degrees of freedom.

\begin{tabular}{lllll}
\hline & Term & F & df & P \\
\hline Litter derived C & Soil & 4.101 & 2,54 & 0.022 \\
& Litter & 183.915 & 2,54 & $<0.0005$ \\
& Nitrogen & 5.682 & 1,54 & 0.021 \\
& Soil x litter & 3.924 & 4,54 & 0.007 \\
& Soil x nitrogen & 0.022 & 2,54 & 0.978 \\
& Litter x nitrogen & 1.684 & 2,54 & 0.195 \\
& Soil x litter x nitrogen & 0.139 & 4,54 & 0.967 \\
\hline Primed C & Soil & 11.023 & 2,54 & $<0.0005$ \\
& Litter & 182.693 & 2,54 & $<0.0005$ \\
& Nitrogen & 0.475 & 1,54 & 0.494 \\
& Soil x litter & 0.934 & 4,54 & 0.451 \\
& Soil x nitrogen & 0.580 & 2,54 & 0.564 \\
& Litter x nitrogen & 1.955 & 2,54 & 0.152 \\
& Soil x litter x nitrogen & 0.430 & 4,54 & 0.787 \\
\hline Primed C / litter derived C Coil & 0.120 & 2,54 & 0.887 \\
& Sitter & 2.271 & 2,54 & 0.075 \\
& Nitrogen & 0.029 & 1,54 & 0.865 \\
& Soil x litter & 0.573 & 4,54 & 0.683 \\
& Soil x nitrogen & 0.747 & 2,54 & 0.479 \\
& Litter x nitrogen & 0.794 & 2,54 & 0.457 \\
& Soil x litter x nitrogen & 0.407 & 4,54 & 0.803 \\
\hline
\end{tabular}

Litter type and soil type significantly affected primed $\mathrm{C}\left(\mathrm{F}_{2,54}=182.693, \mathrm{P}<0.001 ; \mathrm{F}_{2,54}=\right.$ 11.023, $P<0.001$ respectively). Generally, maize and bent litters induced the highest PEs (Fig. 1D-F and Table 2), and priming was lowest in forest soils (Fig 1D-F). Nitrogen addition had no effect on PEs $\left(F_{1,54}=0.475, P=0.494\right)$.

The three-way interaction between soil type, litter type and nitrogen addition did not affect the amount of litter-derived $\mathrm{CO}_{2}\left(\mathrm{~F}_{4,54}=0.139, \mathrm{P}=0.967\right)$ and $\mathrm{PEs}\left(\mathrm{F}_{4,54}=0.430, \mathrm{P}=\right.$ 
0.787). The ratio between primed $\mathrm{C}$ and litter derived $\mathrm{C}$ (Fig. $1 \mathrm{G}-\mathrm{I}$ ) tended to be highest for beech litter in all soils (Litter type effect: $F_{2,54}=2.271, P=0.075$; Table 2), indicating that beech litter had a stronger impact on PE relative to litter decomposition compared to the other litter types.

The regression analysis showed a linear relationship between litter derived $\mathrm{CO}_{2}$ and $\mathrm{PE}$ $\left(R^{2}=0.7803 ; P<0.0001\right)$ (Fig. S2A). When the analyses were done for each litter type separately we found a linear relationship between litter derived $\mathrm{CO}_{2}$ and $\mathrm{PE}$ for beech and bent litters $\left(R^{2}=0.5414 ; P<0.0001\right.$ and $R^{2}=0.3802 ; P \leq 0.001$, respectively) but not for maize litter $\left(R^{2}=0.0757 ; P=0.1931\right)$ (Fig. S2B).

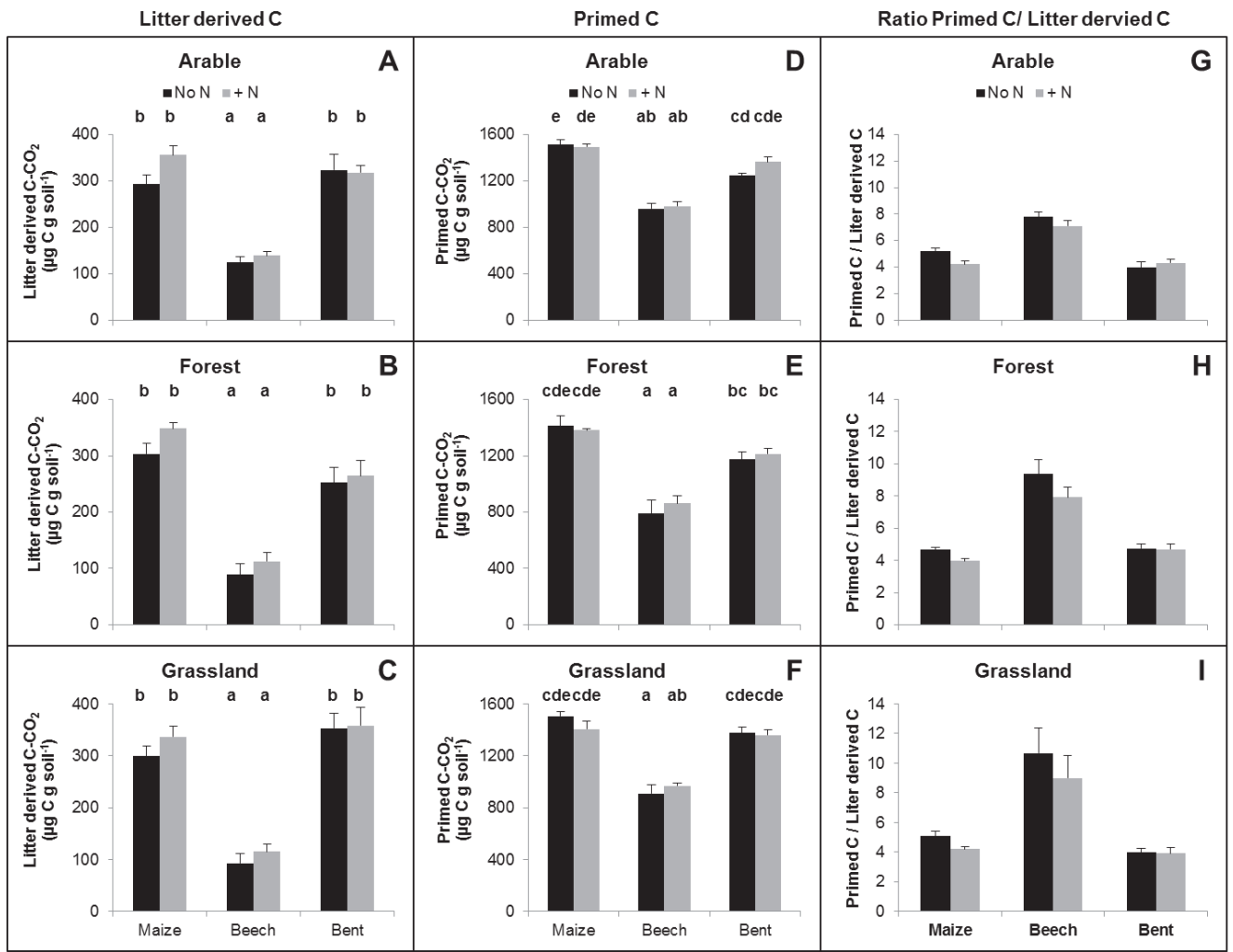

Fig. 1: A-C: Litter derived $\mathrm{CO}_{2}\left(\mu \mathrm{g} \mathrm{C}-\mathrm{CO}_{2} \mathrm{~g} \mathrm{soil}^{-1}\right)$ induced by three different litter types (maize, beech and bent) in three soils (arable, forest and grassland soil) after 30 days of incubation. D-F: Primed $\mathrm{CO}_{2}\left(\mu \mathrm{g} \mathrm{C}-\mathrm{CO}_{2} \mathrm{~g} \mathrm{soil}^{-1}\right)$ induced by three different litter types (maize, beech and bent) in three soils (arable, forest and grassland soil after 30 days of incubation. G-I: Ratio between Primed $\mathrm{CO}_{2}$ and litter derived $\mathrm{CO}_{2}$ after 30 days of incubation. Statistically significant differences $(P<0.05$, Tukey's HSD test) among litter types are marked with different letters. No letters indicate no significant differences. $\mathrm{N}$ : $\mathrm{NH}_{4} \mathrm{NO}_{3}$. Error bars represent standard errors $(n=4)$. ANOVA results are presented in Table 1. 
Home field advantage in litter decomposition and priming of SOM

The HFA index (percentage of additional decomposition at home as compared to all away sites) calculated for both litter HFA and priming HFA was not significantly different from zero $(P>0.05)$ (Table S3) for any of the treatments (Fig. 2). However, we found significant differences between the treatments for litter HFA $\left(F_{18,5}=3.474, P=0.023\right)$. Litter homefield effects were significantly higher in grasslands than in maize fields amended with nitrogen. In contrast, we did not find significant differences between litter types and soil types for priming HFA $\left(\mathrm{F}_{18,5}=2.075, \mathrm{P}=0.116\right)$ (Fig. 2). Furthermore, we did not find a significant effect of nitrogen addition on both litter HFA and priming HFA (Table S4).

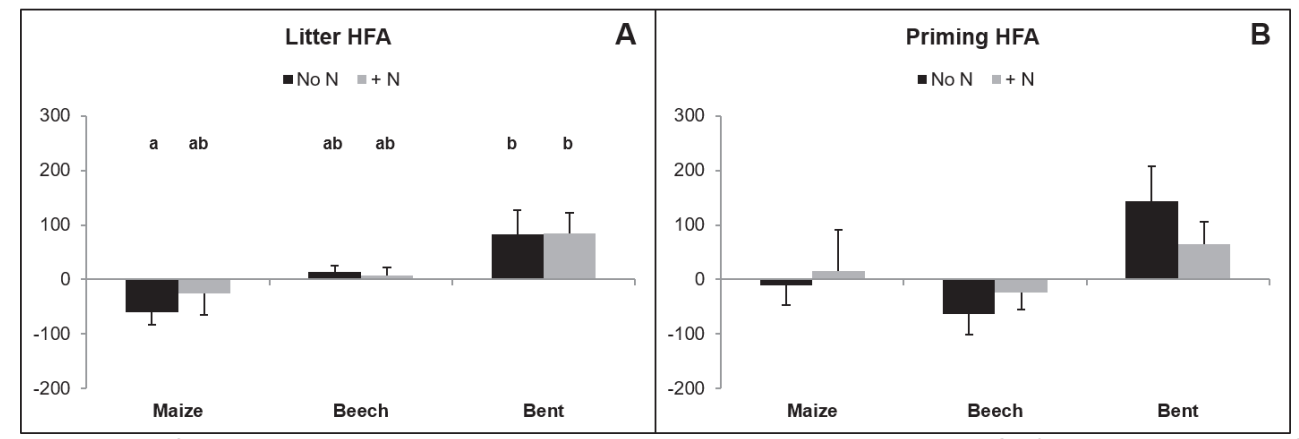

Fig. 2: Home-field advantage (calculated as the additional decomposition at home in Gießelmann et al. 2011) of the cumulative litter derived $\mathrm{CO}_{2}(\mathrm{~A})$ and cumulative primed $\mathrm{CO}_{2}(\mathrm{~B})$ after 30 days of incubation. Statistically significant differences $(P<0.05$, Tukey's HSD test) are marked with different letters. No letters indicate no significant differences. Error bars represent standard errors $(n=4)$.

The regression analysis showed a linear relationship between litter HFA and priming HFA indices for treatments without $\mathrm{N}$ addition $\left(\mathrm{R}^{2}: 0.43 ; \mathrm{F}=7.545 ; \mathrm{P}=0.021\right)$ (Fig. 3 ) while it was not for treatments with $\mathrm{N}$ addition $\left(\mathrm{R}^{2}: 0.11 ; \mathrm{F}=1.290 ; \mathrm{P}=0.283\right)$ (Fig. 3).

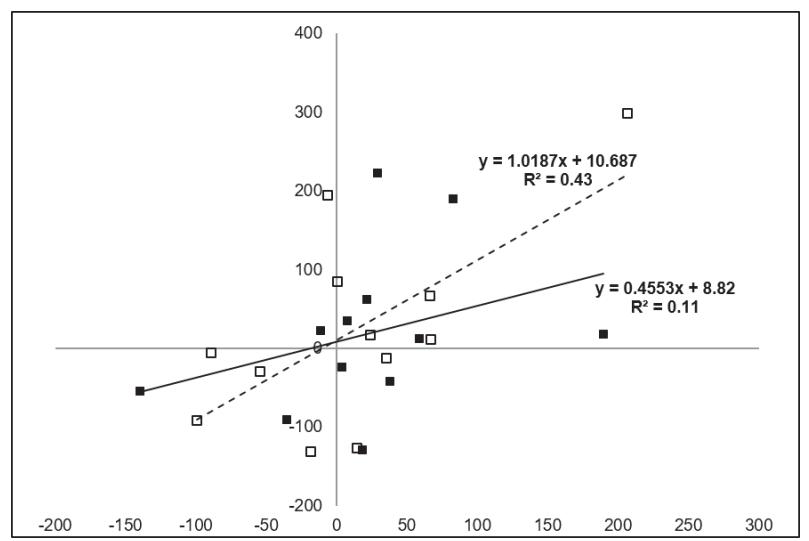

Fig. 3: Relationship between litter HFA and priming HFA for samples without $\mathrm{N}$ addition (dashed line, open squares) and samples with $\mathrm{N}$ addition (solid line, full squares). 


\section{Discussion}

Decomposition of plant litter and SOM are fundamental processes controlling the soil C balance. Several studies have focused on describing the mechanisms and main controllers of plant litter and SOM decomposition in different ecosystems in order to predict responses to global change (e.g, Gholz et al. 2000, Sayer et al. 2011, Makkonen et al. 2012, Chen et al. 2014). It was suggested that specific interactions between plant residues and decomposer communities in the soil may be an important factor in controlling the rate of C turnover (Fontaine et al., 2007; Wang et al., 2015). HFA and PEs are two processes where the composition and functioning of microbial communities can play an important role with impact on loss of $C$ from the soil (Fontaine et al., 2011; Keiser et al., 2014). However, little is known about the interaction of these two mechanisms. Here, we show for the first time that there is a positive relationship between litter HFA (percentage of additional litter decomposition in home soils as compared to away soils) and priming HFA (percentage of additional PE in home soils as compared to away soils), indicating that the rates of both litter decomposition and PEs may be affected in the same manner by home combinations of soil and litter versus away combinations.

\section{Litter decomposition and priming effects}

Both litter-derived carbon $\left({ }^{13} \mathrm{C}\right)$ and PEs $\left({ }^{12} \mathrm{C}\right)$ were affected by litter type (i.e., generally lowest decomposition rates for beech litter) and soil type (i.e., generally lowest decomposition rates in forest soils). This is in line with previous studies showing that litter characteristics (e.g., Cornwell et al. 2008, Pascault et al. 2013, Cleveland et al. 2014, Fanin and Bertrand 2016) and biotic and abiotic soil conditions (Bradford, 2014; Keeler et al., 2009; Knorr et al., 2005; Qiao et al., 2016; Wang et al., 2015), can exert a major control on the decomposition of litter and SOM. However, in contrast with previous findings that high quality litter (often indicated as litter with a low $\mathrm{C}: \mathrm{N}$ ratio) generally decomposes faster than low quality litter (Cornwell et al., 2008; Makkonen et al., 2012; Veen et al., 2015a), we found that beech litter decomposed much slower then bent litter, while they did not differ in C:N ratio (Rousk et al., 2007; Rousk and Bååth, 2007). Hence, other litter chemical properties than $\mathrm{C}: \mathrm{N}$ ratio alone were probably important for describing litter quality in our study, such as the lignin content. Indeed, beech litter is rich in recalcitrant $\mathrm{C}$ compounds and its decomposition is mostly driven by lignin: $\mathrm{N}$ ratio (Berg and McClaugherty, 2003). The strong influence of litter type on PEs is in accordance with recent findings that the complexity of organic substrates added to a soil drives the magnitude of priming effects (Di Lonardo et al., 2017). The ratio and the correlation between primed $\mathrm{C}$ and litter-derived $\mathrm{C}$ tended to be higher for beech litter than for other litter types in all soils. This indicates that beech litter had a stronger impact on PEs compared to all other litter types, although it was less decomposed. This may be explained by the higher chemical similarity between 
the added litter and SOM. Beech is more lignin-rich than the other litter types (Berger and Berger, 2014; John et al., 2011), possibly resembling more the SOM fractions thereby leading to higher PEs (van der Wal and de Boer, 2017).

\section{Relationship between litter- and priming home-field advantage effects}

We found that both litter HFA and priming HFA did not differ significantly from zero, indicating that litter decomposition and PEs were not accelerated or decelerated in home compared to away soils for any of the treatments. This finding contrasts previous work which showed that litter transplants between contrasting habitats, such as the forest and grassland in our work, often result in high HFA (Ayres et al., 2009; Cornelissen et al., 2012; Veen et al., 2015a). However, the short time span of our experiment may explain weak HFA effects, since colonization by slow growing K-strategists which can consume the more recalcitrant compounds in plant litter may take longer (Fontaine et al., 2003). Still we found differences in litter HFA between the three types of ecosystems, with the lowest litter HFA for arable fields and the highest for grasslands. This suggests that decomposer communities from grasslands were more specialized to decompose their own litter than communities from arable fields.

The variation in HFA between treatments, as well as the variation between individual samples (Fig. 2), shows that there were differences in the magnitude of litter and priming HFA for individual locations or treatments. We used this variation to test whether sites with high litter HFA also had high priming HFA and vice versa. We hypothesized that decomposers that are specialized to breakdown their home litter will also accelerate the breakdown of SOM thereby enhancing PEs. Our results showed a slightly positive relationship between litter HFA and priming HFA, indicating that our hypothesis may be true. However, we observed relatively weak HFA effects in our study. This could have been a result of the short duration of our experiment period, as it could take longer to observe HFA, while PE appears rapidly (Blagodatskaya and Kuzyakov, 2008). However the soils used already had a long history with the litter types and therefore were expected to have built up a specialized decomposer community. Other studies showed that under such conditions HFA can already occur after a few weeks (Fanin et al., 2016) and does not necessarily become stronger with experimental duration (Veen et al., 2018). Alternatively, weak HFA could have resulted from the absence of macrofauna in our study (Milcu and Manning, 2011).

A previous study showed that PEs occur in soils with litter HFA, but the use of a standard litter type to test PEs in this study did not allow to test for priming HFA, i.e., whether PEs with "home" litter were higher than with "away" litter (Fanin et al., 2016). We now show for the first time, that in line with HFA for litter decomposition, there might be also HFA for $P E s$ suggesting that both rates of litter decomposition and priming may be affected in the 
same manner by home combinations of soil and litter versus away combinations. As a result, a specialized litter decomposer community driving HFA may further accelerate soil $\mathrm{C}$ mineralization via enhanced induction of PEs. This possibly implies that soil $\mathrm{C}$ dynamics may be more strongly affected by specialized interactions between soil microbial communities, soil organic matter and litter than we have assumed before (Fontaine et al., 2003; van der Wal and de Boer, 2017).

The finding that litter and SOM decomposition can be impacted by specialized soil communities via both litter HFA and priming HFA, also suggests that decoupling of plants and soil communities may alter soil $\mathrm{C}$ dynamics. Decoupling of plant-soil interactions may occur when responses in plant and soil communities to global-changes happen at a different rate (Berg et al., 2010; van der Putten, 2012). Experimental work has shown that legacy effects of decoupled litter-decomposer interactions on $\mathrm{C}$ mineralization rates may remain for at least a few generations of plant growth (Keiser et al., 2011). Yet, the impact of decoupled plant-soil interactions are often temporary as soil communities will respond to new plant species (Diez et al., 2010). How the impact of decoupling of plant-litter interactions on litter and priming HFA impacts $\mathrm{C}$ cycling in a complex field community, where individual plants potentially experience different home-field effects (Freschet et al., 2012; Perez et al., 2013), requires further research.

The positive relationship between litter HFA and priming HFA may indicate that indigenous soil communities can both accelerate or decelerate litter decomposition and PEs. To better understand when and where stimulation or reduction of litter decomposition and PEs occur, it will be important to determine which environmental factors are drivers of HFA effects. Previous work has suggested that litter quality (Veen et al., 2015a) or the similarity between the chemical composition of a litter type and the soil matrix (Freschet et al., 2012) could be important determining the strength and direction of HFA. However, evidence is mixed with some studies showing high HFA for low-quality litters (Milcu and Manning, 2011; Wallenstein et al., 2013), while others found no relationship (Veen et al., 2015b) or showed that high HFA mainly occurred for high-quality litter (Fanin et al., 2014; Perez et al., 2013). The difference in litter HFA and priming HFA between the systems in our study do not appear to link directly to the quality of the litters, as HFA for maize litter was not different from that of beech, while $\mathrm{C}: \mathrm{N}$ ratios and rates of decomposition strongly differed between these litter types. Therefore, even though we found that litter and priming HFA were positively related, it is still hard to predict for which type of litters positive or negative home-field effects occur (Austin et al., 2014; Veen et al., 2015a).

\section{The impact of nitrogen addition}

In line with our second hypothesis that $\mathrm{N}$ addition would modify the relationship between litter HFA and priming HFA, we found that the positive relationship between litter HFA and 
priming HFA disappeared when $\mathrm{N}$ was added. This could be due to changes in the stoichiometric balance between the microbial decomposer communities and the organic matter sources (litter and SOM). The addition of $\mathrm{N}$ and litter to the soil microcosms might have altered the demands necessary for microbial growth, litter decomposition and PEs (Mooshammer et al., 2014b). For example, $\mathrm{N}$ addition can reduce microbial mining for $\mathrm{N}$ and, consequently, SOM decomposition (Chen et al., 2014) and thus the magnitude of PEs (Dijkstra et al., 2013). However, in our study the effect of $\mathrm{N}$ addition on litter decomposition, PEs (Table 2), litter HFA and priming HFA (Fig 2) were limited, providing a limited explanation for the weaker relationship between litter and priming HFA under fertilization. This could be because the effects of $\mathrm{N}$ addition on decomposition processes have inconsistent effects on both litter decomposition and PEs (e.g., Knorr et al. 2005, Cleveland et al. 2006, Craine et al. 2007). Alternatively, different processes, such as accelerated decomposition by a relief of $\mathrm{N}$ limitation or reduction of decomposition by the suppressing of lignin-degrading enzyme activities (Carreiro et al., 2000; Frey et al., 2004; Sinsabaugh et al., 2005) may interact, making it difficult to explain the mechanism of the effect of $\mathrm{N}$ addition on litter- and priming HFA.

\section{Conclusions}

In this study we investigated the relationship between litter and priming HFA for an arable, a grassland and a forest system using a full-factorial litter transplant experiment. Even though the HFA index did not differ from zero for any of our treatments, there was a slightly positive relationship between HFA of litter decomposition and HFA of priming of SOM. This could indicate that specialized decomposer communities may not only affect soil $\mathrm{C}$ mineralization via accelerated litter decomposition, but also via enhanced PEs. Consequently, the impact of specialized decomposer communities on soil $\mathrm{C}$ dynamics may be greater than has been assumed previously. To better understand when and where indigenous soil microbes will accelerate or decelerate soil $\mathrm{C}$ cycling in response to own litter, it will be crucial to elucidate the environmental drivers of both litter and priming HFA (Billings et al., 2010; Veen et al., 2015a). This will allow us to improve predictions of how global-change induced decoupling of plant and soil communities impact soil $\mathrm{C}$ dynamics.

\section{Acknowledgements}

We thank Machiel Bosch of Natuurmonumenten for permission to sample the grassland soils and Derks family for sampling the arable soils. We are thankful to Stijn van Gils, Jan Geert Bruggink and Iris Chardon for their practical help in the field and lab. DPDL was sponsored by a CSE-KNAW grant. MM was sponsored by an ERC grant (ERC-Adv 26055290). GFV was sponsored by a NWO-VENI grant No. 863.14.013. This is publication number 6579 of the NIOO-KNAW Netherlands Institute of Ecology. Raw data are available on: https://dataverse.nl/dvn/dv/nioo-me. 


\section{Supplementary information}

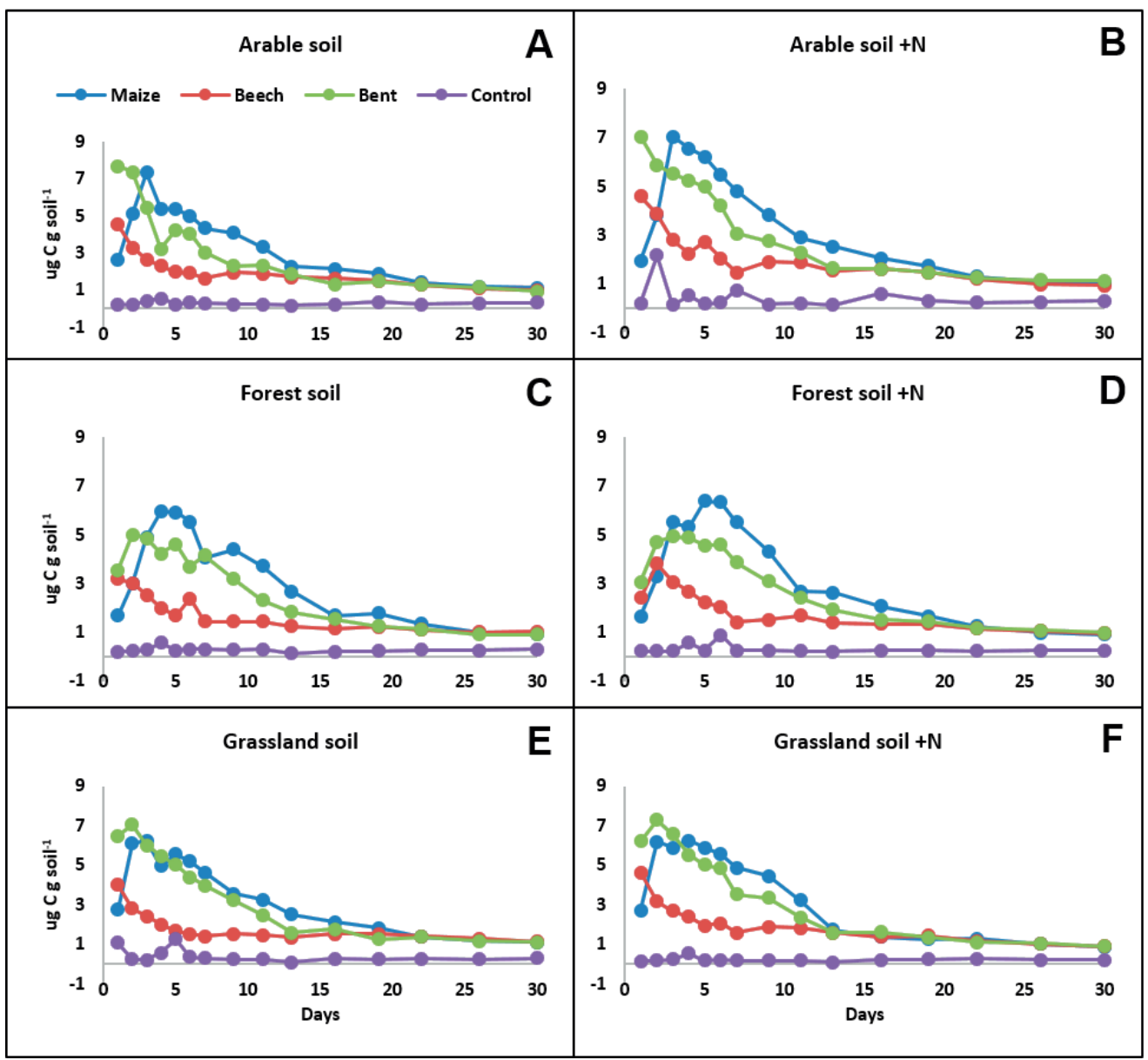

Fig. S1: CO2 release over 30 days of incubation ( $\mu \mathrm{g} \mathrm{C}-\mathrm{CO} 2 \mathrm{~g}$ soil-1) induced by three different litter types (maize, beech and bent) in three soils (arable, forest and grassland soil).

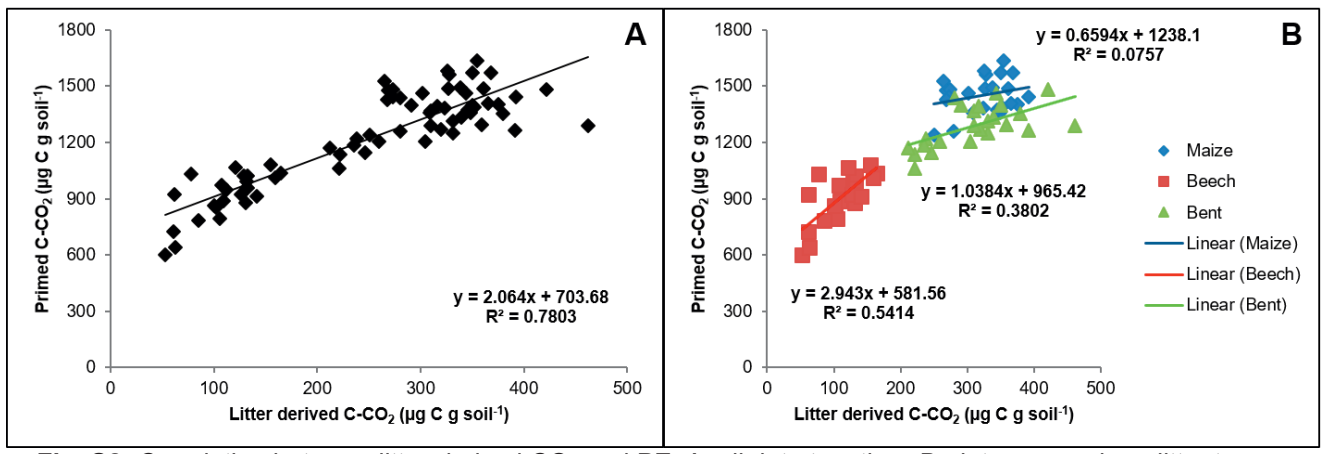

Fig. S2: Correlation between litter-derived $\mathrm{CO}_{2}$ and PE. A: all data together; $\mathrm{B}$ : data grouped per litter types. 
Table S1: Geographical locations of the sampled soils.

\begin{tabular}{|c|c|c|c|c|c|}
\hline Sampling day & Soil type & Name & Code & Coordinate & Dominant species \\
\hline $26-8-2015$ & Arable soil & Derks farm & DE1 & N $51^{\circ} 38^{\prime} 27^{\prime \prime}$ E $5^{\circ} 40^{\prime} 44^{\prime \prime}$ & Zea mays $L$. \\
\hline $26-8-2015$ & Arable soil & Derks farm & DE2 & N 51ํ39'13" E 540'21" & Zea mays $L$. \\
\hline $26-8-2015$ & Arable soil & Derks farm & DE3 & N 513ㅇ'54" E 5⒋ $41^{\prime} 11^{\prime \prime}$ & Zea mays $L$. \\
\hline $26-8-2015$ & Arable soil & Derks farm & DE4 & 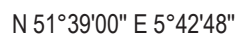 & Zea mays $L$. \\
\hline $26-8-2015$ & Beech forest soil & Odiliapeelse bossen & OD1 & N 51ํ38'24" E 542'01" & Fagus sylvatica $L$. \\
\hline $26-8-2015$ & Beech forest soil & Odiliapeelse bossen & OD2 & 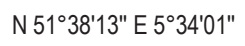 & Fagus sylvatica $L$. \\
\hline $26-8-2015$ & Beech forest soil & Bosdreef & B01 & N $51^{\circ} 40^{\prime} 51^{\prime \prime}$ E $5^{\circ} 38^{\prime} 03^{\prime \prime}$ & Fagus sylvatica $L$. \\
\hline $26-8-2015$ & Beech forest soil & Bosdreef & $\mathrm{BO} 2$ & N $51^{\circ} 41^{\prime} 06^{\prime \prime}$ E $5^{\circ} 37^{\prime} 36^{\prime \prime}$ & Fagus sylvatica $L$. \\
\hline $27-8-2015$ & Grassland soil & Nieuw Reemst & NR & N $52^{\circ} 2^{\prime} 33^{\prime \prime}$ E $5^{\circ} 46^{\prime} 29^{\prime \prime}$ & $\begin{array}{l}\text { Holcus lanatus (64\%), } \\
\text { Agrostis capilaris (20\%) }\end{array}$ \\
\hline $27-8-2015$ & Grassland soil & Wolfhezer Veld & WV & 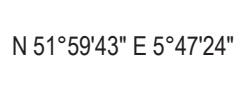 & $\begin{array}{c}\text { Agrostis capilaris (47\%), } \\
\text { Holcus lanatus (27\%) }\end{array}$ \\
\hline $27-8-2015$ & Grassland soil & Mosselse Veld & MV & N $52^{\circ} 4^{\prime} 23^{\prime \prime}$ E $5^{\circ} 44^{\prime} 13^{\prime \prime}$ & $\begin{array}{c}\text { Agrostis capilaris (38\%), } \\
\text { Plantago lanceolata (28\%), } \\
\text { Holcus lanatus (11\%) }\end{array}$ \\
\hline $27-8-2015$ & Grassland soil & Dennenkamp & DK & N $52^{\circ} 01^{\prime} 43^{\prime \prime}$ E $5^{\circ} 48^{\prime} 2^{\prime \prime}$ & $\begin{array}{c}\text { Plantago lanceolata (29\%), } \\
\text { Agrostis capilaris (25\%), } \\
\text { Holcus lanatus }(22 \%)\end{array}$ \\
\hline
\end{tabular}

Table S2: Information about the ${ }^{13} \mathrm{C}$ labelled leaf litters (IsoLife BV, Wageningen, The Netherlands).

\begin{tabular}{|c|c|c|c|c|c|}
\hline Litter type & Isotopic abundance & Age (plants) & Physical form & Appearance & Processed \\
\hline $\begin{array}{c}\text { European beech } \\
\text { (Fagus sylvatica) }\end{array}$ & $\begin{array}{c}\text { Uniform, } 97 \text { atom } \% \\
{ }^{33} \mathrm{C}\end{array}$ & $\begin{array}{c}9 \text { months after stem } \\
\text { cutting }\end{array}$ & Intact leaves & $\begin{array}{c}\text { Frozen below } \\
-30^{\circ} \mathrm{C} ; \\
\text { Lyophilised }\end{array}$ \\
\hline $\begin{array}{c}\text { Common bent } \\
\text { (Agrostis capillaris) }\end{array}$ & $\begin{array}{c}\text { Uniform, } 97 \text { atom } \% \\
{ }^{33} \mathrm{C}\end{array}$ & 3 months & Cuttings, intact & Green & $\begin{array}{c}\text { Frozen below } \\
-30^{\circ} \mathrm{C} ; \\
\text { Lyophilised }\end{array}$ \\
\hline Maize (Zea mays) & $\begin{array}{c}\text { Uniform, } 97 \text { atom \% } \\
{ }^{33} \mathrm{C}\end{array}$ & 7 weeks & Cut pieces & Greenish & $\begin{array}{c}\text { Frozen below } \\
-30^{\circ} \mathrm{C} ; \\
\text { Lyophilised }\end{array}$ \\
\hline
\end{tabular}


Table S3: One-sample T test (test value $=0$ ) on litter and priming HFA.

\begin{tabular}{|c|c|c|c|c|c|}
\hline & & Treatment & $t$ & df & Sig. (2-tailed) \\
\hline \multirow{6}{*}{$\begin{array}{l}\text { 荇 } \\
\text { 离 } \\
\text { 至 }\end{array}$} & \multirow{3}{*}{ without N } & Maize & -2.684 & 3 & 0.075 \\
\hline & & Beech & 1.185 & 3 & 0.321 \\
\hline & & Bent & 1.874 & 3 & 0.158 \\
\hline & \multirow{3}{*}{ with $\mathrm{N}$} & Maize & -0.667 & 3 & 0.552 \\
\hline & & Beech & 0.438 & 3 & 0.691 \\
\hline & & Bent & 2.204 & 3 & 0.115 \\
\hline \multirow{6}{*}{ 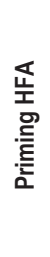 } & \multirow{3}{*}{ without $\mathrm{N}$} & Maize & -0.286 & 3 & 0.794 \\
\hline & & Beech & -1.642 & 3 & 0.199 \\
\hline & & Bent & 2.213 & 3 & 0.114 \\
\hline & \multirow{3}{*}{ with $\mathrm{N}$} & Maize & 0.207 & 3 & 0.849 \\
\hline & & Beech & -0.739 & 3 & 0.514 \\
\hline & & Bent & 1.516 & 3 & 0.227 \\
\hline
\end{tabular}

Table S4: Independent sample T Test on litter and priming HFA.

\begin{tabular}{|c|c|c|c|c|c|}
\hline Treatment & & $\mathbf{F}$ & $\mathbf{P}$ & $\mathrm{t}$ & df \\
\hline \multirow{2}{*}{ Beech litter HFA } & Equal variances assumed & 0.357 & 0.572 & 0.354 & 6 \\
\hline & \multicolumn{2}{|c|}{ Equal variances not assumed } & & 0.354 & 5.532 \\
\hline \multirow{2}{*}{ Maize litter HFA } & Equal variances assumed & 0.972 & 0.362 & -0.767 & 6 \\
\hline & \multicolumn{2}{|c|}{ Equal variances not assumed } & & -0.767 & 4.808 \\
\hline \multirow{2}{*}{ Bent litter HFA } & Equal variances assumed & 0.064 & 0.809 & -0.022 & 6 \\
\hline & \multicolumn{2}{|c|}{ Equal variances not assumed } & & -0.022 & 5.875 \\
\hline \multirow{2}{*}{ Beech priming HFA } & Equal variances assumed & 1.246 & 0.307 & -0.8 & 6 \\
\hline & \multicolumn{2}{|c|}{ Equal variances not assumed } & & -0.8 & 5.784 \\
\hline \multirow{2}{*}{ Maize priming HFA } & Equal variances assumed & 1.363 & 0.287 & -0.311 & 6 \\
\hline & \multicolumn{2}{|c|}{ Equal variances not assumed } & & -0.311 & 4.335 \\
\hline \multirow{2}{*}{ Bent priming HFA } & Equal variances assumed & 1.625 & 0.249 & 1.024 & 6 \\
\hline & \multicolumn{2}{|c|}{ Equal variances not assumed } & & 1.024 & 5.165 \\
\hline
\end{tabular}




\section{Chapter 4}

Effect of the amount of organic trigger compounds and soil microbial biomass on the magnitude of priming of soil organic matter

D.P. Di Lonardo, W. de Boer, H. Zweers, \& A. van der Wal

Revised manuscript (submitted) 


\begin{abstract}
Priming effects (PEs) are defined as short-term changes in the turnover of soil organic matter (SOM) caused by the addition of easily degradable organic compounds to the soil. PEs are ubiquitous but the direction (acceleration or retardation of SOM decomposition) and magnitude in response to organic carbon additions are not easy to predict. Several factors influence PEs and one of them is the ratio between the amount of added PE-trigger substrate to the size of initial soil microbial biomass. There are indications that contrasting effects of low and high trigger substrate to microbial biomass ratios on PEs can be expected. The aim of the current study is to test this for three different ecosystems. We did this by adding three different amounts of ${ }^{13} \mathrm{C}$-glucose with or without addition of mineral $\mathrm{N}\left(\mathrm{NH}_{4} \mathrm{NO}_{3}\right)$ to soils collected from arable lands, grasslands and forests. The addition of ${ }^{13} \mathrm{C}$-glucose was equivalent to $15 \%, 50 \%$ and $200 \%$ of microbial biomass C. After one month of incubation, glucose had induced positive PEs for the majority of soils, with differences in magnitude related to the soil origin and the amount of glucose added. For arable and forest soils, the primed $\mathrm{C}$ increased with increasing amount of glucose added, whereas for grassland soils this relationship was negative. We found positive correlations between glucose-derived $\mathrm{C}$ and primed $\mathrm{C}$ and the strength of these correlations was different among the three ecosystems considered. Generally, the addition of $\mathrm{N}$ to our soil mesocosms had little effect on the flux of substrate-derived $\mathrm{C}$ and primed $\mathrm{C}$. Overall, our study does not support the hypothesis that the trigger-substrate to microbial biomass ratio can be an important predictor of PEs. Rather our results indicate that the amount of energy obtained from decomposing trigger substrates is an important factor for the magnitude of PEs.
\end{abstract}




\section{Introduction}

Priming effects (PEs) are defined as short-term changes in the turnover of soil organic matter (SOM) caused by the input of easily degradable organic compounds (e.g. plant residues, root exudates, excretes of soil animals) to the soil (Kuzyakov et al., 2000). So far, a reliable prediction of the direction (acceleration or retardation of SOM decomposition) and magnitude of PEs in response to organic carbon additions cannot be given. Several environmental factors influence PEs, such as the amount and chemical structure of added substrates (Di Lonardo et al., 2017; Guenet et al., 2010; Whitaker et al., 2014), the inorganic nutrient availability (Dijkstra et al., 2013; Kuzyakov et al., 2000) and the microbial biomass and community structure (Blagodatskaya and Kuzyakov, 2008; Fontaine et al., 2011, 2003). A meta-analysis by Blagodatskaya and Kuzyakov (2008) indicated that the magnitude and direction of PEs are dependent on the ratio of the amount of added substrate to the size of the microbial biomass. Their analysis revealed a linear increase in PEs with increasing amount of trigger compounds as long as the added $\mathrm{C}$ substrate is less than $15 \%$ of the size of the microbial biomass. In contrast, an exponential decrease in PEs was found when the amount of trigger compounds was more than $50 \%$ of the size of the soil microbial biomass. This decrease in PEs with high amount of trigger compounds is suggested to be due to the so called preferential microbial substrate utilization (Cheng and Kuzyakov, 2005; Kuzyakov, 2002) where soil microbes switch to utilize added easily degradable $\mathrm{C}$ sources instead of native soil $\mathrm{C}$.

The meta-analysis of Blagodatskaya and Kuzyakov ( 2008) considered all publications on PEs with information on microbial biomass $C$. However, it is known that the structure and functioning of microbial communities and quality of soil organic matter greatly differ among ecosystems (Blagodatskaya et al., 2014; Schimel and Schaeffer, 2012) and that this can have a strong impact on PEs (Qiao et al., 2016). Moreover, the studies taken into consideration in the meta-analysis included both single and multiple applications of the trigger substrates. Single and multiple applications will differently affect soil microbial biomass as well as community structure. These differences can have an impact on PEs (Blagodatskaya et al., 2007; Conde et al., 2005; De Nobili et al., 2001; Falchini et al., 2003; Hamer and Marschner, 2005; Luna-Guido et al., 2001; Mondini et al., 2006; Perelo and Munch, 2005; Santruckova et al., 2004; Shen and Bartha, 1997).

The effects of concentrations of trigger compounds on PEs was recently tested by (Liu et al., 2017). In their study different amounts of the same trigger compound (glucose) were added to different soil ecosystems collected along an elevation gradient. The doses of added glucose were based on the initial size of the soil microbial biomass and they used multiple additions rather than a single one to resemble the temporal dynamics of labile $\mathrm{C}$ input in the field. The main finding was that PEs are increasing with higher amounts of trigger substrates and, therefore, not strongly related to the initial size of the soil microbial 
biomass. Yet, the magnitude of increase of PEs with increasing amount of glucose varied among the ecosystems included in their study.

The current study was already started when the paper of Liu et al. (2017) appeared and had basically the same purpose: to investigate if the effects of trigger substrate to microbial biomass ratios on PEs are in agreement with the outcome of the meta-analysis of Blagodatskaya and Kuzyakov (2008). In particular, we were interested in this since most studies on PE use an amount of trigger substrate that is at least $45 \%$ of soil microbial biomass (e.g., Di Lonardo et al., 2017; Mason-Jones et al., 2018; Sullivan and Hart, 2013; Whitaker et al., 2014), which is far higher than recommended by Blagodatskaya and Kuzyakov (2008). Based on the meta-analysis of Blagodatskaya and Kuzyakov (2008), we hypothesized that the trigger-substrate to microbial biomass ratio is an important predictor of PEs. To test the general validity of this hypothesis, we included three different ecosystems in our study, namely arable fields, grasslands and forests. Like most other studies, we have used single trigger substrate additions, whereas the study of Liu et al, (2017) used multiple applications.

Concurrently with addition of different amounts of a PE-trigger substrate $\left({ }^{13} \mathrm{C}\right.$-glucose $)$ we added ammonium nitrate $\left(\mathrm{NH}_{4} \mathrm{NO}_{3}\right)$ to study the effect of nitrogen on PEs, as the availability of $\mathrm{N}$ can also influence the magnitude of PEs (Dijkstra et al., 2013). According to the "microbial nitrogen mining" hypothesis microbes use labile $\mathrm{C}$ as an energy source to decompose recalcitrant organic matter in order to obtain mineral $\mathrm{N}$ (Moorhead and Sinsabaugh, 2006). Hence, $\mathrm{N}$ addition may reduce mining for $\mathrm{N}$ and consequently SOM decomposition (Chen et al., 2014). However, the $\mathrm{N}$ mining theory has been challenged as simultaneous addition of $\mathrm{C}$ and $\mathrm{N}$ was shown to stimulate rather than decrease priming (Chowdhury et al., 2014; Di Lonardo et al., 2017; Tian et al., 2016). Stimulation of decomposition can be driven by the stoichiometry of substrates, with the highest decomposition rates observed when the ratios of supplies of $\mathrm{C}$ and $\mathrm{N}$ to microbes match their demands (Hessen et al., 2004; Sterner and Elser, 2002). Hence, simultaneous addition of $\mathrm{C}$ and $\mathrm{N}$ compounds can alleviate the stoichiometric constraint (Chen et al., 2014; Drake et al., 2013), causing a better match with $\mathrm{N}$ demands necessary for microbial growth and enzyme production and, consequently, resulting in higher PEs (Di Lonardo et al., 2017). Based on these considerations and our previous results (Di Lonardo et al., 2017) we hypothesized that addition of $\mathrm{N}$ will not have a negative effect on PEs.

Our results support those of Liu et al. (2017) with respect to the lack of predictability of trigger substrate to microbial biomass ratios but only partly with respect to a consistent increase of positive PE with increasing concentrations of trigger substrates. Effects of $\mathrm{N}$ addition gave no evidence for $\mathrm{N}$-mining as important factor in PEs. 


\section{Materials and Methods}

Soil sampling and processing

In August 2015, soil $(0-10 \mathrm{~cm})$ was collected from three different ecosystems in the central part of the Netherlands (Di Lonardo et al., 2018), i.e. arable fields, beech forests and natural grasslands developed on abandoned arable fields. The arable fields were planted with maize (Zea mays L.), the dominant plant species in the forests was beech (Fagus sys/vatica L.) and the natural grasslands were dominated by grasses such as common bent (Agrostis capillaris L.), tufted grass (Holcus lanatus L.) and forbs such as narrowleave plantain (Plantago lanceolata L.) (Di Lonardo et al., 2018). For each ecosystem type, we collected soils from four separate sites that were about $1 \mathrm{~km}$ apart, representing four ecosystem replicates (Di Lonardo et al., 2018). In the laboratory, fresh soil from each plot was sieved $(4 \mathrm{~mm})$ and homogenized, removing fine roots and other plant debris. Fieldmoist soil was then stored at $4{ }^{\circ} \mathrm{C}$ until further use.

\section{Measurement of biotic and abiotic soil properties}

Detailed descriptions of the methods used for the evaluation of soil chemical properties and microbial biomass are reported in Chapter 3. Properties of soils included $\mathrm{pH}$, water content, water holding capacity, total nitrogen, total carbon and orthophosphate fraction. Chemical properties of the soils are listed in Table 1.

Table 1: Mean values $( \pm \mathrm{SE})$ of chemical soil properties for each of the three soil types (arable, grassland, forest).

\begin{tabular}{cccccc}
\hline Soil & $\mathbf{p H}$ & $\mathbf{C}: \mathbf{N}$ ratio & $\begin{array}{c}\mathbf{N}-\left(\mathrm{NO}_{3}+\mathrm{NO}_{2}\right) \\
{\left[\mathrm{mg} \mathrm{kg}^{-1}\right]}\end{array}$ & $\begin{array}{c}\mathbf{N}-\left(\mathrm{NH}_{4}\right) \\
{\left[\mathrm{mg} \mathrm{kg}^{-1}\right]}\end{array}$ & $\begin{array}{c}\mathbf{P}-\left(\mathbf{P O}_{4}\right) \\
{\left[\mathrm{mg} \mathrm{kg}^{-1}\right]}\end{array}$ \\
\hline $\begin{array}{c}\text { Arable } \\
\text { Grassland }\end{array}$ & $5.7 \pm 0.3$ & $17.4 \pm 0.4$ & $31.5 \pm 5.4$ & $0.2 \pm 0.1$ & $231.5 \pm 15.9$ \\
Forest & $5.5 \pm 0.1$ & $17.7 \pm 0.9$ & $5.1 \pm 0.5$ & $0.3 \pm 0.3$ & $99.7 \pm 6.8$ \\
\hline
\end{tabular}

While microbial biomass measurements included DNA extractions, quantitative PCRs (for bacterial biomass quantification), and ergosterol analysis (for fungal biomass quantification). The qPCR results, expressed as $16 \mathrm{~S}$ rRNA gene copy numbers $\mathrm{g}^{-1}$ of dry weight soil, were used to calculate the bacterial cell numbers using a conversion factor of 4.1 copies per cell (Santelli et al., 2008) and bacterial biomass $C$ as described by (Bloem et al., 1995). The ergosterol data, expressed as $\mathrm{mg} \mathrm{kg}^{-1}$ dry weight soil, were used to calculate the fungal biomass using a conversion factor of $5.4 \mathrm{mg}$ ergosterol g $\mathrm{g}^{-1}$ biomass C (Klamer and Baath, 2004). 


\section{Mesocom set-up}

Glass bottles $(500 \mathrm{ml})$ were filled with moist soil equivalent to $80 \mathrm{~g}$ of dry weight and the soil was pre-incubated in a climate chamber for an acclimatization period of 15 days at $20^{\circ} \mathrm{C}$. The acclimatization period was based on the results of a previous pilot experiment (data not shown), where soil $\mathrm{CO}_{2}$ efflux rates were regularly checked to confirm stabilization of the soil microbial activity.

Soil samples were mixed with three different aqueous solutions of uniformly labelled 99 atom $\%{ }^{13} \mathrm{C}$-glucose (Campro Scientific $\mathrm{GmbH}$ ). The amount of glucose-C added was equivalent to $15 \%, 50 \%$, and $200 \%$, of the microbial biomass carbon (Table 2) (Blagodatskaya and Kuzyakov, 2008). The solutions were stirred into the soils to ensure a homogeneous mixture. Half of the microcosms received a solution containing ${ }^{13} \mathrm{C}$ glucose and $\mathrm{NH}_{4} \mathrm{NO}_{3}$, with a C-substrate: $\mathrm{N}$ ratio of 15:1 (Fontaine et al., 2011). Controls were treated in the same way as the substrate-amended soils, meaning that they received the same amount of water but without the addition of glucose or nitrogen. Each treatment included four soil replicates per ecosystem type. Soils were incubated at $20^{\circ} \mathrm{C}$ in the dark for 30 days. The soil moisture was maintained at $60 \%$ of the water holding capacity throughout the incubation period by weighing the microcosms once a week and watering with deionized water when needed. After 4 days (time period based on the development of total $\mathrm{CO}_{2}$ respiration) and 30 days (end of the experiment) of incubation, soil was sampled from each treatment using an ethanol- cleaned tweezer to minimize contamination. These soil samples were used for microbial biomass measurements. The samples were frozen $\left(-20^{\circ} \mathrm{C}\right)$ prior to DNA and ergosterol extractions.

Table 2: Mean values ( \pm SE) of fungal and bacterial biomass ( $\mathrm{mg} \mathrm{C} \mathrm{g}^{-1} \mathrm{dw}$ soil) of the sampled soils and amount of C-glucose added ( $\mathrm{mg} \mathrm{C} \mathrm{g}^{-1} \mathrm{dw}_{\text {soil) }}$ to the soils in a quantity of $\mathrm{C}$ equal to $15 \%, 50 \%$, and $200 \%$ of the microbial biomass carbon. Statistically significant differences $(P<0.05)$ are marked with different letters. Fungal and bacterial biomass are estimated on basis of ergosterol (fungal) and qPCR-16SrDNA (bacteria).

\begin{tabular}{|c|c|c|c|c|c|c|}
\hline & $\begin{array}{c}\text { Fungal } \\
\text { biomass }\end{array}$ & Bacterial biomass & $\begin{array}{c}\text { Tot Microbial } \\
\text { biomass }\end{array}$ & \multicolumn{3}{|c|}{ C-glucose (mg C g ${ }^{-1} \mathrm{dw}_{\text {soil) }}$} \\
\hline Soil type & & (mg C g ${ }^{-1} \mathrm{dw}_{\text {soil) }}$ & & $15 \%$ & $50 \%$ & $200 \%$ \\
\hline Arable & $0.19 \pm 0.01 \mathrm{a}$ & $0.21 \pm 0.04$ a & $0.40 \pm 0.05^{a}$ & $0.06 \pm 0.01$ & $0.20 \pm 0.03$ & $0.81 \pm 0.10$ \\
\hline Forest & $0.52 \pm 0.04 b$ & $0.17 \pm 0.04 \mathrm{a}$ & $0.69 \pm 0.05^{c}$ & $0.10 \pm 0.10$ & $0.34 \pm 0.03$ & $1.38 \pm 0.11$ \\
\hline Grassland & $0.28 \pm 0.03$ a & $0.30 \pm 0.02 \mathrm{a}$ & $0.59 \pm 0.05 \mathrm{ab}$ & $0.09 \pm 0.09$ & $0.29 \pm 0.03$ & $1.17 \pm 0.10$ \\
\hline
\end{tabular}

\section{$\mathrm{CO}_{2}$ measurements}

For $\mathrm{CO}_{2}$ efflux measurements, the bottles containing the soils were tightly closed 24 hours before sampling. Headspace $\mathrm{CO}_{2}$ was sampled through the lid septa and directly injected into $5.9 \mathrm{~mL}$ evacuated Exetainer vials (Labco Ltd., Buckinghamshire, UK). We sampled at 0.2 (5 hours), 1, 2, 3, 4, 5, 7, 9, 11, 15, 21, 30 days of incubation (12 sampling times in total). An aliquot of the gas samples ( $250 \mu \mathrm{l}$ for each vial) was injected using an autosampler in the Ultra GC gas chromatograph (Interscience, Breda, The Netherlands) equipped with a flame ionization detector (FID) and a Rt-QBOND (30 m, $0.32 \mathrm{~mm}$, ID) 
capillary column. Helium was used as carrier gas and the oven temperature was kept at $50{ }^{\circ} \mathrm{C}$ with a flow of $5 \mathrm{ml}$. For the analysis of the ${ }^{13} \mathrm{C}-\mathrm{CO}_{2}$ we used a Thermo Scientific gaschromatograph with combustion interface (Conflo III) system connected to a Thermo Scientific Delta V Plus isotope ratio mass spectrometer (Thermo Scientific, Bremen, Germany). A second aliquot of the gas samples (250 $\mu \mathrm{l})$ was injected into the split injector (split ratio 1:10) and eluted with helium (5 ml/min) on Rt-QBOND (30 m, $0.32 \mathrm{~mm}$, ID) capillary column at $31^{\circ} \mathrm{C}$. The reference gas was calibrated with Methane $\delta \mathrm{C}$ (VPDB) 38.25 (Arndt Schimmelmann, Indiana University, Bloomington, USA). $\mathrm{CO}_{2}$ concentrations of 12 air samples per bottle were used to calculate the cumulative respiration for the whole incubation period. Cumulative fluxes were calculated by linear interpolation between measuring times.

\section{Priming effect calculations}

The percentage of respired $\mathrm{CO}_{2}$ derived from ${ }^{13} \mathrm{C}$ substrate was calculated for all treatments and sampling times according to the formula:

$$
\% \mathrm{C}_{\text {substrate derived }}=[(\delta \mathrm{C}-\delta \mathrm{T}) /(\delta \mathrm{C}-\delta \mathrm{L})] \times 100
$$

Where $\delta \mathrm{C}$ is the $\delta^{13} \mathrm{C}$ value of the respired $\mathrm{CO}_{2}$ from control soils, $\delta \mathrm{T}$ is the $\delta^{13} \mathrm{C}$ value in respired $\mathrm{CO}_{2}$ from treated soils and $\delta \mathrm{L}$ is the $\delta^{13} \mathrm{C}$ value of the labelled substrate (Nottingham et al., 2012). Data were expressed in $\mu \mathrm{g} \mathrm{C} \mathrm{g}^{-1}$ dry weight soil. PE was then calculated as the total respired $\mathrm{CO}_{2}$ in treated soils minus the substrate-derived $\mathrm{CO}_{2}$ and minus the respired $\mathrm{CO}_{2}$ in the control and expressed in $\mu \mathrm{g} \mathrm{g} \mathrm{g}^{-1}$ dry weight soil (Qiao et al., 2016):

$$
\text { Primed } \mathrm{C}=\mathrm{C}_{\text {total }}-\mathrm{C}_{\text {substrate }}-\mathrm{C}_{\text {control }}
$$

\section{Statistical analysis}

To test for differences in PEs and microbial biomass between treatments One-way ANOVA, followed by post-hoc Tukey's test, was performed using IBM SPSS Statistics 22. In case of unequal variances among treatments, statistical comparisons were performed by Tamhane's test. We used one-sample T-tests to test whether PEs were different from zero. We used a regression analysis to test the relationship between the amount of added ${ }^{13} \mathrm{C}$-glucose $(15 \%, 50 \%$, and $200 \%$ of the microbial biomass C) and PE. Moreover, we 
used Pearson's correlation coefficient to test for the relationships between substrate derived $\mathrm{C}$ and total respired $\mathrm{C}$, and between substrate derived $\mathrm{C}$ and primed $\mathrm{C}$.

\section{Results}

$\mathrm{CO}_{2}$ effluxes and priming effect

The highest $\mathrm{CO}_{2}$ effluxes were observed in the arable and forest soils that received the highest amount of glucose (C-glucose equal to $200 \%$ of the microbial biomass carbon) ( $P$ $<0.05$ ). In contrast, the lowest levels of $\mathrm{CO}_{2}$ evolution were seen for grassland soils amended with the highest amount of glucose (Fig. S1). Almost none of the additions of Cglucose equal to $15 \%$ and $50 \%$ of the microbial biomass carbon resulted in significant extra total $\mathrm{CO}_{2}$ evolution as compared to the control $(P>0.05)$. For grassland soils there were no significant differences in $\mathrm{CO}_{2}$ evolution for any of the carbon and nitrogen additions (Fig. S1) $(P>0.05)$.

This $\mathrm{CO}_{2}$ evolution pattern was generally the same as compared to the release of substrate-derived $\mathrm{C}\left({ }^{13} \mathrm{CO}_{2}\right.$, released from labeled glucose) (Fig. 1). The positive relationship between substrate-derived $\mathrm{CO}_{2}$ and total soil respiration is confirmed by correlation analysis $\left(R^{2}=0.4577 ; P<0.001\right.$; Fig. S2A). Yet, the strength of the relationship between substrate derived $\mathrm{CO}_{2}$ and total respiration decreased for the different soils following this order: arable soils $\left(R^{2}=0.6977 ; P<0.0001\right)>$ grassland soils $\left(R^{2}=0.3576\right.$; $P=0.002)>$ forest soils $\left(R^{2}=0.2938 ; P=0.006\right)$. The highest amounts of substratederived $\mathrm{C}$ were observed for arable and forest soils that received C-glucose equal to $200 \%$ $(\mathrm{P}<0.05$; Fig. $1 \mathrm{G}$ and $1 \mathrm{H})$. On the contrary, for the grasslands soils the amount of substrate-derived $\mathrm{C}$ were highest in the treatments with the lowest amount of added glucose $(P<0.05$; Fig. 1I). 


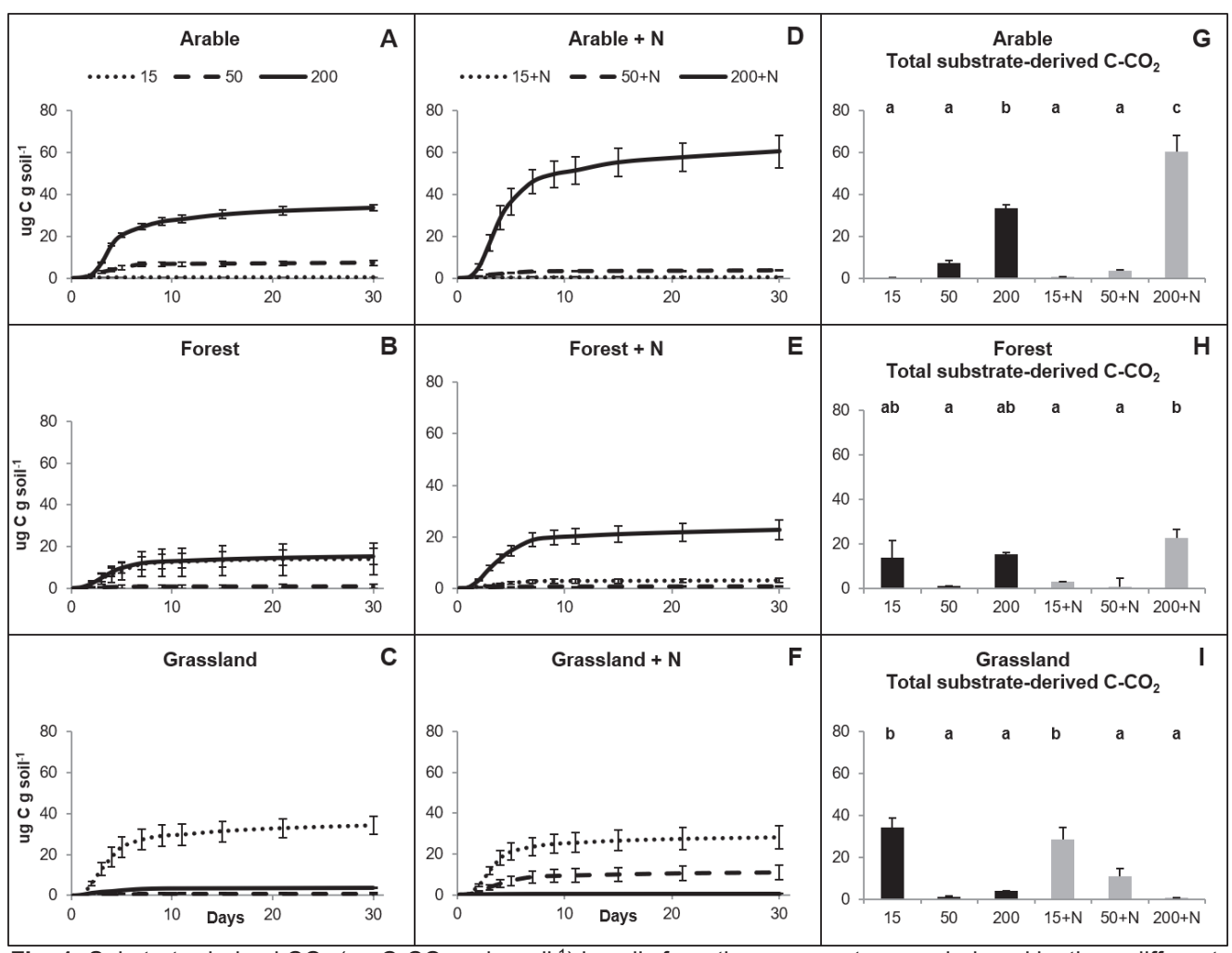

Fig. 1: Substrate-derived $\mathrm{CO}_{2}\left(\mu \mathrm{g} \mathrm{C}-\mathrm{CO}_{2} \mathrm{~g} \mathrm{dw} \mathrm{soil}^{-1}\right)$ in soils from three ecosystems as induced by three different amounts of ${ }^{13} \mathrm{C}$-glucose $(15 \%, 50 \%$, and $200 \%$ of the microbial biomass carbon). A-F: Cumulative accumulation of substrate-derived $\mathrm{CO}_{2}$ over 30 days of incubation. $\mathrm{G}-\mathrm{H}$ : Total substrate-derived $\mathrm{CO}_{2}$ after 30 days of incubation. $\mathrm{N}$ : $\mathrm{NH}_{4} \mathrm{NO}_{3}$. Statistically significant differences $(P<0.05)$ are marked with different letters. NS: no significant differences. Error bars represent standard errors $(n=4)$. 
After 30 days of incubation, glucose had induced a positive PE (increase of respiration of unlabeled $\mathrm{C}$ ) in the majority of the soils (Fig. 2; Table S1). Primed C in arable soils increased with increasing amount of glucose added (Fig. $2 G)(P<0.05)$. In forest soils this pattern was less clear although the highest amounts of primed $\mathrm{C}$ were also seen for the highest glucose additions (Fig. 2H). The responses of the grassland soils to the different amount of glucose added were not significantly different in magnitude from each other in all treatments $(P>0.05)$. However, $P E$ becomes significantly different from zero when glucose additions were combined with mineral $\mathrm{N}$ additions (Table S1). For several additions in the forest and grassland soils we observed an initial ( $<10$ days) negative PE (Fig. 2).

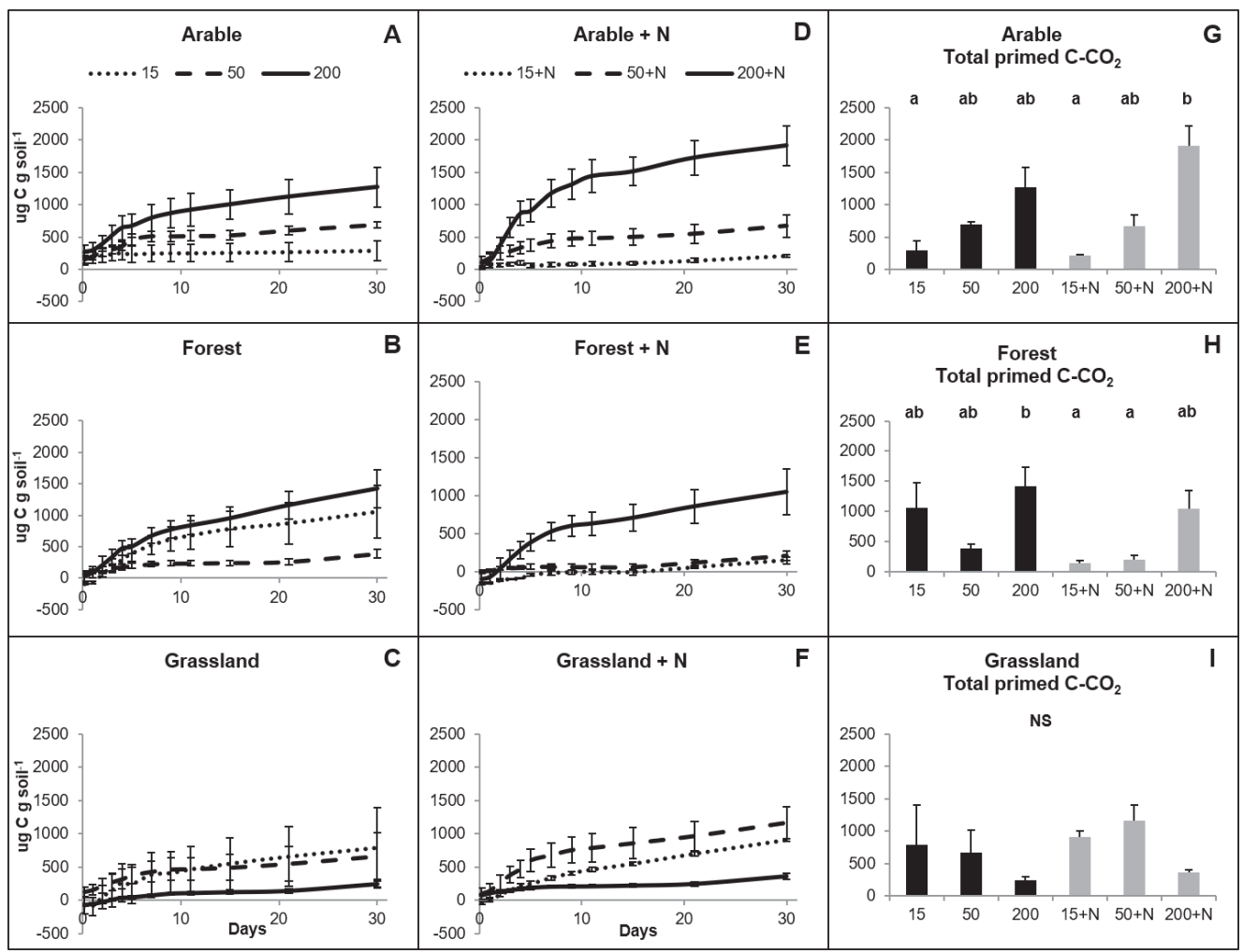

Fig. 2: Primed $\mathrm{CO}_{2}\left(\mu \mathrm{g} \mathrm{C}-\mathrm{CO}_{2} \mathrm{~g} \mathrm{dw}\right.$ soil-1 $)$ in soils from three ecosystems as induced by three different amounts of ${ }^{13} \mathrm{C}$-glucose $(15 \%, 50 \%$, and $200 \%$ of the microbial biomass carbon) after 30 days of incubation. A-F: Cumulative accumulation of primed $\mathrm{CO}_{2}$ over 30 days of incubation. G-H: Total primed $\mathrm{CO}_{2}$ after 30 days of incubation. $\mathrm{N}: \mathrm{NH}_{4} \mathrm{NO}_{3}$. Statistically significant differences $(\mathrm{P}<0.05)$ are marked with different letters. NS: no significant differences. Error bars represent standard errors $(n=4)$. 
The regression analysis showed a significant positive linear relationship between the amount of the added $\mathrm{C}$ expressed as \% of the microbial biomass $\mathrm{C}$ and primed $\mathrm{C}$ for arable soils $\left(R^{2}=0.5747 ; P<0.0001\right)$ and forest soils $\left(R^{2}=0.2999 ; P=0.006\right)$, respectively (Fig. 3). For the grassland soils this was a negative relationship $\left(R^{2}=0.1775\right.$; $P=0.04)$.

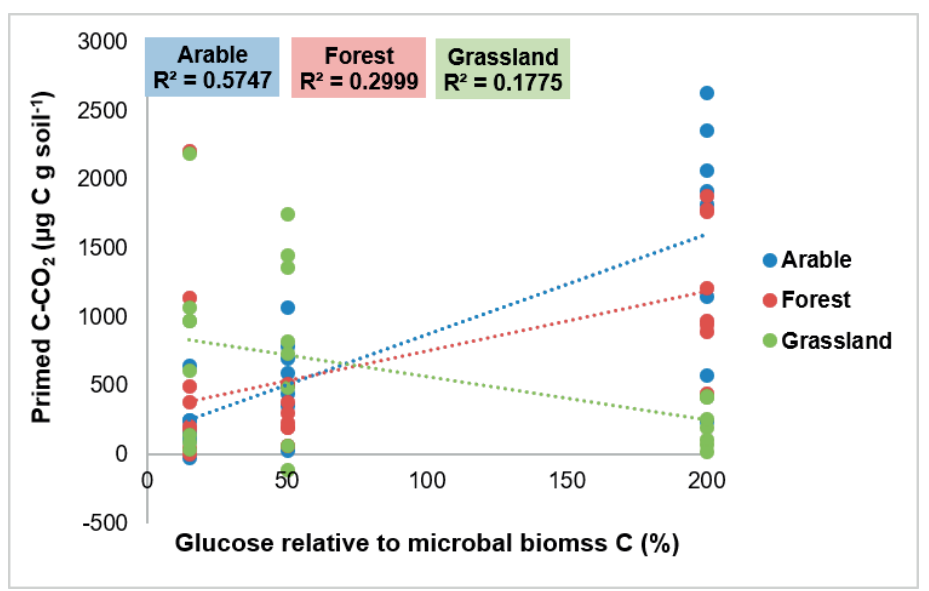

Fig. 3: Regression analysis for the amount of added C-glucose expressed as \% of microbial biomass $(15 \%, 50 \%$ and $200 \%$ ) versus primed $\mathrm{C}_{-}-\mathrm{CO}_{2}$. Treatments are grouped together according to the ecosystems from which the soils were obtained.

We found a positive correlation between substrate-derived $\mathrm{CO}_{2}$ and $\mathrm{PE}$ for the different ecosystems (Fig. S2B). In this case the strength of the positive relationship between substrate derived $\mathrm{CO}_{2}$ and $P E$ decreased from the arable soils $\left(R^{2}=0.72 ; P<0.0001\right)$ to forest soils $\left(R^{2}=0.2702 ; P=0.009\right)$ and grassland soils $\left(R^{2}=0.1856 ; P=0.03\right)$.

The ratio between primed $C$ to substrate-derived $C$ was highest for the arable soils amended with the lowest amount of $C$-glucose combined with $N(P<0.05$; Fig. S3). This relative strong impact of low doses of glucose on $\mathrm{PE}$ was not seen for the soils originating from natural ecosystems (Fig. S3B and S3C).

In general, addition of $\mathrm{N}$ had no significant effect on substrate-derived $\mathrm{C}$ and $\mathrm{PE}(\mathrm{P}>$ $0.05)$. It stimulated higher substrate derived respiration only in arable soils amended with C-glucose equal to $200 \%$ of the microbial biomass carbon $(P<0.01)$ and had the same tendency for primed $C(P=0.007)$ (Fig. $1 G$ and Fig. 2G).

\section{Microbial biomass}

Initial microbial biomass was highest for forest soils, followed by grassland and arable soils $(P<0.05$, Table 2 ). In addition, we found the highest initial fungal biomass in forest 
soils $(P<0.05)$, whereas there were no differences between arable and grassland soils. The three ecosystems did not differ in terms of soil bacterial biomass $(P>0.05$, Table 2$)$. After 4 days and 30 days of incubation, soils were sampled from each treatment to estimate the microbial biomass carbon. Generally, the microbial biomass remained constant throughout the incubation period, showing no particular differences $(P<0.05)$ among arable soils and no significant differences among forest and grassland treatments (Fig. 4). The proportion of fungal and bacterial biomass fluctuated between treatments but without a consistent pattern. Yet, we observed a trend for all the treatments amended with nitrogen, namely a decrease in total microbial biomass over time (Fig. 4D, E and F). This appeared to be mainly caused by a decrease in bacterial biomass (Fig. S4).

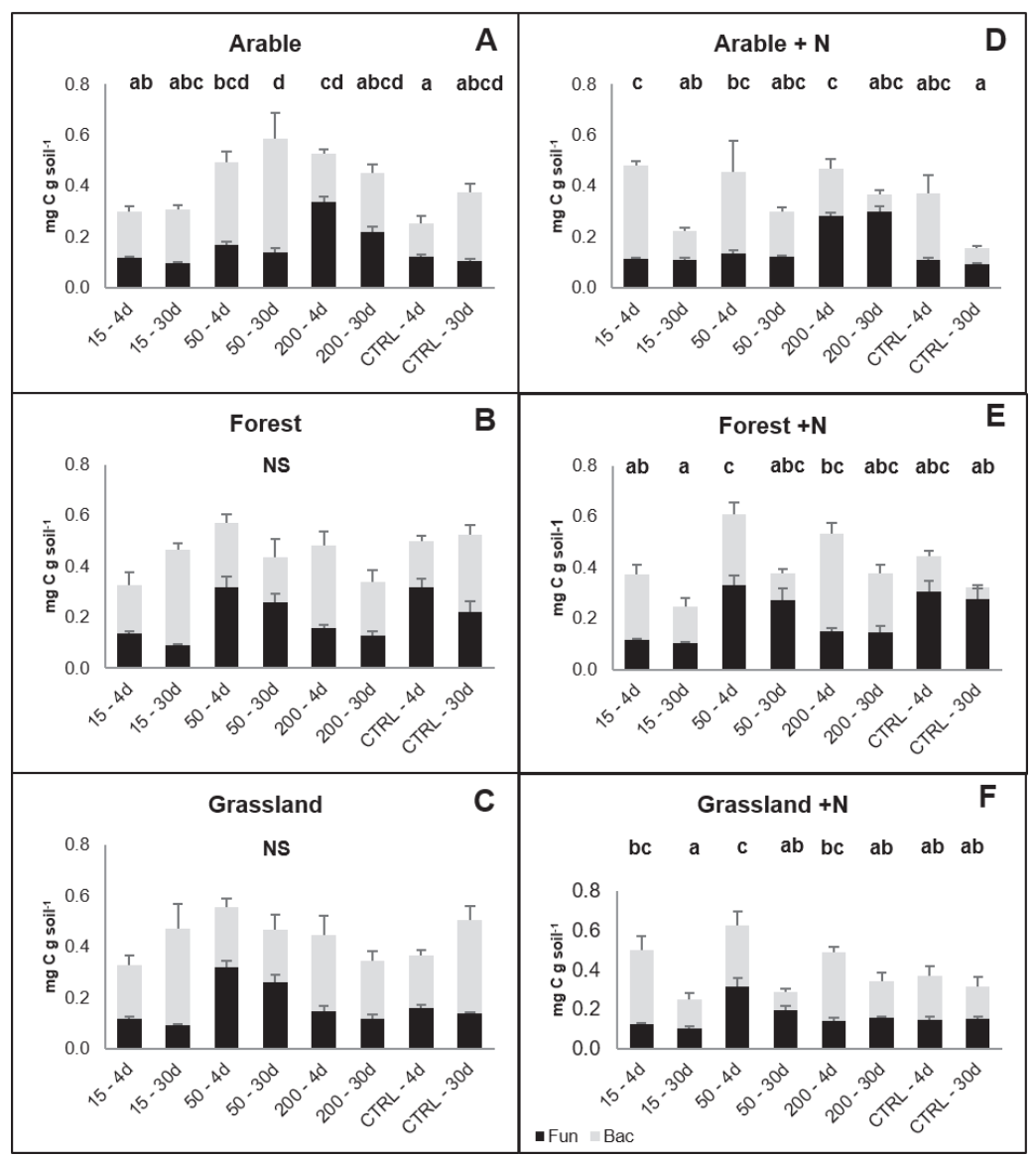

Fig. 4: Microbial biomass (fungi + bacteria, $\mathrm{mg} \mathrm{C} \mathrm{g} \mathrm{dw} \mathrm{soil-}^{-1}$ ) measured at 4 and 30 days of incubation of glucose-amended soils from three ecosystems. Fungal and bacterial biomass are estimated on basis of ergosterol (fungal) and qPCR-16SrDNA (bacteria). 15, 50 and 200 represent the quantity of glucose-C added representing $15 \%, 50 \%$, and $200 \%$ of the initial microbial biomass carbon. $4 \mathrm{~d}$ : fourth day of incubation. $30 \mathrm{~d}$ : thirtieth day of incubation. CTRL: control treatment. $\mathrm{N} \mathrm{NH}_{4} \mathrm{NO}_{3}$. Statistically significant differences $(P<0.05)$ are marked with different letters. NS: no significant differences. Error bars represent standard errors $(n=4)$. Black columns: fungal biomass. Grey columns: bacterial biomass. 


\section{Discussion}

Amount of trigger compound and PE

Linear regression between the amount of added $C$ relative to the initial microbial biomass and primed $\mathrm{C}$ revealed contrasting results for the different ecosystems. The meta-analysis by Blagodatskaya and Kuzyakov (2008) has indicated that additions of trigger compounds up to $15 \%$ of microbial biomass $C$ induce a linear increase in PEs. In contrast, when the added amount of trigger compounds is higher than $50 \%$ of the microbial biomass $\mathrm{C}$, an exponential decrease in PEs was seen. Our study could not confirm their findings and therefore the ratio between the amount of added $\mathrm{C}$ to the size of the soil microbial biomass does not appear to be a universal predictor for soil organic matter PE. A similar conclusion has recently been drawn by Liu et al. (2017).

In contrast to our observations, Liu and colleagues (2017) found a positive linear relationship between increasing $C$ additions and PEs in the natural ecosystems they studied, including grassland and forest ecosystems. These contrasting results might be related to different composition and structure of the soil microbial communities investigated in the two studies (Ushio et al., 2008). In our case, the strongest positive relationship of PEs with the amount of added glucose was seen for arable soils. A common agricultural practice is to amend soils with different organic matter residues such as manure and compost. Therefore, microbes in agricultural soils may be better adapted to receive high inputs of easily degradable organic matter and this could be the reason why they can cope better with temporary high organic carbon additions than soil microbes in natural ecosystems (Arcand et al., 2017; Bowles et al., 2014; Lupwayi et al., 2017).

We found a positive correlation between substrate-derived $C\left({ }^{13} \mathrm{C}\right)$ and primed $C\left({ }^{12} \mathrm{C}\right)$ albeit that the strength of this correlation was different for the three ecosystems included. Arable soils showed the strongest correlation, followed by forest and grassland soils. These results indicate that the amount of energy obtained from decomposing trigger substrates is an important factor that defines the magnitude of PEs (Wild et al., 2014). A strong positive correlation between substrate derived $\mathrm{CO}_{2}$ and primed $\mathrm{CO}_{2}$ was recently also observed by Mason-Jones et al. (2018). Yet, the accumulation curves between substrate-derived $C$ and primed $C$ differed (Fig. 1 and 2). Substrate-derived $C$ accumulation was completed during the first week of incubation whereas primed $\mathrm{C}$ increased until the end of the experiment (30 days). This has been reported before and indicates that the initial microbial activation by the added glucose continued for a longer period (Blagodatskaya and Kuzyakov, 2008; Kuzyakov and Bol, 2006).

Arable soils showed a different pattern of PE stimulation than natural soils as the lowest amount of glucose resulted in the highest ratio between primed $C$ to substrate-derived $C$, in particular when glucose was combined with $\mathrm{N}$ (Fig. S3). This indicates a relatively stronger impact of low trigger substrate concentrations on $\mathrm{PE}$, which may be ascribed to 
the higher temporal heterogeneity of availability of energy sources in arable soils. In such an environment, microbes may have a strategy to become highly activated when easily degradable substrates become available.

It is largely assumed that lack of $\mathrm{N}$ in soils will induce high PE since soil microbes are triggered to mine SOM to acquire this nutrient (Dijkstra et al., 2013; Liu et al., 2017). Following this so-called microbial $\mathrm{N}$ mining theory, a less strong PE is expected when $\mathrm{C}$ substrate is added together with $\mathrm{N}$. In line with our hypothesis, we found that $\mathrm{N}$ addition had no or little effect on PEs. Arable and grassland soils did not differ in C:N ratio, while forest soils had the highest one. Hence, according to the $\mathrm{N}$ mining theory, the strongest negative effect of $\mathrm{N}$ addition on PE could have been expected for the forest soils. This was not the case, indicating that other SOM properties are probably more important for describing the effect of $\mathrm{N}$ on PE (Schmidt et al., 2011). Several other studies did also show that simultaneous addition of $\mathrm{C}$ and $\mathrm{N}$ can increase or have no effect on PEs (Chowdhury et al., 2014; Di Lonardo et al., 2018, 2017; Tian et al., 2016). In line with these studies N mining theory was recently challenged (Mason-Jones et al., 2018) since in its current form it does not contribute to an explanation for PE.

In grassland and forest soils, amended with the lowest glucose input, we observed a temporary decrease in the decomposition of SOM after the first few days of incubation. Negative PE was previously shown in the early phases after $\mathrm{C}$ addition to soils (Di Lonardo et al., 2017; Liu et al., 2017; Wang et al., 2015). The shift of microbes from SOM decomposition to uptake of added $\mathrm{C}$ and $\mathrm{N}$ substrates is indicated to be the underlying mechanism of negative PEs (Kuzyakov, 2002; Kuzyakov and Bol, 2006). Liu et al. (2017) found an overall negative PE for the whole incubation period with multiple low $\mathrm{C}$ additions and attributed this to a minimum amount of energy (threshold) needed to overcome $\mathrm{N}$ limitation. Qiao et al. (2016) indicated that different mechanisms can be responsible for negative PE depending on the intrinsic $\mathrm{C}: \mathrm{N}$ ratios of soil organic matter and $\mathrm{C}: \mathrm{N}$ ratios of the trigger substrates. In our case, negative PE is followed by positive PE and is therefore more likely to be the result of initial activation of microbes using internal reserve material (negative apparent PE, Blagodatskaya and Kuzyakov, 2008).

The lack of respiration response (Fig. S1) and the very low PE that we have seen in the grassland soils that received high $\mathrm{C}$ substrate additions might be due to a glucose oversaturation of microorganisms. Microbes present in the grassland samples receiving the highest amount of ${ }^{13} \mathrm{C}$-glucose started using this substrate but due to possible osmotic stress the total activity subsequently declined (Csonka, 1989).

The discrepancy in the results between our work and other studies investigating PEs might be due to differences in experimental approaches, such as the ecosystems under investigation, the length of the experiments, the simultaneous amendments of $\mathrm{C}$ and $\mathrm{N}$ versus only $\mathrm{C}$ additions and the frequency of $\mathrm{C}$ input (single versus repeated $\mathrm{C}$ additions). 
With respect to the latter, single versus multiple additions might influence PE differently (Qiao et al., 2016) as they have different impacts on the ability of microbes to invest energy in the synthesis of SOM-degrading enzymes (Fontaine et al., 2003; Liu et al., 2017; Mason-Jones et al., 2018). Single substrate applications represent short-term pulses which can be expected to happen in reality, like litterfall in the forest soils, manure application in arable soils and release of root exudates. Such pulses of easily accessible and degradable substrates produce hotspots of microbial activity that induce accelerated decomposition process rates (Kuzyakov and Blagodatskaya, 2015).

\section{Microbial biomass response}

In our study the microbial biomass remained overall constant during the whole incubation period of the experiment although we found differences in PEs among soils. Generally, glucose did not stimulate the growth of fungi and bacteria differently, and both microbial groups appeared to play a role in PEs. The addition of the trigger compound could have served as energy source for the soil microbial community, stimulating the production of extracellular enzymes with subsequent increase in the decomposition of SOM (Schimel and Weintraub, 2003).

We observed a decrease in microbial biomass in all treatments amended with $\mathrm{N}$. Reduction of bacterial and fungal biomass in response to $\mathrm{N}$ fertilization is consistent with previous studies (Demoling et al., 2008; Knorr et al., 2005; Ramirez et al., 2012). The addition of glucose and $\mathrm{N}$ to the soil mesocosms might have altered the demands necessary for microbial growth (Mooshammer et al., 2014b). Furthermore, the effects of $\mathrm{N}$ fertilization can depend on the soil conditions prior to fertilization (Demoling et al., 2008). Yet, in our study the effect of $\mathrm{N}$ addition it is mostly attributed to a decrease in soil bacterial biomass. A possible explanation might be that $\mathrm{N}$ addition stimulated the growth of protozoa (Elliott and Coleman, 1977; Forge et al., 2005; Verhagen et al., 1994), consequently enhancing their predation on bacteria.

\section{Conclusions and Perspectives}

In our study we investigated the effect of different ratios of the amount of organic trigger compounds to initial soil microbial biomass on PE. We did not find the contrasting effects of low and high ratios as predicted by the meta-analysis of Blagodatskaya and Kuzyakov (2008). In arable and forest soils the primed C increased with an increasing amount of added glucose, but this was not the case for grassland soils. Hence, the proposed predictive value of trigger-substrate concentrations for explaining PEs (Liu et al., 2017) does need more investigations. Yet, we observed a significant relationship between the mineralization of the added trigger substrate and PEs for all soil types, indicating the 
importance of energy obtained from trigger-substrates for PEs. $\mathrm{N}$ additions together with glucose had little or no effect on PE, rejecting the $\mathrm{N}$ mining theory. To be able to explain mechanisms of PEs and integrate PEs in global soil carbon models, more studies of soils with different properties are needed. Furthermore, it is important to understand how the quality and quantity of added compounds affect PEs in arable soils in order to improve the management of soil organic carbon dynamics.

\section{Acknowledgments}

We thank Machiel Bosch of Natuurmonumenten for permission to sample the grassland soils and Derks family for sampling the arable soils. We are thankful to Stijn van Gils, Jan Geert Bruggink and Iris Chardon for their practical help in the field and lab. 


\section{Supplementary information}

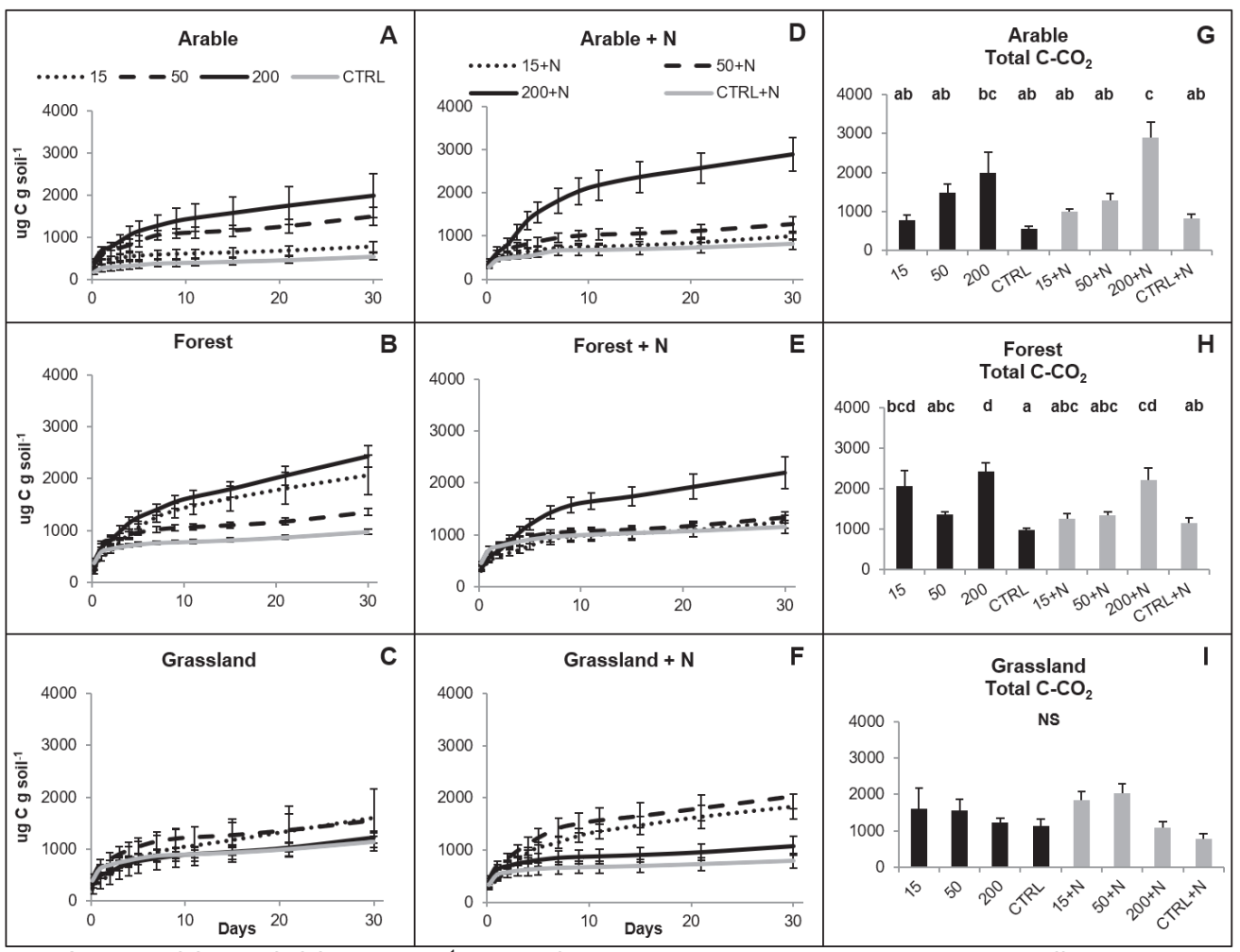

Fig. S1: Total $\mathrm{CO}_{2}\left(\mu \mathrm{g} \mathrm{C}-\mathrm{CO}_{2} \mathrm{~g} \mathrm{dw}_{\text {soil }}{ }^{-1}\right)$ in soils from three ecosystems as induced by three different amounts of ${ }^{13} \mathrm{C}$-glucose $(15 \%, 50 \%$, and $200 \%$ of the microbial biomass carbon) after 30 days of incubation. A-F:

Cumulative accumulation of total $\mathrm{CO}_{2}$ over 30 days of incubation. $\mathrm{G}-\mathrm{H}$ : total $\mathrm{CO}_{2}$ after 30 days of incubation.

CTRL: control treatment. Statistically significant differences $(P<0.05)$ are marked with different letters. NS: no significant differences. $\mathrm{N}$ : $\mathrm{NH}_{4} \mathrm{NO}_{3}$. Error bars represent standard errors $(\mathrm{n}=4)$. 


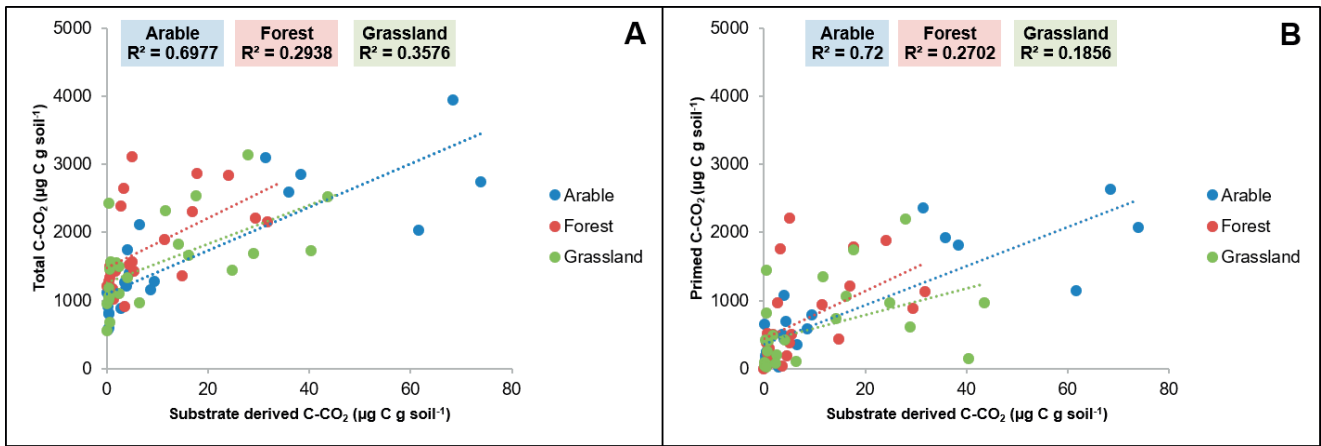

Fig. S2: Pearson correlation analysis for substrate-derived $\mathrm{C}-\mathrm{CO}_{2}$ versus total $\mathrm{C}-\mathrm{CO}_{2}(\mathrm{~A})$ and for substratederived $\mathrm{C}-\mathrm{CO}_{2}$ versus primed $\mathrm{C}-\mathrm{CO}_{2}(\mathrm{~B})$. Treatments are grouped together according to the soil type.

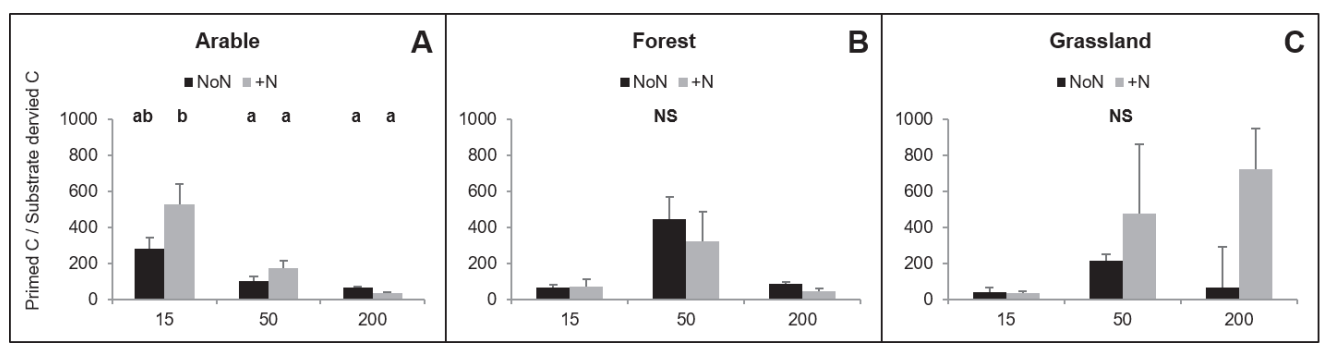

Fig. S3: Ratio between primed $\mathrm{CO}_{2}$ and substrate-derived $\mathrm{CO}_{2}$ after 30 days of incubation of glucose-amended soils from three ecosystems. $\mathrm{N}_{\mathrm{NH}} \mathrm{NHO}_{3}$. Statistically significant differences $(P<0.05)$ are marked with different letters. NS: no significant differences. Error bars represent standard errors $(n=4)$.

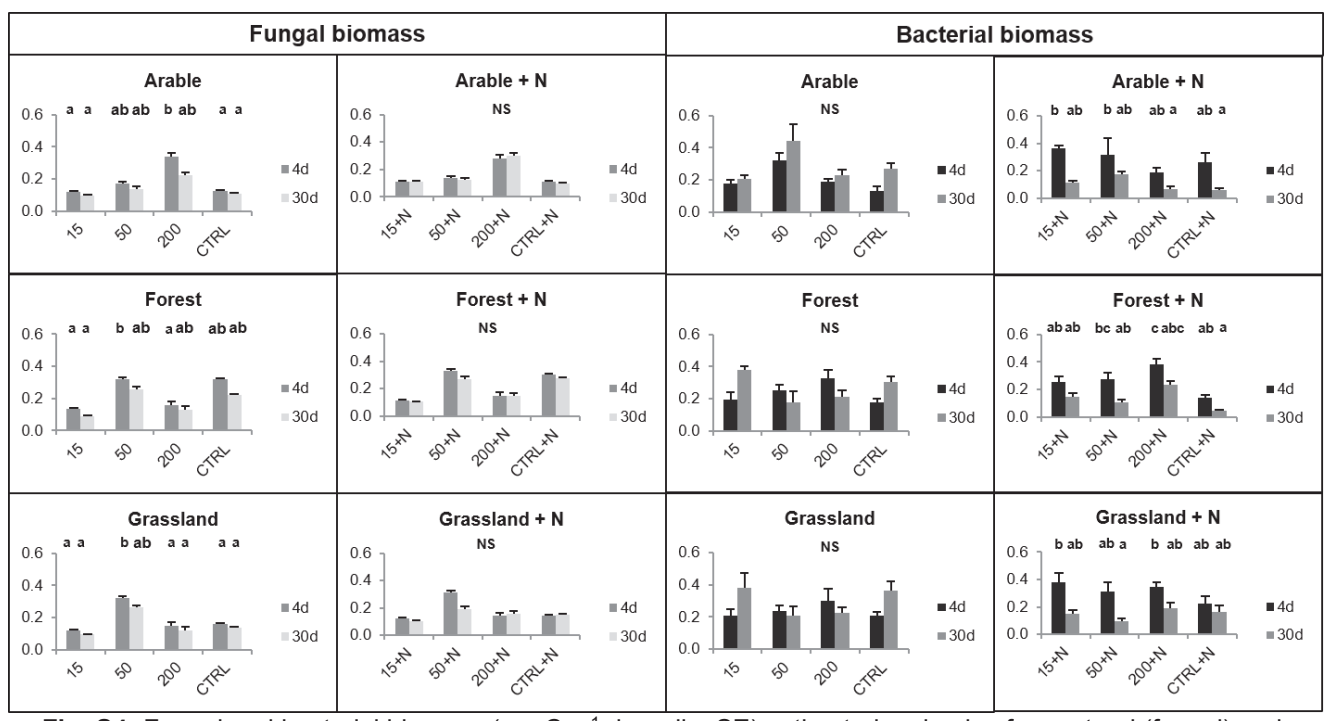

Fig. S4: Fungal and bacterial biomass $\left(\mathrm{mg} \mathrm{C} \mathrm{g}^{-1} \mathrm{dw}\right.$ soil $\left.\pm \mathrm{SE}\right)$ estimated on basis of ergosterol (fungal) and qPCR-16SrDNA (bacteria) measurements at 4 and 30 days of incubation. 15, 50 and 200 represent the quantity of $\mathrm{C}$ added as equal to $15 \%, 50 \%$, and $200 \%$ of the initial microbial biomass carbon. $4 \mathrm{~d}$ : fourth day of incubation. 30d: thirtieth day of incubation. CTRL: control treatment. $\mathrm{N}$ : $\mathrm{NH}_{4} \mathrm{NO}_{3}$. 
Table S1: One-sample T test (test value $=0$ ) on significance of primed $\mathrm{CO}_{2}-\mathrm{C}$ accumulation. 15, 50 and 200 represent the quantity of $\mathrm{C}$ added as equal to $15 \%, 50 \%$, and $200 \%$ of the microbial biomass carbon. $\mathrm{N}: \mathrm{NH}_{4} \mathrm{NO}_{3}$. *: Significant values $(\mathrm{P}<0.05)$.

\begin{tabular}{|l|c|c|c|}
\hline \multicolumn{1}{|c|}{ Treatment } & & & \\
& & df & Sig. (2-tailed) \\
& & & \\
\hline Arable 15 & 1.632 & 3 & 0.244 \\
Arable 15+N & 10.122 & 3 & $0.002^{*}$ \\
Arable 50 & 12.038 & 3 & $0.007^{*}$ \\
Arable 50+N & 3.358 & 3 & 0.078 \\
Arable 200 & 2.480 & 3 & 0.089 \\
Arable 200+N & 6.220 & 3 & $0.008^{*}$ \\
Forest 15 & 2.517 & 3 & 0.086 \\
Forest 15+N & 2.803 & 3 & 0.107 \\
Forest 50 & 5.373 & 3 & $0.013^{*}$ \\
Forest 50+N & 3.196 & 3 & $0.049^{*}$ \\
Forest 200 & 6.843 & 3 & $0.006^{*}$ \\
Forest 200+N & 3.458 & 3 & $0.041^{*}$ \\
Grassland 15 & 1.127 & 3 & 0.377 \\
Grassland 15+N & 8.924 & 3 & $0.003^{*}$ \\
Grassland 50 & 1.625 & 3 & 0.246 \\
Grassland 50+N & 4.875 & 3 & $0.016^{*}$ \\
Grassland 200 & 2.620 & 3 & 0.120 \\
Grassland 200+N & 6.974 & 3 & $0.020^{*}$ \\
\hline
\end{tabular}




\section{Chapter 5}

\section{Effect of nitrogen on fungal growth efficiency}

D.P. Di Lonardo, A. van der Wal, P. Harkes \& W. de Boer

A slightly modified version of this manuscript was submitted for publication 


\begin{abstract}
Fungi are important actors in soil organic matter (SOM) dynamics as they play a major role in decomposition as well as in stabilization of soil organic carbon via promotion of soil aggregate formation. In addition, high fungal biomass has been linked to lower $\mathrm{N}$ losses from soils.

The contribution of fungi to $\mathrm{C}$ and $\mathrm{N}$ cycling is related to their growth efficiency. Growth efficiency is defined as the amount of biomass produced per unit of substrate utilized. Several environmental factors, such as the concentration and availability of $\mathrm{N}$, influence the activity and growth efficiency of saprotrophic fungi. When $\mathrm{N}$ is scarce in soils, fungi have to invest more energy to obtain soil $\mathrm{N}$, which could result in lower growth efficiencies. Yet, the effect of $\mathrm{N}$ on growth efficiencies of individual species of soil fungi has not been studied extensively.

In this study we investigated the influence of different concentrations of mineral $\mathrm{N}$ on the growth efficiency of two common soil fungi, Trichoderma harzanium and Mucor hiemalis in a soil-like environment. We hypothesized that a higher nitrogen availability will coincide with higher biomass production and growth efficiency. To test this, we measured fungal biomass production as well as the respiration fluxes in sand microcosms amended with cellobiose and mineral $\mathrm{N}$ at different $\mathrm{C}: \mathrm{N}$ ratios. We found that for both fungal species lower $\mathrm{C}: \mathrm{N}$ ratios resulted in the highest biomass production as well as the highest growth efficiency. This may imply that when $\mathrm{N}$ is applied concurrently with a degradable $\mathrm{C}$ source, a higher amount of $\mathrm{N}$ will be temporarily immobilized into fungal biomass. Therefore, our results might suggest that the $\mathrm{C}$ and $\mathrm{N}$ contents of fertilizers applied to agricultural soils can be adapted in such a way that fungal biomass response is optimal, thereby reducing $\mathrm{N}$ losses.
\end{abstract}




\section{Introduction}

Fungi play a major role in terrestrial decomposition processes. They produce a wide range of enzymes that degrade complex plant polymers such as cellulose, xylan, and lignin (van der Wal et al., 2013). They are important actors in soil organic matter (SOM) dynamics. Fungi are able to connect sources of easily-available carbon with stable SOM via transport through their hyphae (Boberg et al., 2011) and they are thought to have a relevant contribution to the decomposition of the stable organic carbon pool (Fontaine et al., 2011, 2007). On the other hand, filamentous fungi promote the formation of macroaggregates by binding soil particles with their hyphae, but also by producing cell wall materials that act as adhesives (Willis et al., 2013). Aggregate formation promotes C sequestration by providing physical protection against decomposers and their degradative enzymes (Wilson et al., 2009).

It is generally assumed that soil microbial communities dominated by fungi have more efficient nitrogen (N) cycling than those dominated by bacteria (Van Der Heijden et al., 2008; Wardle et al., 2004). However, the application of N-containing fertilizers generally causes a shift in the soil microbial community structure, from a fungal dominated towards a bacterial dominated one. High $\mathrm{N}$ fertilizer additions have been indicated to be the cause of decrease in soil fungal biomass (de Vries et al., 2007, 2006). Whilst, the cessation of $\mathrm{N}$-fertilizer use, can cause a shift from bacterial to fungal dominated systems (Bardgett and McAlister, 1999; de Vries et al., 2007, 2006; Postma-Blaauw et al., 2010). These increases in the abundance of fungi have been linked to a higher efficiency of $\mathrm{N}$ cycling and lower $\mathrm{N}$ losses from soils (de Vries et al., 2011, 2006; Gordon et al., 2008).

Growth efficiency is defined as the amount of biomass produced per unit of substrate utilized (Mooshammer et al., 2014b; Sinsabaugh et al., 2013). Information on growth efficiency is essential to have a good estimate of the role of fungi in carbon and nutrient dynamics. Several abiotic and biotic factors influence the activity and growth of saprotrophic fungi and, consequently, the growth efficiency. When fungi grow on organic C substrates, it is estimated that their growth efficiency is roughly equal to $30 \%$ (Deacon, 2006). On average the C: $\mathrm{N}$ ratio of fungi is higher than that of bacteria and it varies between 8 and 15 (Deacon, 2006). Therefore, fungi require less $\mathrm{N}$ per unit biomass than bacteria. This may explain why fungal to bacterial ratios are higher in soils with high $\mathrm{C}: \mathrm{N}$ ratios (Fierer et al., 2009). A prerequisite for soil fungi to be active is the availability of organic energy sources and inorganic nutrients. Microbial activity is highest when the C:N ratio of the substrate matches the demands of microbes (Hessen et al., 2004). According to the stoichiometric decomposition theory (Craine et al., 2007), decay processes are driven by the stoichiometry of substrates. The stoichiometric imbalance between decomposer communities and the organic substrates decreases from recently produced plant residues (e.g. litter) to partially decayed organic matter (Mooshammer et al., 2014b). Adjustment in growth efficiencies may be the most important mechanism by which 
microbes regulate their biomass stoichiometry (Mooshammer et al., 2014b). Fungi, and decomposers in general, drive soil $\mathrm{C}$ cycling by converting organic carbon into biomass and releasing it as $\mathrm{CO}_{2}$. It is expected that growth efficiencies are influenced by the $\mathrm{C}: \mathrm{N}$ ratios of the organic substrates. When $\mathrm{N}$ is scarce in soils, fungi have to invest more energy in obtaining it, likely resulting in a low growth efficiency. A high growth efficiency will coincide with fungal biomass increase and likely $\mathrm{C}$ stabilization in soils and, vice versa, a low growth efficiency will favor respiration (Manzoni et al., 2012). Generally, knowledge on microbial growth efficiency is of special interest for industrial applications (e.g., to obtain higher biomass or biosynthesized products). However, growth efficiencies have received increased attention of ecologists, due to its important implications for environmental processes (Geyer et al., 2016). Most of the ecological studies focused on soil microbial communities (e.g., Dijkstra et al., 2015; Geyer et al., 2018; Koranda et al., 2014; Mooshammer et al., 2014a; Sinsabaugh et al., 2013). Fungal biomass production in soil microbial communities is not only affected by growth responses but also by other processes such as predation and competition. Hence, to have a basic understanding of the effect of substrate $\mathrm{C}: \mathrm{N}$ ratio on fungal growth responses studies with single fungal species are needed.

In this study we investigated the influence of different concentrations of mineral $\mathrm{N}$ on the growth efficiency of two common soil fungi, Trichoderma harzanium and Mucor hiemalis in a soil-like environment. Species belonging to the genus Trichoderma (anamorphic stage of Hypocrea) are among the most commonly isolated saprotrophic fungi in soils from different ecosystems. They are well known for their ability to predate on other fungi when nutrient sources are limited (Vinale et al., 2008). Mucor hiemalis is a saprotrophic fungus belonging to the Mucorales and is also very common in soil environments. Like most members of the Mucorales, it has little ability to attack recalcitrant substrates, such as crystalline cellulose and lignin, and depends more on simple, soluble carbon sources such as root exudates and amorphous cellulose (De Boer et al., 2005). M. hiemalis has large hyphae that spread rapidly allowing them to quickly reach new energy sources. The mycelial C:N ratio is around 12 and 8 for Trichoderma sp. and Mucor sp., respectively (Mouginot et al., 2014). As a carbon source we have chosen cellobiose as a model compound for an easily degradable plant-derived carbohydrate (Martínez et al., 2005). We hypothesized that higher nitrogen availability will coincide with higher fungal biomass production and growth efficiency. To test this we measured fungal biomass production as well as respiration fluxes. 


\section{Materials and Methods}

\section{Sand microcosm set up and $\mathrm{CO}_{2}$ measurements}

Petri dishes ( $8.5 \mathrm{~cm}$ diameter) were filled with $60 \mathrm{~g}$ autoclaved, acid-washed quartz sand (granulation 0.1-0.5 mm; Honeywell Specialize Chemicals Seelze $\mathrm{GmbH}$, Seelze, Germany). The lids of the Petri dishes contained butyl rubber stoppers (Rubber BV, Den Haag, The Netherlands) to allow sampling the gas from the headspace of the plates. The sand was amended with $10 \%(\mathrm{w} / \mathrm{w})$ of a nutrient solution that contained $\left(\mathrm{g} \mathrm{I}^{-1}\right.$ demineralized water): $\mathrm{KH}_{2} \mathrm{PO}_{4}, 0.10 ; \mathrm{K}_{2} \mathrm{SO}_{4}, 0.20$; Yeast extract (Bacto ${ }^{\mathrm{TM}}$; Becton, Dickinson and Company), 0.05; D-(+)-Cellobiose (Sigma-Aldrich), 5.0; MES (2-(Nmorpholino) ethanesulfonic acid, Sigma) 5.85. The latter compound was added because acid-washed sand has no buffering capacity. To test the effect of different $\mathrm{C}: \mathrm{N}$ ratios on fungal growth, the above described nutrient solution received also ammonium nitrate $\left(\mathrm{NH}_{4} \mathrm{NO}_{3}\right)$ in different amounts. Three nutrient solutions were prepared: i) C-cellobiose: $\mathrm{N}$ = 8:1, ii) C-cellobiose: $\mathrm{N}=15: 1$ and iii) C-cellobiose: $\mathrm{N}=50: 1$. The control treatment did not receive any ammonium nitrate addition. The $\mathrm{pH}$ of the nutrient solutions was adjusted to 6.5 with $\mathrm{NaOH}$. Before the addition of the nutrient solutions, sand was sterilized by two cycles of autoclaving ( $30 \mathrm{~min}$ at $121^{\circ} \mathrm{C}$, the second one after 24 hours). Next, it was dried at $120^{\circ} \mathrm{C}$ for two hours.

Fungal spores of Trichoderma harzanium and Mucor hiemalis were obtained from pure cultures grown on Oatmeal agar (6 g/l Difco, France) and agar powder ( 2 g/l BOOM CMN, the Netherlands), containing four different antibacterial compounds, namely Chloramphenicol (50 ppm, $12.5 \mathrm{mg} / \mathrm{ml}$ final concentration), Streptomycine (50 ppm, 5 $\mathrm{mg} / \mathrm{ml}$ final concentration), Vancomycine (10 ppm, $2 \mathrm{mg} / \mathrm{ml}$ final concentration) and Oxytetracycline (50 ppm, $5 \mathrm{mg} / \mathrm{ml}$ final concentration). After 3 weeks of incubation $\left(20^{\circ} \mathrm{C}\right.$ in the dark), the spores were washed from the plates with sterile deionized water, collected through Miracloth (Calbiochem, USA) and stored at $-80^{\circ} \mathrm{C}$. Fungal spores $\left(10^{4}\right.$ spores $\mathrm{g}$ soil- ${ }^{1}$ ) of Trichoderma harzanium and Mucor hiemalis were mixed with the nutrientcontaining sand.

In total eight experimental treatments were prepared: $T$. harzanium in sand with no nitrogen (TH No-N), with C:N=8 (TH 8:1), with $\mathrm{C}: \mathrm{N}=15$ (TH 15:1) and with $\mathrm{C}: \mathrm{N}=50$ (TH $50: 1)$; M. hiemalis in sand with no nitrogen $(\mathrm{MH}$ No-N), with $\mathrm{C}: \mathrm{N}=8(\mathrm{MH} \mathrm{8:1})$, with $\mathrm{C}: \mathrm{N}=15$ $(\mathrm{MH}$ 15:1) and with $\mathrm{C}: \mathrm{N}=50$ (MH 50:1). Each treatment consisted of five replicates, giving a total of 40 Petri dishes. They were sealed with one layer of Diversified Biotech Petri Seal ${ }^{\mathrm{TM}}$ tape and one layer of Parafilm, to avoid gas exchange with the external environment and maintaining air-tightness. Plates were incubated in the dark at $20^{\circ} \mathrm{C}$.

During the 14-day incubation period, headspace $\mathrm{CO}_{2}$ was sampled through the lid septa and directly injected into $5.9 \mathrm{~mL}$ evacuated Exetainer vials (Labco Ltd., Buckinghamshire, UK) and measured using Ultra GC gas chromatograph (Interscience, The Netherlands) 
equipped with a flame ionization detector (FID) and at Rt-QBOND (30 m, $0.32 \mathrm{~mm}$, ID) capillary column. We used helium as a carrier gas and set the oven temperature at $50{ }^{\circ} \mathrm{C}$. $\mathrm{CO}_{2}$ was analysed at 2, 4, 7, 9, 11 and 14 days. After each measurement the Petri dishes were opened under the flow cabinet for aeration and sealed again after 15 minutes. At the end of the incubation period, soil was homogenized by mixing, it was sampled and kept in aliquots in the freezer at $-20^{\circ} \mathrm{C}$ for ergosterol and DNA extractions.

\section{DNA extraction and $q P C R$ assay}

DNA was extracted from sand using the PowerSoil ${ }^{\circledR}$ DNA Isolation Kit (MOBIO Laboratories, Carlsbad, California, USA) according to the manufacturer's instruction with some modifications: after adding solution $\mathrm{C} 1$ (causing cell lysis), samples were incubated at $60{ }^{\circ} \mathrm{C}$ for $30 \mathrm{~min}$; solutions $\mathrm{C} 2$ and $\mathrm{C} 3$ (for the removal of contaminating inorganic and organic matter) were added (100 $\mu \mathrm{l}$ each) to the samples; after adding solution $\mathrm{C} 6$ (releasing DNA from spin filter), samples were incubated at $30{ }^{\circ} \mathrm{C}$ for $10 \mathrm{~min}$. DNA was then collected in Eppendorf tubes and stored at $-20^{\circ} \mathrm{C}$.

To determine the amount of DNA present in the samples, quantitative PCR assays were performed using different primer combinations based on taxon-characteristic internal transcribed spacer (ITS) regions (Table S1). The total end volume of the qPCR assays was $20 \mu \mathrm{l}$ containing: $3 \mu \mathrm{l}$ of 100 times diluted DNA, $1 \mu \mathrm{l}$ of each primer (final concentration: $10 \mathrm{ng} / \mu \mathrm{l}$ ), $5 \mu \mathrm{l}$ of Milli-Q water and $10 \mu \mathrm{l}$ iQ SYBR Green Supermix (BioRad). The following temperature profile was run on a Biorad iQ5 thermal cycler: $95^{\circ} \mathrm{C}$ for $3 \mathrm{~min}$ followed by $40 \times\left(95^{\circ} \mathrm{C}, 30 \mathrm{~s} ; 60{ }^{\circ} \mathrm{C}, 30 \mathrm{~s} ; 72{ }^{\circ} \mathrm{C}, 30 \mathrm{~s}\right)$. To establish the relationship between Ct-values and the concentration of target fungal DNA (ng/ $\mu \mathrm{l}), \mathrm{a}$ calibration curve was made for each primer combination using a dilution series of the corresponding DNA as a template. The concentration of DNA was measured using a NanoDrop ND-1000 UV-VIS spectrophotometer (NanoDrop Technologies).

\section{Ergosterol and growth efficiency}

Ergosterol, a sterol found in fungal membranes, was used as a biomarker for fungal biomass in the sand (de Ridder-Duine et al., 2006). Briefly, $4 \mathrm{~g}$ of moist sand was shaken with $6 \mathrm{ml}$ of methanol in the presence of glass beads, to disrupt the fungal mycelium and to release the ergosterol into the extractant. After centrifugation and filtration, ergosterol was measured on a 1260 Bio-inert LC coupled with a 6460 QQQ (Agilent, Santa Clara, USA).

We calculated the growth efficiency for each fungus on basis of the amount of ergosterol or ITS copy numbers per amount of $\mathrm{CO}_{2}$ released. Growth efficiencies were expressed as relative growth efficiencies where efficiencies of the $\mathrm{C}: \mathrm{N}=8$ treatments were set at $100 \%$. 


\section{Statistical analyses}

Differences in respiration, ergosterol, DNA copy numbers and growth efficiencies between treatments were tested with one-way ANOVA followed by post-hoc Tukey's test, using IBM SPSS Statistics 22. In some cases, due to unequal variances, Tukey's test was not possible and statistical comparisons were performed by Tamhane's T2 test. We used linear regression analysis to test the relationship between the different amounts of added $\mathrm{N}$ and ergosterol concentrations, and the DNA copy numbers.

\section{Results}

For both fungi, $\mathrm{CO}_{2}$ production strongly increased in treatments with extra $\mathrm{N}$ additions during the first 2 to 4 days of incubation followed by a gradual increase until the end of incubation (Fig. 1A). The $\mathrm{CO}_{2}$ production in sand microcosms without extra $\mathrm{N}$ addition was gradually increasing throughout the whole incubation period. Total amount of accumulated $\mathrm{CO}_{2}$ was significantly stimulated by extra addition of nitrogen $(\mathrm{P}<0.05$; Fig. 1B). Yet, increasing doses of nitrogen did not result in increasing amounts of total $\mathrm{CO}_{2}$ accumulation (Fig. 1B). For both fungi, ergosterol concentrations in the sand microcosms showed a significant increase $(P<0.05)$ with an increasing amount of added nitrogen (Fig. 2A). There was no significant difference between $M$. hiemalis and T. harzianum in the amount of ergosterol produced in sand for any of the C: $\mathrm{N}$ treatments.

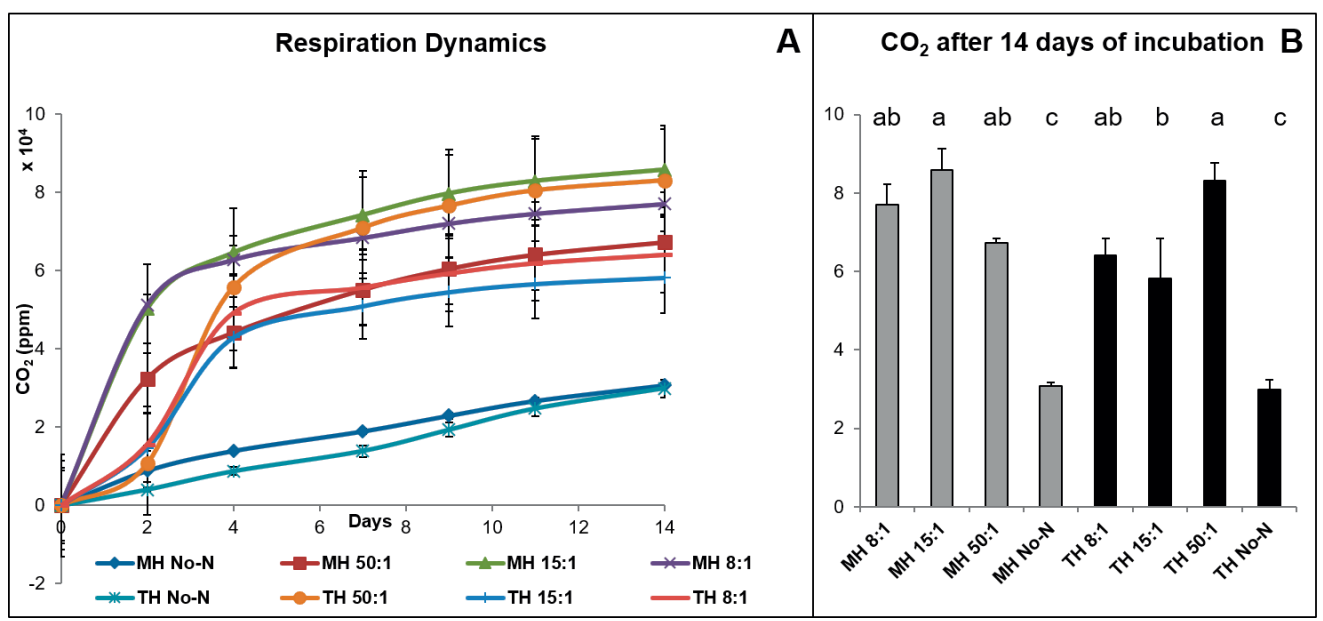

Fig. 1: A) Accumulation dynamics of $\mathrm{CO}_{2}$ during 14 days of incubation of $M$. hiemalis and $T$. harzianum in sand microcosms at different $\mathrm{C}: \mathrm{N}$ ratios; B) Total accumulated $\mathrm{CO}_{2}$ concentrations after 14 days of incubation. Statistically significant differences $(\mathrm{P}<0.05)$ between treatments are indicated with different letters. $\mathrm{MH}: M$. hiemalis; TH: T. harzanium. No-N: no addition of $\mathrm{N} ; 50: 1$ is $\mathrm{C}: \mathrm{N}=50 ; 15: 1$ is $\mathrm{C}: \mathrm{N}=15 ; 8: 1$ is $\mathrm{C}: \mathrm{N}=8$. Vertical bars represent standard errors. 
DNA copy numbers for both fungal species showed an overall decrease with a decreasing amount of $\mathrm{N}$ (Fig. 2B). However, when tested with one-way ANOVA, only M. hiemalis grown in sand with $\mathrm{C}: \mathrm{N}$ ratios 8 and 15 had significant higher DNA copy numbers $(\mathrm{P}<$ $0.05)$.

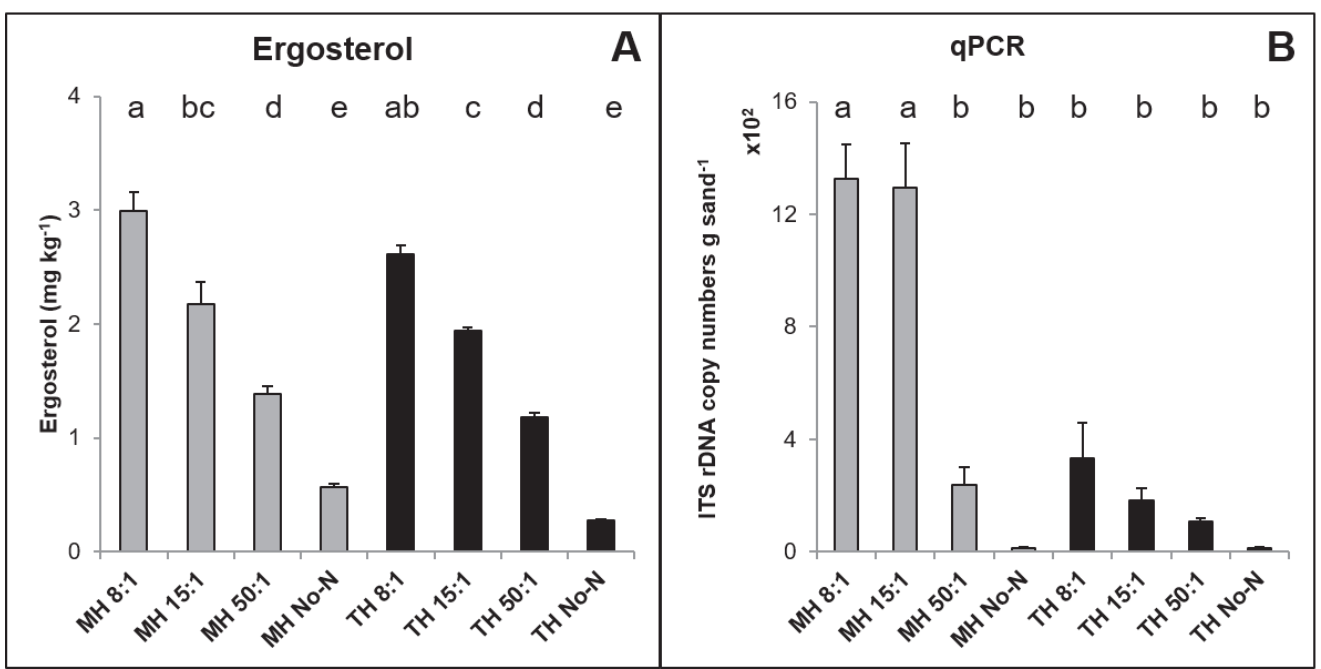

Fig. 2: Concentrations of ergosterol (A) and ITS rDNA copy numbers (B) of M. hiemalis and T. harzianum grown for 14 days in sand microcosms at different $\mathrm{C}: \mathrm{N}$ ratios. Statistically significant differences $(P<0.05)$ are indicated with different letters. $\mathrm{MH}:$ M. hiemalis; $\mathrm{TH}$ : T. harzanium. No-N: no addition of $\mathrm{N} ; 50: 1$ is $\mathrm{C}: \mathrm{N}=50 ; 15: 1$ is $\mathrm{C}: \mathrm{N}=$ $15 ; 8: 1$ is $\mathrm{C}: \mathrm{N}=8$. Vertical bars represent standard errors.

The linear regression analysis showed a significant positive linear relationship between the amount of added $\mathrm{N}$ and ergosterol concentrations $\left(R^{2}=0.8860 ; P<0.0001\right.$ and $R^{2}=$ 0.8944; $\mathrm{P}<0.0001$, for $M$. hiemalis and $T$. harzanium respectively; Fig. $3 \mathrm{~A}$ ) and between the amount of added $N$ and DNA copy numbers $\left(R^{2}=0.7609 ; P<0.0001\right.$ and $R^{2}=0.3523$; $\mathrm{P}=0.006$, for $M$. hiemalis and $T$. harzanium respectively; Fig. 3B).

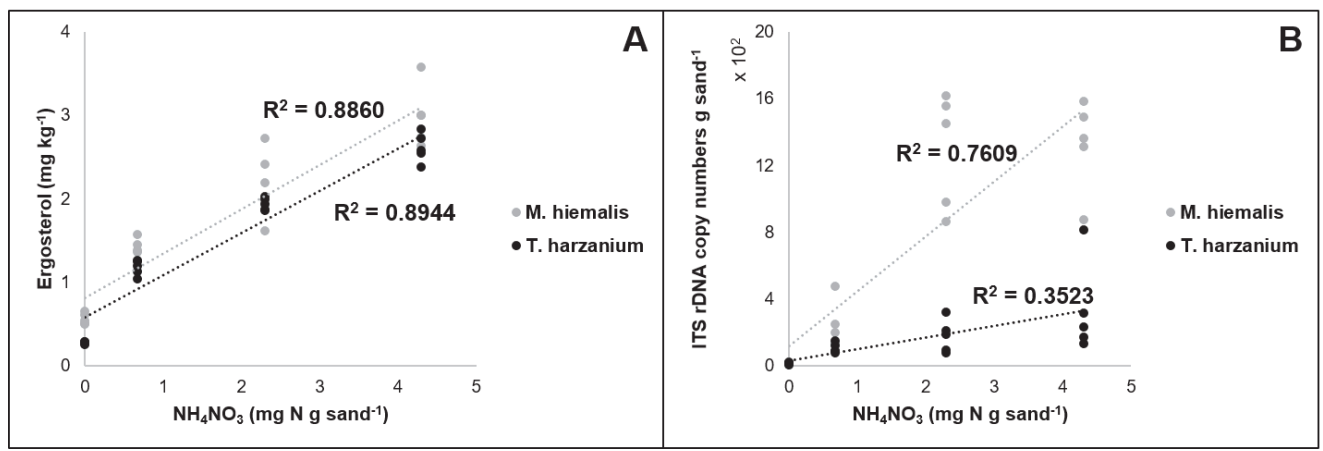

Fig. 3: Linear regression analysis between the different amounts of added ammonium nitrate $\left(\mathrm{NH}_{4} \mathrm{NO}_{3}\right)$ and concentrations of ergosterol (A), and ITS rDNA copy numbers (B) of $M$. hiemalis and $T$. harzianum grown for 14 days in sand microcosms. 
Growth efficiencies, as based on both ergosterol and DNA copy numbers, showed the same trend for both fungal species, namely an increase with increasing $\mathrm{N}$ concentrations (Fig. 4A and 4B, $\mathrm{P}<0.05$ ).

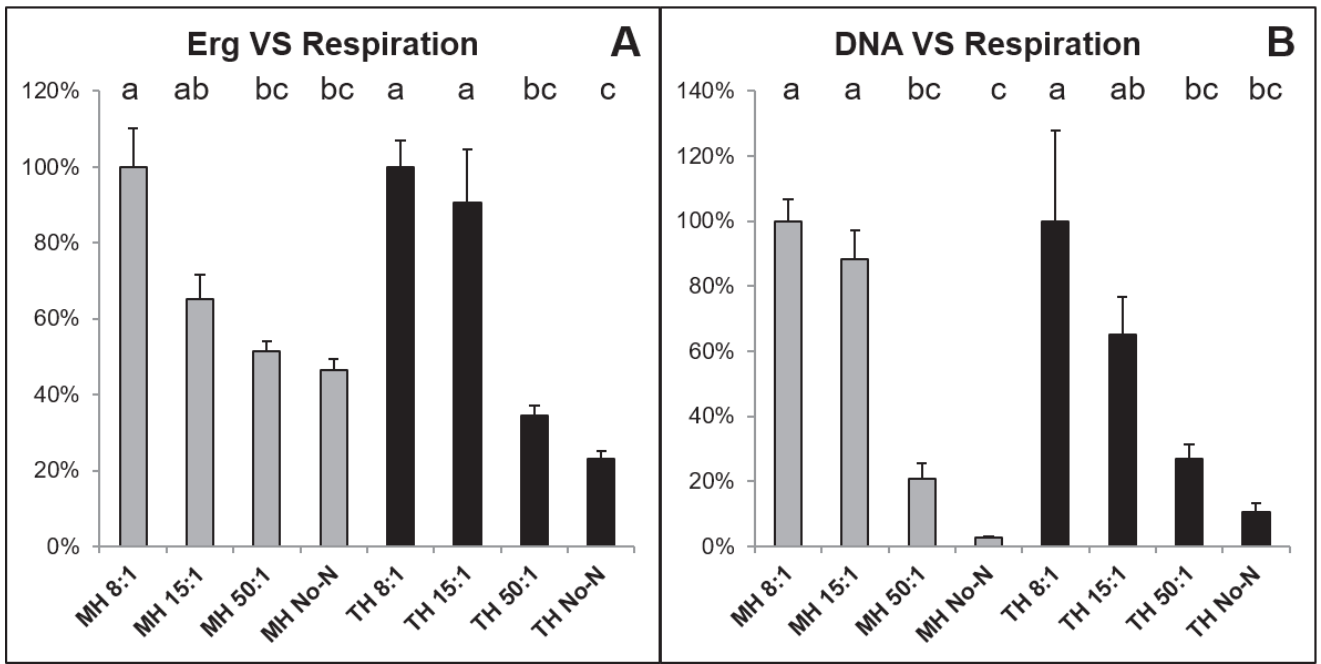

Fig. 4: Relative (\%) fungal growth efficiencies in sand microcosms containing different C:N ratios after 14 days of incubation. Growth efficiency for each fungus is based on the amount of ergosterol (A) or ITS copy numbers (B) per amount of $\mathrm{CO}_{2}$ released. Growth efficiencies of the $\mathrm{C}: \mathrm{N}=8$ treatments were set at $100 \%$. Statistically significant differences $(\mathrm{P}<0.05)$ are indicated with different letters. $\mathrm{MH}$ : M. hiemalis; TH: T. harzanium. No-N: no addition of $N ; 50: 1$ is $C: N=50 ; 15: 1$ is $C: N=15 ; 8: 1$ is $C: N=8$. Vertical bars represent standard errors.

\section{Discussion}

To test the effect of different $\mathrm{C}: \mathrm{N}$ ratios on fungal growth and growth efficiency, we cultured two different fungal species in cellobiose-containing sand with different concentrations of mineral nitrogen. For both $M$. hiemalis and $T$. harzanium, biomass production and growth efficiency increased with decreasing $\mathrm{C}: \mathrm{N}$ ratios. On the other hand, respiration fluxes did not decrease with increasing $\mathrm{C}: \mathrm{N}$ ratios. This indicates that more $\mathrm{C}$-cellobiose was metabolized at lower $\mathrm{C}: \mathrm{N}$ ratio, implying that not all $\mathrm{C}$-cellobiose has been metabolized in the treatments $\mathrm{C}: \mathrm{N}=15$ and $\mathrm{C}: \mathrm{N}=50$, and certainly not in the control treatments, where there was no addition of mineral $\mathrm{N}$. Our results are in line with our hypothesis, namely that the highest growth efficiency is expected with higher nitrogen availability. A similar growth efficiency pattern was observed for a litter-decomposing fungus grown on maize litter, where the efficiencies decreased accordingly with decreasing $\mathrm{N}$ availability in the plant material (Lashermes et al., 2016). In addition, our results suggest that when $\mathrm{N}$ becomes a limiting factor, fungi invest extra energy to obtain $\mathrm{N}$, for instance by recycling their cellular $\mathrm{N}$ via controlled autolysis (Santamaria and Reyes, 1988) or allocating $\mathrm{N}$ to essential metabolic processes (Wicklow, 2006). In nature, another possible solution to $\mathrm{N}$ limitation 
is to recruit extra $\mathrm{N}$ while mining the soil organic matter (Craine et al., 2007; Moorhead and Sinsabaugh, 2006).

It is well known that $\mathrm{N}$ stimulates fungal respiration (Boberg et al., 2008, 2011) as well as growth (Rousk and Bååth, 2007) and enhancing $N$ availability strongly increases fungal degradation of organic carbon substrates (Allison et al., 2009; Boberg et al., 2008; Koranda et al., 2014; van der Wal et al., 2007). Soils with a higher fungal biomass have lower $\mathrm{N}$ losses than soils with a lower fungal biomass (de Vries et al., 2006) and, consequently, a higher fungal biomass in soils can be considered as an indicator of higher soil $\mathrm{N}$ retention (de Vries et al., 2011). Applications of fertilizers to agricultural soils can result in $\mathrm{N}$ losses when crops are not actively taken up the added $\mathrm{N}$ or after heavy rain fall, and part of the $\mathrm{N}$ can be lost via leaching and denitrification (de Vries and Bardgett, 2012). Our study indicates that when $N$ is applied concurrently with a degradable $C$ source, a higher amount of $\mathrm{N}$ is built into fungal biomass, thereby possibly reducing $\mathrm{N}$ losses (Liang and Balser, 2011; Simpson et al., 2007). Furthermore, considering that competitive interactions between fungal species for resources are very common in litter and soil (Boddy, 2000), we can reasonably expect that the outcome of these interactions will impact growth efficiency and release of mineral $\mathrm{N}$ as well (Baldrian, 2004; Hiscox et al., 2015; Maynard et al., 2017; Song et al., 2012; Tiunov and Scheu, 2005).

Saprotrophic fungi are influenced by plant-derived carbon (Buée et al., 2009; Christensen, 1989). When root-derived products enter the soil, they can be rapidly metabolized by fungi (Hannula et al., 2012). Root exudates containing $N$ and $C$ can alleviate the stoichiometric constraint for fungi, possibly increasing exoenzyme production that will cause a change in the turnover of SOM, known as the priming effect (Drake et al., 2013). Furthermore, adding $\mathrm{N}$ together with labile $\mathrm{C}$ can result in higher microbial growth rates and efficiencies, likely resulting in more priming (Di Lonardo et al., 2017; Fontaine et al., 2011).

Carbon use efficiency (CUE) is defined as the ratio of $\mathrm{C}$ invested in biomass and total $\mathrm{C}$ uptake (Sinsabaugh et al., 2013). Despite the relative simple definition, CUE estimations are complex, since they are mediated by multiple factors (Manzoni et al., 2018). Furthermore, absolute values of CUE are not so easy to calculate when they are based on chemical indicators. For instance, there are uncertainties with respect to applying the right conversion factors to define fungal $\mathrm{C}$ on basis of ergosterol content and DNA copy numbers (Baldrian et al., 2013; Fierer et al., 2005; Klamer and Baath, 2004). The amount of ergosterol in fungal cells is dependent on the growth conditions and it can vary when fungal strains are cultured in liquid media or in soil (Montgomery et al., 2000). Therefore, we calculated the relative growth efficiency based on ergosterol and DNA copy numbers without conversion to fungal $\mathrm{C}$. The general picture remains the same, namely that higher efficiency is related to lower $\mathrm{C}: \mathrm{N}$ ratios. 
Our study provides information on how nitrogen influences fungal biomass production and growth efficiency. Knowledge on this influence is critical for the assessment of soil $\mathrm{C}$ and $\mathrm{N}$ budgets. A better understanding of fungal biomass dynamics upon $\mathrm{C}$ and $\mathrm{N}$ additions might be helpful to reduce the losses of $\mathrm{N}$ fertilizers in agricultural soils.

\section{Acknowledgments}

We are thankful to Jan Geert Bruggink for help in the lab. 


\section{Supplementary information}

Table S1: Primers used for the qPCR assay. Fungal primers are based on taxon-characteristic internal transcribed spacer (ITS) regions.

\begin{tabular}{|c|c|c|c|c|c|c|c|}
\hline \multirow[t]{2}{*}{ Target } & \multicolumn{2}{|r|}{$\begin{array}{l}\text { Pri mer sequence3' (5' } \\
\text { F: forward, R: reverse }\end{array}$} & \multirow[t]{2}{*}{ Reference } & \multirow[t]{2}{*}{$\mathrm{T}_{\mathrm{a}}$} & \multicolumn{3}{|c|}{$\begin{array}{l}\text { Parameters defining the linear } \\
\text { relationship between } C_{t} \text { and } \\
\text { DNA concentration } \\
\left(C_{t}=a \times{ }^{10} \log [\text { concentration] }+b)\right.\end{array}$} \\
\hline & & & & & $a$ & $\mathrm{~b}$ & $\mathrm{R}^{2}$ \\
\hline \multirow[b]{2}{*}{ Ascomycota } & $\mathrm{F}$ & GGAAGTAAAAGTCGTAACAAGG & \multirow{2}{*}{$\begin{array}{c}\text { Nikolcheva et al., } \\
\text { 2005; White et al., } \\
1990\end{array}$} & \multirow{2}{*}{$\begin{array}{l}60 \\
{ }^{\circ} \mathrm{C}\end{array}$} & \multirow[b]{2}{*}{-3.04} & \multirow[b]{2}{*}{18.73} & \multirow[b]{2}{*}{0.981} \\
\hline & $R$ & CGTTACTRRGGCAATCCCTGTTG & & & & & \\
\hline \multirow{2}{*}{$\begin{array}{c}\text { Zygomycota } \\
\text { (Mucorales) }\end{array}$} & $\mathrm{F}$ & CAGTTAAAACGTCCGTAGTCAA & \multirow{2}{*}{ Harkes et al., 2017} & 60 & \multirow{2}{*}{-4.55} & \multirow{2}{*}{14.56} & \multirow{2}{*}{0.988} \\
\hline & $\mathrm{R}$ & CACCACCACCCATAGAATCTA & & ${ }^{\circ} \mathrm{C}$ & & & \\
\hline
\end{tabular}





\section{Chapter 6}

General discussion 
Priming effects are ubiquitous and yet a thorough comprehension of the mechanisms is lacking. With this thesis research, I have tried to increase understanding of the mechanisms underlying soil priming, with a focus on the roles of the properties of PEtrigger substrates, the availability of nitrogen and soil microbial characteristics. Moreover, I studied the influence of different nitrogen concentrations on fungal growth efficiencies to obtain a better understanding of the influence of soil organic matter quality on carbon flows during decomposition.

In this chapter, I start with summarizing the results obtained during my thesis research. Next, after comparing the results with the existing ideas on PEs, I propose a new conceptual model on PEs. Finally, I discuss the thesis results in the context of global change scenarios and give an outlook on future research directions.

\section{New insights on priming effects}

The physicochemical properties of PE-trigger substrates have been indicated to be important for the direction and magnitude of PEs. In particular, two properties that have received attention are the chemical resemblance to recalcitrant fractions of SOM and the metabolic usable energy for microbes (Brant et al., 2006; Fontaine and Barot, 2005; van der Wal and de Boer, 2017). The results described in Chapter 2 indicated that the effect of chemical structure of added compounds on PEs is much larger than the effect of energy-content. When corrected for energy available for microbial growth, the highest stimulation of priming was seen for addition of vanillic acid, which is a phenolic compound. Phenolic compounds are part of the recalcitrant fractions of soil organic matter (SOM). Hence, the structural resemblance of PE-trigger substrates to recalcitrant fractions of SOM may indeed be an important factor in PEs. Similar observations were made in Chapter $\mathbf{3}$ where different plant litter types were used as PE-trigger compounds. Beech litter, which was the most complex litter type (e.g., litter rich in lignin), had a stronger impact on PEs (highest ratio of primed $\mathrm{C}$ to litter derived $\mathrm{C}$ ) as compared to other less recalcitrant litter types. Altogether, these results point at the relevance of specialized soil decomposer communities in PEs, producing enzymes that are involved in the decomposition of both the added substrates and SOM. When only one type of trigger-substrate is used, as was done with glucose in Chapter 4, the amount of energy obtained is also an important factor in PEs. Low concentrations of glucose may not provide enough energy for the activation of extracellular enzyme production by soil microbes (Liu et al., 2017), whereas high concentrations may cause reduced activities due to osmotic problems (Chapter 4). The optimum concentration of glucose which results in the highest PE is somewhere between these extremes but appears to be different for different ecosystems (Chapter 4). An optimum concentration of PE-trigger substrates is in line with the meta-analysis of Blagodatskaya and Kuzyakov (2008). However, unlike the suggestion made by 
Blagodatskaya and Kuzyakov (2008), this optimum concentration seems not to be determined by the amount of microbial biomass.

One of the hypotheses of my thesis study was that the contribution of fungi to PEs was more important than that of bacteria because of their ability to penetrate solid SOM fractions (hyphal growth) and to produce a range of SOM-degrading enzymes (Fontaine et al., 2011). However, this was not confirmed. Results of Chapter 2 showed that bacteria and fungi were equally important for PEs. This was also the case for the most recalcitrant trigger-substrate, vanillic acid, indicating that bacteria were well able to decompose phenolic compounds. Hence, in general, soil $\mathrm{C}$ additions may trigger both bacteria and fungi to switch from a dormant to an active state (Blagodatskaya and Kuzyakov, 2008).

A comparison of studies using different soils and trigger compounds indicates that several microbial groups, including Gram-negative bacteria, Gram-positive bacteria, actinomycetes and fungi, can take the lead in PEs (e.g., Dungait et al., 2013; GarciaPausas and Paterson, 2011; Sullivan and Hart, 2013; Whitaker et al., 2014) and this can change over time (Blagodatskaya et al., 2014). However, in Chapter 2, the addition of different substrates to an ex-arable soil did not stimulate the growth of different bacterial classes, although differences in PEs among the treatments were observed. These differences in PEs could be due to stimulation of different enzyme systems within similar bacterial taxa.

It is largely assumed that lack of $\mathrm{N}$ in soils will induce high PEs since soil microbes are triggered to mine SOM to acquire this nutrient (Dijkstra et al., 2013; Liu et al., 2017). Following this so-called microbial $\mathrm{N}$ mining theory, a less strong PE is expected when $\mathrm{C}$ substrate is added together with $\mathrm{N}$. In Chapter 2, $\mathbf{3}$ and 4, the results of co-addition of $\mathrm{N}$ to soils did not support this theory. Indeed, the simultaneous addition of mineral $\mathrm{N}$ with organic $\mathrm{C}$ had generally little or no impact on PEs. In Chapter 5 it was shown that adding $\mathrm{N}$ together with labile $\mathrm{C}$ results in higher fungal growth rates and efficiencies, possibly increasing exo-enzyme production and PEs since the stoichiometric constraint for fungi is released. Several other studies did also show that simultaneous addition of $\mathrm{C}$ and $\mathrm{N}$ can increase or have no effect on PEs (Chowdhury et al., 2014; Tian et al., 2016). In line with these studies, the $\mathrm{N}$ mining theory was recently challenged since in its current form it cannot represent a universal explanation for PEs (Mason-Jones et al., 2018). Finally, in Chapter 3 and 4, C:N ratio of the soil organic matter could not explain the differences in $\mathrm{PEs}$ after the addition of mineral $\mathrm{N}$. Hence, for a greater understanding of the role played by $\mathrm{N}$ on PEs our attention should move to other SOM properties, such as the chemical structure of the compounds present in SOM (Schmidt et al., 2011).

Overall, the results of this thesis indicate that 1) increasing the resemblance of the chemical structure of the added substrates to SOM fractions and 2) providing conditions for the optimal use of energy of the added substrates by soil microorganisms will stimulate 
the growth and activity of SOM degrading community, resulting in positive priming effects (Fig. 1).

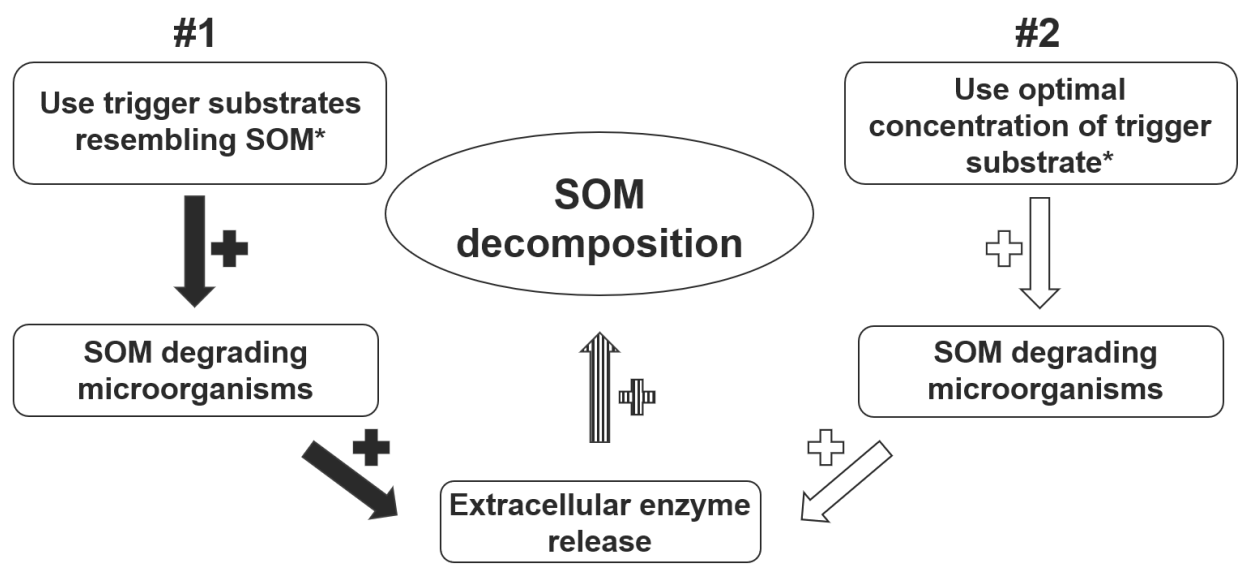

*SOM resemblance and optimal concentration can differ for different ecosystems

Fig.1: Conceptual model for increasing positive priming effects by stimulating the production of extracellular enzymes that will cause an extra decomposition of SOM. Use of 1) trigger substrates that resemble fractions of SOM and 2) supply the optimal concentration of trigger substrate for microbial growth.

It has been suggested that plants stimulate SOM mineralization via priming by a regular and slow exudation of rhizodeposits (Fontaine et al., 2003). It has been estimated that $20 \%$ to $50 \%$ of the carbon obtained by plants via photosynthetic assimilation is transferred to the roots and about half of this is further released into the soil (Kuzyakov and Domanski, 2000). This release of root exudates strongly affects the soil microbial composition and activity close to the roots (D. L. Jones et al., 2009). Therefore, in terms of the conceptual model proposed here, more complex organic rhizodeposit compounds that induce the production of enzymes able to decompose SOM and rhizodeposits with high energetic contents, will result in higher priming effects. It will also be interesting to study how combinations of both compound classes affect PEs. An optimal composition of PE-trigger compounds in root exudates will be of benefit for plants to obtain mineral nutrients from SOM.

\section{Priming effects in the context of global change}

Human activities are greatly impacting ecosystems to the extent that much of the planet surface has been totally transformed by a series of global change phenomena (Steffen et al., 2015). As part of the global change scenario, increased atmospheric $\mathrm{CO}_{2}$ levels and increasing rates of $\mathrm{N}$ enrichment to soils affect ecosystem $\mathrm{C}$ dynamics through their 
indirect effects on soil biota and the processes they drive. It was argued that many aspects of the structure and functioning of soils cannot be totally understood if we do not take into account the anthropogenic influence on them (Bardgett, 2005).

\section{Increasing atmospheric $\mathrm{CO}_{2}$ levels}

Higher atmospheric $\mathrm{CO}_{2}$ levels lead to increased photosynthesis, with a subsequent increase in above- and belowground plant biomass (Ainsworth and Long, 2005). As shown in this thesis (Chapter 3, 4 and 5), increased allocation of $C$ to the soil, in the form of plant litter or labile organic $\mathrm{C}$, can stimulate microbial activity, generating positive PEs that will enhance SOM turnover, thereby reducing soil C storage (Dijkstra and Cheng, 2007; Fontaine et al., 2004a). More specifically, the intensity of PEs controls the response of ecosystem C fluxes to global change (Heimann and Reichstein, 2008), as microbial priming of SOM can be responsible for the lack of SOM accumulation in ecosystems exposed to elevated $\mathrm{CO}_{2}$ (Drake et al., 2011; Hoosbeek et al., 2004; Iversen et al., 2012; Talhelm et al., 2009). Natural and managed terrestrial ecosystems can act as a sink for C. Managing soils for $\mathrm{C}$ sequestration is most relevant for agricultural and degraded soils, which offer great potential to act as C sinks under considerate management (Lal, 2004). Several strategies have been proposed for long-term increase of the $\mathrm{C}$ pool in agricultural and degraded soils, such as adoption of no tillage agriculture and the use of cover crops. In this respect, it is important to consider how the quality and quantity of the addition of organic substrates to agricultural soils as well as root exudates of cash crops and cover crops can affect PEs, in order to improve agronomical practices that will steer the balance between mineralization of organic compounds to $\mathrm{C}$ sequestration to mitigate climate change.

\section{Nitrogen enrichment to soils}

Depending on the ecosystem, $\mathrm{N}$ enrichments can have a positive, neutral or negative effect on soil C sequestration (Hobbie, 2000; Mack et al., 2004; Nadelhoffer et al., 1999; Ramirez et al., 2012; Resh et al., 2002). N enrichment can increase both the quantity and quality of litter inputs to soils, thereby promoting soil biological activity and nutrient cycling (Knorr et al., 2005). Microbial activity and their enzyme production in ecosystems with high quality litter (litter with a low $\mathrm{C}: \mathrm{N}$ ratio) respond positively to $\mathrm{N}$ deposition, whereas in ecosystems with more recalcitrant litter (litter with higher lignin content) microbial activity tend to respond negatively (Waldrop et al., 2004). These differences are a consequence of the effect of $\mathrm{N}$ enrichment on the activities of extracellular enzymes involved in cellulose and lignin degradation, as the microbial synthesis of cellulases is usually enhanced by $\mathrm{N}$ enrichment, whereas the synthesis of ligninolytic enzymes can be suppressed (Carreiro 
et al., 2000; Frey et al., 2004). In this thesis, I showed that the positive relationship between litter HFA and priming HFA disappeared when N was added (Chapter 3 ). This indicates that $\mathrm{N}$ amendments decoupled the link between accelerated litter decomposition and enhanced SOM mineralization. Indeed, microbial communities are functionally different and specialized to break down litter from plants with which they are associated (Gholz et al., 2000). Moreover, the differences in C:N ratios between SOM and litter and the higher amount of easy degradable compounds in litter as compared to SOM are important factors that can help explaining the different effects of $\mathrm{N}$ amendments (Qiao et al., 2016). Such findings have a clear implication for soil $C$ sequestration, suggesting that $\mathrm{N}$ enrichment influences $\mathrm{C}$ storage.

One of the effects of soil $\mathrm{N}$ enrichment is a depression in the biomass of decomposer fungi, leading to a shift towards a bacterial-dominated food web (de Vries et al., 2007, 2006). Yet, in Chapter 4, soil $\mathrm{N}$ addition did not affect fungal biomass while bacterial biomass was decreased. In addition, as shown in Chapter 5, fungi grown under low C:N conditions had the highest biomass production as well as the highest growth efficiency. Therefore, knowledge on the influence of $\mathrm{N}$ on fungal growth is critical for the assessment of soil $\mathrm{C}$ and $\mathrm{N}$ budgets. In fact, a better understanding of fungal and bacterial biomass dynamics upon $\mathrm{C}$ and $\mathrm{N}$ additions might be helpful to reduce losses of $\mathrm{N}$ fertilizers in agricultural soils.

\section{Future research directions}

I suggest that future studies should focus on the enzymes degrading both the added compounds and SOM (Chapter 2). The dynamics of the pool of such enzymes seems to be essential to understand PEs. Extracellular enzymes are directly responsible for SOM decomposition (Burns et al., 2013). Yet, the factors regulating their production and activity in soils are not completely clear (Allison et al., 2010).

Extracellular enzymes production brings high energetic costs for the microbial producers (Burns et al., 2013). Therefore, it is reasonable to expect that their synthesis is deeply controlled (Allison et al., 2010). Furthermore, taken into consideration the positive relationship between substrate mineralization and PE (Chapter 4), it is likely that production of SOM degrading enzymes is regulated by microbial energy status (MasonJones et al., 2018).

The importance of the physicochemical properties of trigger-substrates for PEs can be further examined. Combinations of trigger-substrates are also very interesting in this respect. To better explain PE mechanisms, fractions of SOM should be better described enabling the selection of substrates that chemically resemble SOM compounds. In addition, substrates with high energetic content or $\mathrm{C}: \mathrm{N}$ ratios that match microbial biomass 
stoichiometry can be selected. The effects of combinations of these trigger substrates on PEs can then be experimentally tested.

Microbial taxa contribute differently to extracellular enzyme activities and generally fungi have higher levels of enzyme production and complexity than bacteria (Baldrian et al., 2010). Yet, in the research described in Chapter 2, differences in PEs appeared to be due to the stimulation of different enzyme systems within similar phylogenetic bacterial communities. Therefore, a closer inspection of specialization of the microbial decomposer communities and their enzyme productions is needed to understand when and where soil microbes will accelerate or decelerate soil $\mathrm{C}$ cycling. 


\section{List of references}

Aerts, R., 1997. Climate, leaf litter chemistry and leaf litter decomposition in terrestrial Ecosystems: a triangular relationship. Oikos 79, 439. doi:10.2307/3546886

Ainsworth, E.A., Long, S.P., 2005. What have we learned from 15 years of free-air $\mathrm{CO}_{2}$ enrichment (FACE)? A meta-analytic review of the responses of photosynthesis, canopy properties and plant production to rising CO2. New Phytologist 165, 351-372. doi:10.1111/j.1469-8137.2004.01224.x

Allison, S.D., Chacon, S.S., German, D.P., 2014. Substrate concentration constraints on microbial decomposition. Soil Biology and Biochemistry 79, 43-49. doi:10.1016/j.soilbio.2014.08.021

Allison, S.D., LeBauer, D.S., Ofrecio, M.R., Reyes, R., Ta, A.-M., Tran, T.M., 2009. Low levels of nitrogen addition stimulate decomposition by boreal forest fungi. Soil Biology and Biochemistry 41, 293-302. doi:10.1016/j.soilbio.2008.10.032

Allison, S.D., Weintraub, M.N., Gartner, T.B., Waldrop, M.P., 2010. EvolutionaryEconomic Principles as Regulators of Soil Enzyme Production and Ecosystem Function. Springer, Berlin, Heidelberg, pp. 229-243. doi:10.1007/978-3-642-14225-3_12

Amann, R.I., Binder, B.J., Olson, R.J., Chisholm, S.W., Devereux, R., Stahl, D.A., 1990. Combination of $16 S$ rRNA-targeted oligonucleotide probes with flow cytometry for analyzing mixed microbial populations. Applied and Environmental Microbiology 56, 1919-1925. doi:10.1111/j.1469-8137.2004.01066.x

Aneja, M.K., Sharma, S., Fleischmann, F., Stich, S., Heller, W., Bahnweg, G., Munch, J.C., Schloter, M., 2006. Microbial colonization of beech and spruce litter-influence of decomposition site and plant litter species on the diversity of microbial community. Microbial Ecology 52, 127-35. doi:10.1007/s00248-006-9006-3

Arcand, M.M., Levy-Booth, D.J., Helgason, B.L., 2017. Resource legacies of organic and conventional management differentiate soil microbial carbon use. Frontiers in Microbiology 8, 1-17. doi:10.3389/fmicb.2017.02293

Austin, A.T., Vivanco, L., González-Arzac, A., Pérez, L.I., 2014. There's no place like home? An exploration of the mechanisms behind plant litter-decomposer affinity in terrestrial ecosystems. New Phytologist 204, 307-314. doi:10.1111/nph.12959

Ayres, E., Steltzer, H., Simmons, B.L., Simpson, R.T., Steinweg, J.M., Wallenstein, M.D., Mellor, N., Parton, W.J., Moore, J.C., Wall, D.H., 2009. Home-field advantage accelerates leaf litter decomposition in forests. Soil Biology and Biochemistry 41, 606610. doi:10.1016/j.soilbio.2008.12.022 
Bååth, E., Anderson, T.-H., 2003. Comparison of soil fungal/bacterial ratios in a $\mathrm{pH}$ gradient using physiological and PLFA-based techniques. Soil Biology and Biochemistry 35, 955-963. doi:10.1016/S0038-0717(03)00154-8

Baldrian, P., 2004. Increase of laccase activity during interspecific interactions of white-rot fungi. FEMS Microbiology Ecology 50, 245-253. doi:10.1016/j.femsec.2004.07.005

Baldrian, P., Merhautová, V., Petránková, M., Cajthaml, T., Šnajdr, J., 2010. Distribution of microbial biomass and activity of extracellular enzymes in a hardwood forest soil reflect soil moisture content. Applied Soil Ecology 46, 177-182. doi:10.1016/j.apsoil.2010.08.013

Baldrian, P., Větrovský, T., Cajthaml, T., DobiáŠová, P., Petránková, M., Šnajdr, J., Eichlerová, I., 2013. Estimation of fungal biomass in forest litter and soil. Fungal Ecology 6, 1-11. doi:10.1016/j.funeco.2012.10.002

Ball, B.A., Hunter, M.D., Kominoski, J.S., Swan, C.M., Bradford, M.A., 2008. Consequences of non-random species loss for decomposition dynamics: Experimental evidence for additive and non-additive effects. Journal of Ecology 96, 303-313. doi:10.1111/j.1365-2745.2007.01346.x

Barder, M.J., Crawford, D.L., 1981. Effects of carbon and nitrogen supplementation on lignin and cellulose decomposition by a Streptomyces. Canadian Journal of Microbiology 27, 859-63.

Bardgett, R.D., 2005. The biology of soil: a community and ecosystem approach. Oxford University Press.

Bardgett, R.D., McAlister, E., 1999. The measurement of soil fungal:bacterial biomass ratios as an indicator of ecosystem self-regulation in temperate meadow grasslands. Biology and Fertility of Soils 29, 282-290. doi:10.1007/s003740050554

Barns, S.M., Takala, S.L., Kuske, C.R., 1999. Wide distribution and diversity of members of the bacterial kingdom Acidobacterium in the environment. Applied and Environmental Microbiology 65, 1731-7.

Berg, B., McClaugherty, C., 2003. Plant Litter: Decomposition, Humus Formation, Carbon Sequestration. Springer Berlin Heidelberg.

Berg, M.P., Toby Kiers, E., Driessen, G., van der Heijden, M., Kooi, B.W., Kuenen, F., Liefting, M., Verhoef, H.A., Ellers, J., 2010. Adapt or disperse: Understanding species persistence in a changing world. Global Change Biology 16, 587-598. doi:10.1111/j.13652486.2009.02014.x 
Berger, T.W., Berger, P., 2014. Does mixing of beech (Fagus sylvatica) and spruce (Picea abies) litter hasten decomposition? Plant and Soil 377, 217-234. doi:10.1007/s11104-013-2001-9

Bernard, L., Mougel, C., Maron, P.-A., Nowak, V., Lévêque, J., Henault, C., Haichar, F.E.Z., Berge, O., Marol, C., Balesdent, J., Gibiat, F., Lemanceau, P., Ranjard, L., 2007. Dynamics and identification of soil microbial populations actively assimilating carbon from 13C-labelled wheat residue as estimated by DNA- and RNA-SIP techniques. Environmental Microbiology 9, 752-64. doi:10.1111/j.1462-2920.2006.01197.x

Bird, J., Herman, D., Firestone, M., 2011. Rhizosphere priming of soil organic matter by bacterial groups in a grassland soil. Soil Biology and Biochemistry 43, 718-725. doi:10.1016/j.soilbio.2010.08.010

Blagodatskaya, E., Khomyakov, N., Myachina, O., Bogomolova, I., Blagodatsky, S., Kuzyakov, Y., 2014. Microbial interactions affect sources of priming induced by cellulose. Soil Biology and Biochemistry 74, 39-49. doi:10.1016/j.soilbio.2014.02.017

Blagodatskaya, E.V., Blagodatsky, S.A., Anderson, T.-H., Kuzyakov, Y., 2007. Priming effects in Chernozem induced by glucose and $\mathrm{N}$ in relation to microbial growth strategies. Applied Soil Ecology 37, 95-105. doi:10.1016/j.apsoil.2007.05.002

Blagodatskaya, E., Kuzyakov, Y., 2008. Mechanisms of real and apparent priming effects and their dependence on soil microbial biomass and community structure: critical review. Biology and Fertility of Soils 45, 115-131. doi:10.1007/s00374-008-0334-y

Bloem, J., Veninga, M., Shepherd, J., 1995. Fully automatic determination of soil bacterium numbers, cell volumes, and frequencies of dividing cells by confocal laser scanning microscopy and image analysis. Appl Environ Microbiol 61, 926-936.

Boberg, J., Finlay, R., Stenlid, J., Nasholm, T., Lindahl, B., 2008. Glucose and ammonium additions affect needle decomposition and carbon allocation by the litter degrading fungus Mycena epipterygia. Soil Biology and Biochemistry 40, 995-999. doi:10.1016/j.soilbio.2007.11.005

Boberg, J.B., Näsholm, T., Finlay, R.D., Stenlid, J., Lindahl, B.D., 2011. Nitrogen availability affects saprotrophic basidiomycetes decomposing pine needles in a long term laboratory study. Fungal Ecology 4, 408-416. doi:10.1016/j.funeco.2011.03.004

Boddy, L., 2000. Interspecific combative interactions between wood-decaying basidiomycetes. FEMS Microbiology Ecology 31, 185-194.

Bowles, T.M., Acosta-Martínez, V., Calderón, F., Jackson, L.E., 2014. Soil enzyme activities, microbial communities, and carbon and nitrogen availability in organic agroecosystems across an intensively-managed agricultural landscape. Soil Biology and Biochemistry 68, 252-262. doi:10.1016/j.soilbio.2013.10.004 
Bradford, M. a., Fierer, N., Reynolds, J.F., 2008. Soil carbon stocks in experimental mesocosms are dependent on the rate of labile carbon, nitrogen and phosphorus inputs to soils. Functional Ecology 22, 964-974. doi:10.1111/j.1365-2435.2008.01404.x

Bradford, M. a., Keiser, A.D., Davies, C. a., Mersmann, C. a., Strickland, M.S., 2013. Empirical evidence that soil carbon formation from plant inputs is positively related to microbial growth. Biogeochemistry 113, 271-281. doi:10.1007/s10533-012-9822-0

Bradford, M. A., 2014. Ecology: Good dirt with good friends. Nature 505, 486-487. doi:10.1038/nature12849

Bradford, M.A., Ciska, G.F., Bonis, A., Bradford, E.M., Classen, A.T., Cornelissen, J.H.C., Crowther, T.W., De Long, J.R., Freschet, G.T., Kardol, P., Manrubia-Freixa, M., Maynard, D.S., Newman, G.S., Logtestijn, R.S.P., Viketoft, M., Wardle, D.A., Wieder, W.R., Wood, S.A., Van Der Putten, W.H., 2017. A test of the hierarchical model of litter decomposition. Nature Ecology and Evolution 1, 1836-1845. doi:10.1038/s41559-0170367-4

Bradford, M.A., Tordoff, G.M., Eggers, T., Jones, T.H., Newington, J.E., 2002. Microbiota, fauna, and mesh size interactions in litter decomposition. Oikos 99, 317-323. doi:10.1034/j.1600-0706.2002.990212.x

Brant, J.B., Sulzman, E.W., Myrold, D.D., 2006. Microbial community utilization of added carbon substrates in response to long-term carbon input manipulation. Soil Biology and Biochemistry 38, 2219-2232. doi:10.1016/j.soilbio.2006.01.022

Broadbent, F.E., Norman, A. G., 1947. Some Factors Affecting the Availability of the Organic Nitrogen In Soil-A Preliminary Report1. Soil Science Society of America Journal 11, 264. doi:10.2136/sssaj1947.036159950011000C0050x

Broeckling, C.D., Broz, A.K., Bergelson, J., Manter, D.K., Vivanco, J.M., 2008. Root exudates regulate soil fungal community composition and diversity. Applied and Environmental Microbiology 74, 738-744. doi:10.1128/AEM.02188-07

Buée, M., de Boer, W., Martin, F., van Overbeek, L., Jurkevitch, E., 2009. The rhizosphere zoo: An overview of plant-associated communities of microorganisms, including phages, bacteria, archaea, and fungi, and of some of their structuring factors. Plant and Soil 321, 189-212. doi:10.1007/s11104-009-9991-3

Burns, R.G., DeForest, J.L., Marxsen, J., Sinsabaugh, R.L., Stromberger, M.E., Wallenstein, M.D., Weintraub, M.N., Zoppini, A., 2013. Soil enzymes in a changing environment: Current knowledge and future directions. Soil Biology and Biochemistry 58, 216-234. doi:10.1016/j.soilbio.2012.11.009

Butler, J.L., Williams, M. a, Bottomley, P.J., Myrold, D.D., 2003. Microbial Community Dynamics Associated with Rhizosphere Carbon Flow Microbial Community 
Dynamics Associated with Rhizosphere Carbon Flow. Applied and Environmental Microbiology 69, 6793-6800. doi:10.1128/AEM.69.11.6793

Carreiro, M.M., Sinsabaugh, R.L., Repert, D.A., Parkhurst, D.F., 2000. Microbial enzyme shifts explain litter decay responses to simulated nitrogen deposition. Ecology 81, 2359-2365. doi:10.1890/0012-9658(2000)081[2359:MESELD]2.0.CO;2

Chapin, F.S., Matson, P.A. (Pamela A.., Vitousek, P.M., Chapin, M.C., 2011. Principles of terrestrial ecosystem ecology. Springer.

Chen, R., Senbayram, M., Blagodatsky, S., Myachina, O., Dittert, K., Lin, X., Blagodatskaya, E., Kuzyakov, Y., 2014. Soil C and N availability determine the priming effect: microbial $\mathrm{N}$ mining and stoichiometric decomposition theories. Global Change Biology 20, 2356-2367. doi:10.1111/gcb.12475

Cheng, L., Booker, F.L., Tu, C., Burkey, K.O., Zhou, L., Shew, H.D., Rufty, T.W., $\mathrm{Hu}, \mathrm{S} ., 2$ 2012. Arbuscular mycorrhizal fungi increase organic carbon decomposition under elevated CO2. Science (New York, N.Y.) 337, 1084-7. doi:10.1126/science.1224304

Cheng, W., 1996. Measurement of rhizosphere respiration and organic matter decomposition using natural13C. Plant and Soil 183, 263-268. doi:10.1007/BF00011441

Cheng, W., Kuzyakov, Y., 2005. Root Effects on Soil Organic Matter Decomposition 119-144.

Chowdhury, S., Farrell, M., Bolan, N., 2014. Priming of soil organic carbon by malic acid addition is differentially affected by nutrient availability. Soil Biology and Biochemistry 77, 158-169. doi:10.1016/j.soilbio.2014.06.027

Christensen, M., 1989. A View of Fungal Ecology. Mycologia 81, 1. doi: $10.2307 / 3759446$

Cleveland, C., Reed, S., Townsend, A., 2006. Nutrient regulation of organic matter decomposition in a tropical rain forest. Ecology 87, 492-503.

Cleveland, C.C., Reed, S.C., Keller, A.B., Nemergut, D.R., O’Neill, S.P., Ostertag, R., Vitousek, P.M., 2014. Litter quality versus soil microbial community controls over decomposition: A quantitative analysis. Oecologia 174, 283-294. doi:10.1007/s00442013-2758-9

Cole, J.R., Wang, Q., Fish, J.A., Chai, B., McGarrell, D.M., Sun, Y., Brown, C.T., Porras-Alfaro, A., Kuske, C.R., Tiedje, J.M., 2014. Ribosomal Database Project: data and tools for high throughput rRNA analysis. Nucleic Acids Research 42, D633-42. doi:10.1093/nar/gkt1244

Conde, E., Cardenas, M., Ponce-Mendoza, A., Luna-Guido, M.L., CruzMondragón, C., Dendooven, L., 2005. The impacts of inorganic nitrogen application on 
mineralization of 14C-labelled maize and glucose, and on priming effect in saline alkaline soil. Soil Biology and Biochemistry 37, 681-691. doi:10.1016/j.soilbio.2004.08.026

Cornelissen, J.H.C., Sass-Klaassen, U., Poorter, L., et al., 2012. Controls on coarse wood decay in temperate tree species: birth of the LOGLIFE experiment. Ambio 41 Suppl 3, 231-45. doi:10.1007/s13280-012-0304-3

Cornwell, W.K., Cornelissen, J.H.C., Amatangelo, K., Dorrepaal, E., Eviner, V.T., Godoy, O., Hobbie, S.E., Hoorens, B., Kurokawa, H., Pérez-Harguindeguy, N., Quested, H.M., Santiago, L.S., Wardle, D.A., Wright, I.J., Aerts, R., Allison, S.D., Van Bodegom, P., Brovkin, V., Chatain, A., Callaghan, T. V., Díaz, S., Garnier, E., Gurvich, D.E., Kazakou, E., Klein, J.A., Read, J., Reich, P.B., Soudzilovskaia, N.A., Vaieretti, M.V., Westoby, M., 2008. Plant species traits are the predominant control on litter decomposition rates within biomes worldwide. Ecology Letters 11, 1065-1071. doi:10.1111/j.14610248.2008.01219.x

Craine, J.M., Morrow, C., Fierer, N., 2007. Microbial nitrogen limitation increases decomposition. Ecology 88, 2105-2113.

Creamer, C. A., de Menezes, A.B., Krull, E.S., Sanderman, J., Newton-Walters, R., Farrell, M., 2015. Microbial community structure mediates response of soil C decomposition to litter addition and warming. Soil Biology and Biochemistry 80, 175-188. doi:10.1016/j.soilbio.2014.10.008

Crowther, T.W., Todd-Brown, K.E.O., Rowe, C.W., et al., 2016. Quantifying global soil carbon losses in response to warming. Nature 540, 104-108. doi:10.1038/nature20150

Csonka, L.N., 1989. Physiological and genetic responses of bacteria to osmotic stress. Microbiological Reviews 53, 121-47.

de Boer, W., Folman, L.B., Summerbell, R.C., Boddy, L., 2005. Living in a fungal world: Impact of fungi on soil bacterial niche development. FEMS Microbiology Reviews 29, 795-811. doi:10.1016/j.femsre.2004.11.005

de Graaff, M.-A., Classen, A.T., Castro, H.F., Schadt, C.W., 2010. Labile soil carbon inputs mediate the soil microbial community composition and plant residue decomposition rates. New Phytologist 188, 1055-1064. doi:10.1111/j.14698137.2010.03427.x

De Nobili, M., Contin, M., Mondini, C., Brookes, P.., 2001. Soil microbial biomass is triggered into activity by trace amounts of substrate. Soil Biology and Biochemistry 33, 1163-1170. doi:10.1016/S0038-0717(01)00020-7 
de Ridder-Duine, A.S., Smant, W., van der Wal, A., van Veen, J. a., de Boer, W., 2006. Evaluation of a simple, non-alkaline extraction protocol to quantify soil ergosterol. Pedobiologia 50, 293-300. doi:10.1016/j.pedobi.2006.03.004

de Vries, F.T., Bardgett, R.D., 2012. Plant-microbial linkages and ecosystem nitrogen retention: lessons for sustainable agriculture. Frontiers in Ecology and the Environment 10, 425-432. doi:10.1890/110162

de Vries, F.T., Bloem, J., van Eekeren, N., Brusaard, L., Hoffland, E., 2007. Fungal biomass in pastures increases with age and reduced $\mathrm{N}$ input. Soil Biology and Biochemistry 39, 1620-1630. doi:10.1016/j.soilbio.2007.01.013

de Vries, F.T., Hoffland, E., van Eekeren, N., Brussaard, L., Bloem, J., 2006. Fungal/bacterial ratios in grasslands with contrasting nitrogen management. Soil Biology and Biochemistry 38, 2092-2103. doi:10.1016/j.soilbio.2006.01.008

de Vries, F.T., Shade, A., 2013. Controls on soil microbial community stability under climate change. Frontiers in Microbiology 4, 265. doi:10.3389/fmicb.2013.00265

de Vries, F.T., van Groenigen, J.W., Hoffland, E., Bloem, J., 2011. Nitrogen losses from two grassland soils with different fungal biomass. Soil Biology and Biochemistry 43, 997-1005. doi:10.1016/j.soilbio.2011.01.016

Deacon, J.W., 2006. Fungal biology. Blackwell Pub.

Demoling, F., Ola Nilsson, L., Bååth, E., 2008. Bacterial and fungal response to nitrogen fertilization in three coniferous forest soils. Soil Biology and Biochemistry 40 , 370-379. doi:10.1016/j.soilbio.2007.08.019

Di Lonardo, D.P., de Boer, W., Klein Gunnewiek, P.J.A., Hannula, S.E., van der Wal, A., 2017. Priming of soil organic matter: Chemical structure of added compounds is more important than the energy content. Soil Biology and Biochemistry 108, 41-54. doi:10.1016/j.soilbio.2017.01.017

Di Lonardo, D.P., Manrubia, M., de Boer, W., Zweers, H., Veen, G.F., van der Wal, A., 2018. Relationship between home-field advantage of litter decomposition and priming of soil organic matter. Soil Biology and Biochemistry 126, 49-56. doi:10.1016/j.soilbio.2018.07.025

Diez, J.M., Dickie, I., Edwards, G., Hulme, P.E., Sullivan, J.J., Duncan, R.P., 2010. Negative soil feedbacks accumulate over time for non-native plant species. Ecology Letters 13, 803-809. doi:10.1111/j.1461-0248.2010.01474.x

Dijkstra, F. a, Carrillo, Y., Pendall, E., Morgan, J. A., 2013. Rhizosphere priming: a nutrient perspective. Frontiers in Microbiology 4, 216. doi:10.3389/fmicb.2013.00216 
Dijkstra, F.A., Cheng, W., 2007. Interactions between soil and tree roots accelerate long-term soil carbon decomposition. Ecology Letters 10, 1046-1053. doi:10.1111/j.14610248.2007.01095.x

Dijkstra, P., Salpas, E., Fairbanks, D., Miller, E.B., Hagerty, S.B., van Groenigen, K.J., Hungate, B.A., Marks, J.C., Koch, G.W., Schwartz, E., 2015. High carbon use efficiency in soil microbial communities is related to balanced growth, not storage compound synthesis. Soil Biology and Biochemistry 89, 35-43. doi:10.1016/j.soilbio.2015.06.021

Drake, J.E., Darby, B. a., Giasson, M. -A., Kramer, M. a., Phillips, R.P., Finzi, A. C., 2013. Stoichiometry constrains microbial response to root exudation- insights from a model and a field experiment in a temperate forest. Biogeosciences 10, 821-838. doi:10.5194/bg-10-821-2013

Drake, J.E., Gallet-Budynek, A., Hofmockel, K.S., Bernhardt, E.S., Billings, S.A., Jackson, R.B., Johnsen, K.S., Lichter, J., Mccarthy, H.R., Mccormack, M.L., Moore, D.J.P., Oren, R., Palmroth, S., Phillips, R.P., Pippen, J.S., Pritchard, S.G., Treseder, K.K., Schlesinger, W.H., Delucia, E.H., Finzi, A.C., 2011. Increases in the flux of carbon belowground stimulate nitrogen uptake and sustain the long-term enhancement of forest productivity under elevated CO2. Ecology Letters 14, 349-357. doi:10.1111/j.14610248.2011.01593.x

Dungait, J. a J., Kemmitt, S.J., Michallon, L., Guo, S., Wen, Q., Brookes, P.C., Evershed, R.P., 2013. The variable response of soil microorganisms to trace concentrations of low molecular weight organic substrates of increasing complexity. Soil Biology and Biochemistry 64, 57-64. doi:10.1016/j.soilbio.2013.03.036

Edgar, R.C., 2010. Search and clustering orders of magnitude faster than BLAST. Bioinformatics (Oxford, England) 26, 2460-1. doi:10.1093/bioinformatics/btq461

Edgar, R.C., Haas, B.J., Clemente, J.C., Quince, C., Knight, R., 2011. UCHIME improves sensitivity and speed of chimera detection. Bioinformatics 27, 2194-2200. doi:10.1093/bioinformatics/btr381

Elliott, E.T., Coleman, D.C., 1977. Soil protozoan dynamics in a shortgrass prairie. Soil Biology and Biochemistry 9, 113-118. doi:10.1016/0038-0717(77)90046-3

Falchini, L., Naumova, N., Kuikman, P.J., Bloem, J., Nannipieri, P., 2003. $\mathrm{CO}_{2}$ evolution and denaturing gradient gel electrophoresis profiles of bacterial communities in soil following addition of low molecular weight substrates to simulate root exudation. Soil Biology and Biochemistry 35, 775-782. doi:10.1016/S0038-0717(03)00105-6 
Fanin, N., Bertrand, I., 2016. Aboveground litter quality is a better predictor than belowground microbial communities when estimating carbon mineralization along a landuse gradient. Soil Biology and Biochemistry 94, 48-60. doi:10.1016/j.soilbio.2015.11.007

Fanin, N., Fromin, N., Bertrand, I., 2016. Functional breadth and home-field advantage generate functional differences among soil microbial decomposers. Ecology 97, 1023-1037. doi:10.1890/15-1263.1

Fanin, N., Hättenschwiler, S., Fromin, N., 2014. Litter fingerprint on microbial biomass, activity, and community structure in the underlying soil. Plant and Soil 379, 79 91. doi:10.1007/s11104-014-2051-7

Fierer, N., Bradford, M.A., Jackson, R.B., 2007. Toward an ecological classification of soil bacteria. Ecology 88, 1354-1364. doi:10.1890/05-1839

Fierer, N., Jackson, J.A., Vilgalys, R., Jackson, R.B., 2005. Assessment of Soil Microbial Community Structure by Use of Taxon-Specific Quantitative PCR Assays. Applied and Environmental Microbiology 71, 4117-4120. doi:10.1128/AEM.71.7.41174120.2005

Fierer, N., Strickland, M.S., Liptzin, D., Bradford, M. A., Cleveland, C.C., 2009. Global patterns in belowground communities. Ecology Letters 12, 1238-1249. doi:10.1111/j.1461-0248.2009.01360.x

Fontaine, S., Bardoux, G., Abbadie, L., Mariotti, A., 2004a. Carbon input to soil may decrease soil carbon content. Ecology Letters 7, 314-320. doi:10.1111/j.14610248.2004.00579.x

Fontaine, S., Bardoux, G., Benest, D., Verdier, B., Mariotti, A., Abbadie, L., 2004b. Mechanisms of the Priming Effect in a Savannah Soil Amended with Cellulose. Soil Science Society of America Journal 68, 125. doi:10.2136/sssaj2004.0125

Fontaine, S., Barot, S., 2005. Size and functional diversity of microbe populations control plant persistence and long-term soil carbon accumulation. Ecology Letters 8, 1075-1087. doi:10.1111/j.1461-0248.2005.00813.x

Fontaine, S., Barot, S., Barré, P., Bdioui, N., Mary, B., Rumpel, C., 2007. Stability of organic carbon in deep soil layers controlled by fresh carbon supply. Nature 450, 27780. doi:10.1038/nature 06275

Fontaine, S., Henault, C., Aamor, A., Bdioui, N., Bloor, J.M.G., Maire, V., Mary, B., Revaillot, S., Maron, P.A., 2011. Fungi mediate long term sequestration of carbon and nitrogen in soil through their priming effect. Soil Biology and Biochemistry 43, 86-96. doi:10.1016/j.soilbio.2010.09.017 
Fontaine, S., Mariotti, A., Abbadie, L., 2003. The priming effect of organic matter: a question of microbial competition? Soil Biology and Biochemistry 35, 837-843. doi:10.1016/S0038-0717(03)00123-8

Forge, T.A., Bittman, S., Kowalenko, C.G., 2005. Responses of grassland soil nematodes and protozoa to multi-year and single-year applications of dairy manure slurry and fertilizer. Soil Biology and Biochemistry 37, 1751-1762. doi:10.1016/j.soilbio.2004.11.013

Freschet, G.T., Aerts, R., Cornelissen, J.H.C., 2012. Multiple mechanisms for trait effects on litter decomposition: moving beyond home-field advantage with a new hypothesis. Journal of Ecology 100, 619-630. doi:10.1111/j.1365-2745.2011.01943.x

Frey, S.D., Knorr, M., Parrent, J.L., Simpson, R.T., 2004. Chronic nitrogen enrichment affects the structure and function of the soil microbial community in temperate hardwood and pine forests. Forest Ecology and Management 196, 159-171. doi:10.1016/j.foreco.2004.03.018

Frostegård, Å., Tunlid, A., Bååth, E., 1991. Microbial biomass measured as total lipid phosphate in soils of different organic content. Journal of Microbiological Methods 14, 151-163. doi:10.1016/0167-7012(91)90018-L

Garcia-Pausas, J., Paterson, E., 2011. Microbial community abundance and structure are determinants of soil organic matter mineralisation in the presence of labile carbon. Soil Biology and Biochemistry 43, 1705-1713. doi:10.1016/j.soilbio.2011.04.016

Geyer, K., Frey, S., Dijkstra, P., Sinsabaugh, R., 2018. Clarifying the interpretation of carbon use efficiency estimates in soil through methods comparison. Soil Biology and Biochemistry 20, 8564. doi:10.1016/J.SOILBIO.2018.09.036

Geyer, K.M., Kyker-Snowman, E., Grandy, A.S., Frey, S.D., 2016. Microbial carbon use efficiency: accounting for population, community, and ecosystem-scale controls over the fate of metabolized organic matter. Biogeochemistry 127, 173-188. doi:10.1007/s10533-016-0191-y

Gholz, H.L., Wedin, D.A., Smitherman, S.M., Harmon, M.E., Parton, W.J., 2000. Long-term dynamics of pine and hardwood litter in contrasting environments: toward a global model of decomposition. Global Change Biology 6, 751-765. doi:10.1046/j.13652486.2000.00349.x

Gießelmann, U.C., Martins, K.G., Brändle, M., Schädler, M., Marques, R., Brandl, R., 2011. Lack of home-field advantage in the decomposition of leaf litter in the Atlantic Rainforest of Brazil. Applied Soil Ecology 49, 5-10. doi:10.1016/j.apsoil.2011.07.010 
Gordon, H., Haygarth, P.M., Bardgett, R.D., 2008. Drying and rewetting effects on soil microbial community composition and nutrient leaching. Soil Biology and Biochemistry 40, 302-311. doi:10.1016/j.soilbio.2007.08.008

Guenet, B., Camino-Serrano, M., Ciais, P., Tifafi, M., Maignan, F., Soong, J.L., Janssens, I.A., 2018. Impact of priming on global soil carbon stocks. Global Change Biology 24, 1873-1883. doi:10.1111/gcb.14069

Guenet, B., Neill, C., Bardoux, G., Abbadie, L., 2010. Is there a linear relationship between priming effect intensity and the amount of organic matter input? Applied Soil Ecology 46, 436-442. doi:10.1016/j.apsoil.2010.09.006

Hagerty, S.B., van Groenigen, K.J., Allison, S.D., Hungate, B. A., Schwartz, E., Koch, G.W., Kolka, R.K., Dijkstra, P., 2014. Accelerated microbial turnover but constant growth efficiency with warming in soil. Nature Climate Change 4, 3-6. doi:10.1038/nclimate2361

Hamer, U., Marschner, B., 2005. Priming effects in different soil types induced by fructose, alanine, oxalic acid and catechol additions. Soil Biology and Biochemistry 37, 445-454. doi:10.1016/j.soilbio.2004.07.037

Hamer, U., Marschner, B., 2002. Priming effects of sugars, amino acids, organic acids and catechol on the mineralization of lignin and peat. Journal of Plant Nutrition and Soil Science 165, 261-268.

Hannula, S.E., Boschker, H.T.S., de Boer, W., van Veen, J. A., 2012. ${ }^{13} \mathrm{C}$ pulselabeling assessment of the community structure of active fungi in the rhizosphere of a genetically starch-modified potato (Solanum tuberosum) cultivar and its parental isoline. The New Phytologist 194, 784-99. doi:10.1111/j.1469-8137.2012.04089.x

Hannula, S.E., de Boer, W., van Veen, J.A., 2010. In situ dynamics of soil fungal communities under different genotypes of potato, including a genetically modified cultivar. Soil Biology and Biochemistry 42, 2211-2223. doi:10.1016/j.soilbio.2010.08.020

Harkes, P., Verhoeven, A., Sterken, M.G., Snoek, L.B., van den Elsen, S.J.J., Mooijman, P.J.W., Quist, C.W., Vervoort, M.T.W., Helder, J., 2017. The differential impact of a native and a non-native ragwort species (Senecioneae) on the first and second trophic level of the rhizosphere food web. Oikos 126, 1790-1803. doi:10.1111/oik.04530

Heimann, M., Reichstein, M., 2008. Terrestrial ecosystem carbon dynamics and climate feedbacks. Nature 451, 289-292. doi:10.1038/nature06591

Hessen, D., Ågren, G., Anderson, T., 2004. Carbon sequestration in ecosystems: the role of stoichiometry. Ecology 85, 1179-1192. 
Hiscox, J., Savoury, M., Vaughan, I.P., Müller, C.T., Boddy, L., 2015. Antagonistic fungal interactions influence carbon dioxide evolution from decomposing wood. Fungal Ecology 14, 24-32. doi:10.1016/j.funeco.2014.11.001

Ho, A., Di Lonardo, D.P., Bodelier, P.L.E., 2017. Revisiting life strategy concepts in environmental microbial ecology. FEMS Microbiology Ecology 93, fix006. doi:10.1093/femsec/fix006

Hobbie, S.E., 2000. Interactions between litter lignin and soil nitrogen availability during leaf litter decomposition in a Hawaiian montane forest. Ecosystems 3, 484-494. doi:10.1007/s100210000042

Hoosbeek, M.R., Lukac, M., van Dam, D., Godbold, D.L., Velthorst, E.J., Biondi, F.A., Peressotti, A., Cotrufo, M.F., de Angelis, P., Scarascia-Mugnozza, G., 2004. More new carbon in the mineral soil of a poplar plantation under Free Air Carbon Enrichment (POPFACE): Cause of increased priming effect? Global Biogeochemical Cycles 18, n/an/a. doi:10.1029/2003GB002127

Iversen, C.M., Keller, J.K., Garten, C.T., Norby, R.J., 2012. Soil carbon and nitrogen cycling and storage throughout the soil profile in a sweetgum plantation after 11 years of CO 2-enrichment. Global Change Biology 18, 1684-1697. doi:10.1111/j.13652486.2012.02643.x

Jenkins, S.N., Rushton, S.P., Lanyon, C. V., Whiteley, A.S., Waite, I.S., Brookes, P.C., Kemmitt, S., Evershed, R.P., O'Donnell, A.G., 2010. Taxon-specific responses of soil bacteria to the addition of low level C inputs. Soil Biology and Biochemistry 42, 1624 1631. doi:10.1016/j.soilbio.2010.06.002

John, M.G.S., Orwin, K.H., Dickie, I.A., 2011. No "home" versus "away" effects of decomposition found in a grassland-forest reciprocal litter transplant study. Soil Biology and Biochemistry 43, 1482-1489. doi:10.1016/j.soilbio.2011.03.022

Jones, D.L., Nguyen, C., Finlay, R.D., 2009. Carbon flow in the rhizosphere: Carbon trading at the soil-root interface. Plant and Soil 321, 5-33. doi:10.1007/s11104009-9925-0

Jones, R.T., Robeson, M.S., Lauber, C.L., Hamady, M., Knight, R., Fierer, N., 2009. A comprehensive survey of soil acidobacterial diversity using pyrosequencing and clone library analyses. The ISME Journal 3, 442-453. doi:10.1038/ismej.2008.127

Keeler, B.L., Hobbie, S.E., Kellogg, L.E., 2009. Effects of long-term nitrogen addition on microbial enzyme activity in eight forested and grassland sites: implications for litter and soil organic matter decomposition. Ecosystems 12, 1-15. doi:10.1007/s10021-008-9199-z 
Keiser, A.D., Keiser, D.A., Strickland, M.S., Bradford, M.A., 2014. Disentangling the mechanisms underlying functional differences among decomposer communities. Journal of Ecology 102, 603-609. doi:10.1111/1365-2745.12220

Keiser, A.D., Strickland, M.S., Fierer, N., Bradford, M.A., 2011. The effect of resource history on the functioning of soil microbial communities is maintained across time. Biogeosciences 8, 1477-1486. doi:10.5194/bg-8-1477-2011

Kielak, A.M., Barreto, C.C., Kowalchuk, G.A., van Veen, J.A., Kuramae, E.E., 2016a. The Ecology of Acidobacteria: Moving beyond Genes and Genomes. Frontiers in Microbiology 7, 1-16. doi:10.3389/fmicb.2016.00744

Kielak, A.M., Scheublin, T.R., Mendes, L.W., van Veen, J.A., Kuramae, E.E., 2016b. Bacterial Community Succession in Pine-Wood Decomposition. Frontiers in Microbiology 7, 1-12. doi:10.3389/fmicb.2016.00231

Klamer, M., Baath, E., 2004. Estimation of conversion factors for fungal biomass determination in compost using ergosterol and PLFA 18:2w6,9. Soil Biology and Biochemistry 36, 57-65. doi:10.1016/j.soilbio.2003.08.019

Klotzbücher, T., Kaiser, K., Guggenberger, G., Gatzek, C., Kalbitz, K., 2011. A new conceptual model for the fate of lignin in decomposing plant litter. Ecology 92, 1052-62.

Knorr, M., Frey, S.D., Curtis, P.S., 2005. Nitrogen additions and litter decomposition: A meta analysys. Ecology 86, 3252-3257. doi:10.1890/05-0150

Koranda, M., Kaiser, C., Fuchslueger, L., Kitzler, B., Sessitsch, A., ZechmeisterBoltenstern, S., Richter, A., 2014. Fungal and bacterial utilization of organic substrates depends on substrate complexity and N availability. FEMS Microbiology Ecology 87, 14252. doi:10.1111/1574-6941.12214

Koranda, M., Kaiser, C., Fuchslueger, L., Kitzler, B., Sessitsch, A., ZechmeisterBoltenstern, S., Richter, A., 2013. Seasonal variation in functional properties of microbial communities in beech forest soil. Soil Biology and Biochemistry 60, 95-104. doi:10.1016/j.soilbio.2013.01.025

Koster, J., Rahmann, S., 2012. Snakemake--a scalable bioinformatics workflow engine. Bioinformatics 28, 2520-2522. doi:10.1093/bioinformatics/bts480

Kowalchuk, G. A., 2012. Bad News for Soil Carbon Sequestration? Science 337, 1049-1050. doi:10.1126/science.1227303

Kuzyakov, Y., 2010. Priming effects: Interactions between living and dead organic matter. Soil Biology \& Biochemistry 42, 1363-1371. doi:10.1016/j.soilbio.2010.04.003 
Kuzyakov, Y., 2002. Review: Factors affecting rhizosphere priming effects. Journal of Plant Nutrition and Soil Science 165, 382. doi:10.1002/15222624(200208)165:4<382::AID-JPLN382>3.0.CO;2-\#

Kuzyakov, Y., Blagodatskaya, E., 2015. Microbial hotspots and hot moments in soil: Concept \& review. Soil Biology and Biochemistry 83, S29-S36. doi:10.1016/j.soilbio.2015.01.025

Kuzyakov, Y., Bol, R., 2006. Sources and mechanisms of priming effect induced in two grassland soils amended with slurry and sugar. Soil Biology and Biochemistry 38, 747-758. doi:10.1016/j.soilbio.2005.06.025

Kuzyakov, Y., Domanski, G., 2000. Carbon input by plants into the soil. Review. Zeitschrift Für Pflanzenernährung Und Bodenkunde 163, 421-431.

Kuzyakov, Y., Friedel, J.K., Stahr, K., 2000. Review of mechanisms and quantification of priming effects. Soil Biology and Biochemistry 32, 1485-1498. doi:10.1016/S0038-0717(00)00084-5

Kuzyakov, Y., Hill, P.W., Jones, D.L., 2007. Root exudate components change litter decomposition in a simulated rhizosphere depending on temperature. Plant and Soil 290, 293-305. doi:10.1007/s11104-006-9162-8

Lal, R., 2004. Soil carbon sequestration to mitigate climate change. Encyclopedia of Energy 123, 289-298. doi:DOI: 10.1016/j.geoderma.2004.01.032

Lashermes, G., Gainvors-Claisse, A., Recous, S., Bertrand, I., 2016. Enzymatic Strategies and Carbon Use Efficiency of a Litter-Decomposing Fungus Grown on Maize Leaves, Stems, and Roots. Frontiers in Microbiology 7, 1-14. doi:10.3389/fmicb.2016.01315

Lee, C.G., Watanabe, T., Sato, Y., Murase, J., Asakawa, S., Kimura, M., 2011. Bacterial populations assimilating carbon from 13C-labeled plant residue in soil: Analysis by a DNA-SIP approach. Soil Biology and Biochemistry 43, 814-822. doi:10.1016/j.soilbio.2010.12.016

Li, L.J., Zhu-Barker, X., Ye, R., Doane, T.A., Horwath, W.R., 2018. Soil microbial biomass size and soil carbon influence the priming effect from carbon inputs depending on nitrogen availability. Soil Biology and Biochemistry 119, 41-49. doi:10.1016/j.soilbio.2018.01.003

Li, Y.-B., Li, Q., Yang, J.-J., Lü, X.-T., Liang, W.-J., Han, X.-G., Bezemer, M.T., 2017. Home-field advantages of litter decomposition increase with increasing $\mathrm{N}$ deposition rates: a litter and soil perspective. Functional Ecology 38, 42-49. doi:10.1111/13652435.12863 
Liang, C., Balser, T.C., 2011. Microbial production of recalcitrant organic matter in global soils: implications for productivity and climate policy. Nature Reviews Microbiology 9, 75-75. doi:10.1038/nrmicro2386-c1

Liu, W., Qiao, C., Yang, S., Bai, W., Liu, L., 2018. Microbial carbon use efficiency and priming effect regulate soil carbon storage under nitrogen deposition by slowing soil organic matter decomposition. Geoderma 332, 37-44. doi:10.1016/j.geoderma.2018.07.008

Liu, X.-J.A., Sun, J., Mau, R.L., Finley, B.K., Compson, Z.G., van Gestel, N., Brown, J.R., Schwartz, E., Dijkstra, P., Hungate, B.A., 2017. Labile carbon input determines the direction and magnitude of the priming effect. Applied Soil Ecology 109, 7-13. doi:10.1016/j.apsoil.2016.10.002

Löhnis, F., 1926. Nitrogen availability of green manures. Soil Science 22, 253-290. doi:10.1097/00010694-192610000-00001

Lu, Y., Murase, J., Watanabe, A., Sugimoto, A., Kimura, M., 2004. Linking microbial community dynamics to rhizosphere carbon flow in a wetland rice soil. FEMS Microbiology Ecology 48, 179-186. doi:10.1016/j.femsec.2004.01.004

Lueders, T., Pommerenke, B., Friedrich, M.W., 2004. Stable-isotope probing of microorganisms thriving at thermodynamic limits: Syntrophic propionate oxidation in flooded soil. Applied and Environmental Microbiology 70, 5778-5786. doi:10.1128/AEM.70.10.5778-5786.2004

Luna-Guido, M.., Beltrán-Hernández, R.., Dendooven, L., 2001. Dynamics of 14 Clabelled glucose in alkaline saline soil. Soil Biology and Biochemistry 33, 707-719.

Lupwayi, N.Z., Larney, F.J., Blackshaw, R.E., Kanashiro, D.A., Pearson, D.C., 2017. Phospholipid fatty acid biomarkers show positive soil microbial community responses to conservation soil management of irrigated crop rotations. Soil and Tillage Research 168, 1-10. doi:10.1016/j.still.2016.12.003

Mack, M.C., Schuur, E.A.G., Bret-Harte, M.S., Shaver, G.R., Chapin, F.S., 2004. Ecosystem carbon storage in arctic tundra reduce by long-term nutrient fertilization. Nature 431, 440-443. doi:10.1038/nature02887

Makkonen, M., Berg, M.P., Handa, I.T., Hättenschwiler, S., van Ruijven, J., van Bodegom, P.M., Aerts, R., 2012. Highly consistent effects of plant litter identity and functional traits on decomposition across a latitudinal gradient. Ecology Letters 15, 103341. doi:10.1111/j.1461-0248.2012.01826.x

Manzoni, S., Čapek, P., Porada, P., Thurner, M., Winterdahl, M., Beer, C., Brüchert, V., Frouz, J., Herrmann, A.M., Lindahl, B.D., Lyon, S.W., Šantrůčková, H., Vico, G., Way, D., 2018. Reviews and syntheses: Carbon use efficiency from organisms to 
ecosystems \&amp;amp;ndash; Definitions, theories, and empirical evidence. Biogeosciences Discussions 32, 1-29. doi:10.5194/bg-2018-275

Manzoni, S., Taylor, P., Richter, A., Porporato, A., Ågren, G.I., 2012. Environmental and stoichiometric controls on microbial carbon-use efficiency in soils. New Phytologist 196, 79-91. doi:10.1111/j.1469-8137.2012.04225.x

Marinari, S., Masciandaro, G., Ceccanti, B., Grego, S., 2000. Influence of organic and mineral fertilisers on soil biological and physical properties. Bioresource Technology 72, 9-17. doi:10.1016/S0960-8524(99)00094-2

Martínez, A.T., Speranza, M., Ruiz-Dueñas, F.J., Ferreira, P., Camarero, S., Guillén, F., Martínez, M.J., Gutiérrez, A., del Río, J.C., 2005. Biodegradation of lignocellulosics: microbial, chemical, and enzymatic aspects of the fungal attack of lignin. International Microbiology: The Official Journal of the Spanish Society for Microbiology 8, 195-204.

Masella, A.P., Bartram, A.K., Truszkowski, J.M., et al., 2012. PANDAseq: pairedend assembler for illumina sequences. BMC Bioinformatics 13, 31. doi:10.1186/14712105-13-31

Mason-Jones, K., Schmücker, N., Kuzyakov, Y., 2018. Contrasting effects of organic and mineral nitrogen challenge the N-Mining Hypothesis for soil organic matter priming. Soil Biology and Biochemistry 124, 38-46. doi:10.1016/j.soilbio.2018.05.024

Mau, R.L., Dijkstra, P., Schwartz, E., Koch, B.J., Hungate, B.A., 2018. Warming induced changes in soil carbon and nitrogen influence priming responses in four ecosystems. Applied Soil Ecology 124, 110-116. doi:10.1016/j.apsoil.2017.10.034

Maynard, D.S., Crowther, T.W., Bradford, M.A., 2017. Fungal interactions reduce carbon use efficiency. Ecology Letters 20, 1034-1042. doi:10.1111/ele.12801

McDonald, D., Clemente, J.C., Kuczynski, J., et al., 2012. The Biological Observation Matrix (BIOM) format or: how I learned to stop worrying and love the omeome. GigaScience 1, 7. doi:10.1186/2047-217X-1-7

Megharaj, M., Ramakrishnan, B., Venkateswarlu, K., Sethunathan, N., Naidu, R., 2011. Bioremediation approaches for organic pollutants: A critical perspective. Environment International 37, 1362-1375. doi:10.1016/j.envint.2011.06.003

Mikutta, R., Kleber, M., Torn, M.S., Jahn, R., 2006. Stabilization of Soil Organic Matter: Association with Minerals or Chemical Recalcitrance? Biogeochemistry 77, 2556. doi:10.1007/s10533-005-0712-6 
Milcu, A., Manning, P., 2011. All size classes of soil fauna and litter quality control the acceleration of litter decay in its home environment. Oikos 120, 1366-1370. doi:10.1111/j.1600-0706.2010.19418.x

Milstein, O., Vered, Y., Shragina, L., Gressel, J., Flowers, H.M., Huttermann, A., 1983. Metabolism of lignin related aromatic compounds by Aspergillus japonicus. Archives of Microbiology 135, 147-154. doi:10.1007/BF00408025

Mondini, C., Cayuela, M.L., Sanchez-Monedero, M. a., Roig, A., Brookes, P.C., 2006. Soil microbial biomass activation by trace amounts of readily available substrate. Biology and Fertility of Soils 42, 542-549. doi:10.1007/s00374-005-0049-2

Montgomery, H.J., Monreal, C.M., Young, J.C., Seifert, K.A., 2000. Determination of Soil Fungal Biomass from Soil Ergosterol Analyses. Soil Biology and Biochemistry 32, 1207-1217.

Moorhead, D.L., Sinsabaugh, R.L., 2006. A theoretical model of litter decay and microbial interaction. Ecological Monographs 76, 151-174. doi:10.1890/00129615(2006)076[0151:ATMOLD]2.0.CO;2

Mooshammer, M., Wanek, W., Hämmerle, I., Fuchslueger, L., Hofhansl, F., Knoltsch, A., Schnecker, J., Takriti, M., Watzka, M., Wild, B., Keiblinger, K.M., Zechmeister-Boltenstern, S., Richter, A., 2014a. Adjustment of microbial nitrogen use efficiency to carbon:nitrogen imbalances regulates soil nitrogen cycling. Nature Communications 5, 3694. doi:10.1038/ncomms4694

Mooshammer, M., Wanek, W., Zechmeister-Boltenstern, S., Richter, A., 2014b. Stoichiometric imbalances between terrestrial decomposer communities and their resources: Mechanisms and implications of microbial adaptations to their resources. Frontiers in Microbiology 5, 1-10. doi:10.3389/fmicb.2014.00022

Morriën, E., Hannula, S.E., Snoek, L.B., et al., 2017. Soil networks become more connected and take up more carbon as nature restoration progresses. Nature Communications 8, 14349. doi:10.1038/ncomms 14349

Mouginot, C., Kawamura, R., Matulich, K.L., Berlemont, R., Allison, S.D., Amend, A.S., Martiny, A.C., 2014. Elemental stoichiometry of Fungi and Bacteria strains from grassland leaf litter. Soil Biology and Biochemistry 76, 278-285. doi:10.1016/j.soilbio.2014.05.011

Murphy, C.J., Baggs, E.M., Morley, N., Wall, D.P., Paterson, E., 2015. Rhizosphere priming can promote mobilisation of $\mathrm{N}$-rich compounds from soil organic matter. Soil Biology and Biochemistry 81, 236-243. doi:10.1016/j.soilbio.2014.11.027 
Muyzer G, De Waal E. C, Uitterlinden A. G., 1993. Profiling of complex microbial populations by denaturing gradient gel electrophoresis analysis of polymerase chain reaction-amplified genes coding for $16 \mathrm{~S}$ rRNA. Appl Environ Microbiol 59, 695-700.

Nadelhoffer, K.J., Emmett, B.A., Gundersen, P., Kjùnaas, O.J., Koopmans, C.J., Schleppi, P., Tietema, A., Wright, R.F., 1999. <398145a0.Pdf> 398, 1997-2000.

Neufeld, J.D., Dumont, M.G., Vohra, J., Murrell, J.C., 2007. Methodological considerations for the use of stable isotope probing in microbial ecology. Microbial Ecology 53, 435-42. doi:10.1007/s00248-006-9125-x

Nikolcheva, L.G., Bourque, T., Bärlocher, F., 2005. Fungal diversity during initial stages of leaf decomposition in a stream. Mycological Research 109, 246-253. doi:10.1017/S0953756204001698

Nottingham, A.T., Turner, B.L., Chamberlain, P.M., Stott, A.W., Tanner, E.V.J., 2012. Priming and microbial nutrient limitation in lowland tropical forest soils of contrasting fertility. Biogeochemistry 111, 219-237. doi:10.1007/s10533-011-9637-4

Padmanabhan, P., Padmanabhan, S., DeRito, C., Gray, A., Gannon, D., Snape, J.R., Tsai, C.S., Park, W., Jeon, C., Madsen, E.L., 2003. Respiration of 13C-Labeled Substrates Added to Soil in the Field and Subsequent 16S rRNA Gene Analysis of 13CLabeled Soil DNA. Applied and Environmental Microbiology 69, 1614-1622. doi:10.1128/AEM.69.3.1614-1622.2003

Pascault, N., Ranjard, L., Kaisermann, A., 2013. Stimulation of different functional groups of bacteria by various plant residues as a driver of soil priming effect. Ecosystems 16, 810-822. doi:10.1007/s10021-013-9650-7

Paterson, E., Thornton, B., Midwood, A.J., Osborne, S.M., Sim, A., Millard, P., 2008. Atmospheric CO2 enrichment and nutrient additions to planted soil increase mineralisation of soil organic matter, but do not alter microbial utilisation of plant- and soil C-sources. Soil Biology and Biochemistry 40, 2434-2440. doi:10.1016/j.soilbio.2008.06.005

Perelo, L.W., Munch, J.C., 2005. Microbial immobilisation and turnover of $13 \mathrm{C}$ labelled substrates in two arable soils under eld and laboratory conditions. Soil Biology and Biochemistry 37, 2263-2272. doi:10.1016/j.soilbio.2005.02.039

Perez, G., Aubert, M., Decaëns, T., Trap, J., Chauvat, M., 2013. Home-Field Advantage: A matter of interaction between litter biochemistry and decomposer biota. Soil Biology and Biochemistry 67, 245-254. doi:10.1016/j.soilbio.2013.09.004

Perveen, N., Barot, S., Alvarez, G., Klumpp, K., Martin, R., Rapaport, a, Herfurth, D., Louault, F., Fontaine, S., 2014. Priming effect and microbial diversity in ecosystem 
functioning and response to global change: a modeling approach using the SYMPHONY model. Global Change Biology 20, 1174-1190. doi:10.1111/gcb.12493

Postma-Blaauw, M.B., de Goede, R.G.M., Bloem, J., Faber, J.H., Brussaard, L., 2010. Soil biota community structure and abundance under agricultural intensification and extensification. Ecology 91, 460-473. doi:10.1890/09-0666.1

Pruesse, E., Peplies, J., Glockner, F.O., 2012. SINA: Accurate high-throughput multiple sequence alignment of ribosomal RNA genes. Bioinformatics 28, 1823-1829. doi:10.1093/bioinformatics/bts252

Qiao, N., Xu, X., Hu, Y., Blagodatskaya, E., Liu, Y., Schaefer, D., Kuzyakov, Y., 2016. Carbon and nitrogen additions induce distinct priming effects along an organicmatter decay continuum. Scientific Reports 6, 19865. doi:10.1038/srep19865

Quast, C., Pruesse, E., Yilmaz, P., Gerken, J., Schweer, T., Yarza, P., Peplies, J., Glöckner, F.O., 2013. The SILVA ribosomal RNA gene database project: improved data processing and web-based tools. Nucleic Acids Research 41, D590-6. doi:10.1093/nar/gks1219

Ramirez, K.S., Craine, J.M., Fierer, N., 2012. Consistent effects of nitrogen amendments on soil microbial communities and processes across biomes. Global Change Biology 18, 1918-1927. doi:10.1111/j.1365-2486.2012.02639.x

Razanamalala, K., Fanomezana, R.A., Razafimbelo, T., Chevallier, T., Trap, J., Blanchart, E., Bernard, L., 2018. The priming effect generated by stoichiometric decomposition and nutrient mining in cultivated tropical soils: Actors and drivers. Applied Soil Ecology 126, 21-33. doi:10.1016/j.apsoil.2018.02.008

Resh, S.C., Binkley, D., Parrotta, J.A., 2002. Greater soil carbon sequestration under nitrogen-fixing trees compared with Eucalyptus species. Ecosystems 5, 217-231. doi:10.1007/s10021-001-0067-3

Rousk, J., Bååth, E., 2007. Fungal and bacterial growth in soil with plant materials of different $\mathrm{C} / \mathrm{N}$ ratios. FEMS Microbiology Ecology 62, 258-67. doi:10.1111/j.15746941.2007.00398.x

Rousk, J., Bååth, E., Barreiro, A., Bååth, E., Díaz-Raviña, M., Rousk, J., Bååth, E., 2007. Fungal and bacterial growth in soil with plant materials of different $\mathrm{C} / \mathrm{N}$ ratios. FEMS Microbiology Ecology 62, 258-267. doi:10.1111/j.1574-6941.2007.00398.x

Rousk, K., Michelsen, A., Rousk, J., 2016. Microbial control of soil organic matter mineralization responses to labile carbon in subarctic climate change treatments. Global Change Biology 22, 4150-4161. doi:10.1111/gcb.13296 
Rudnick, M.B., van Veen, J.A., de Boer, W., 2015. Baiting of rhizosphere bacteria with hyphae of common soil fungi reveals a diverse group of potentially mycophagous secondary consumers. Soil Biology and Biochemistry 88, 73-82. doi:10.1016/j.soilbio.2015.04.015

Saar, S., Semchenko, M., Barel, J.M., De Deyn, G.B., 2016. Legume presence reduces the decomposition rate of non-legume roots. Soil Biology and Biochemistry 94, 88-93. doi:10.1016/j.soilbio.2015.11.026

Santamaria, F., Reyes, F., 1988. Proteases produced during autolysis of filamentous fungi. Transactions of the British Mycological Society 91, 217-220. doi:10.1016/S0007-1536(88)80207-9

Santelli, C.M., Orcutt, B.N., Banning, E., Bach, W., Moyer, C.L., Sogin, M.L., Staudigel, H., Edwards, K.J., 2008. Abundance and diversity of microbial life in ocean crust. Nature 453, 653-6. doi:10.1038/nature06899

Santruckova, H., Picek, T., Tykva, R., Šimek, M., Bohumil, P., 2004. Short-term partitioning of $14 \mathrm{C}-[\mathrm{U}]$-glucose in the soil microbial pool under varied aeration status. Biology and Fertility of Soils 40, 386-392. doi:10.1007/s00374-004-0790-y

Sauvadet, M., Lashermes, G., Alavoine, G., Recous, S., Chauvat, M., Maron, P.A., Bertrand, I., 2018. High carbon use efficiency and low priming effect promote soil $C$ stabilization under reduced tillage. Soil Biology and Biochemistry 123, 64-73. doi:10.1016/j.soilbio.2018.04.026

Sayer, E.J., Heard, M.S., Grant, H.K., Marthews, T.R., Tanner, E.V.J., 2011. Soil carbon release enhanced by increased tropical forest litterfall. Nature Climate Change 1 , 304-307. doi:10.1038/nclimate1190

Schimel, J., Weintraub, M.N., 2003. The implications of exoenzyme activity on microbial carbon and nitrogen limitation in soil: a theoretical model. Soil Biology and Biochemistry 35, 549-563. doi:10.1016/S0038-0717(03)00015-4

Schimel, J.P., Schaeffer, S.M., 2012. Microbial control over carbon cycling in soil. Frontiers in Microbiology 3, 348. doi:10.3389/fmicb.2012.00348

Schlesinger, W.H., 1997. An analysis of global change, 3rd ed. Academic Press.

Schmidt, M.W.I., Torn, M.S., Abiven, S., Dittmar, T., Guggenberger, G., Janssens, I. a., Kleber, M., Kögel-Knabner, I., Lehmann, J., Manning, D. a. C., Nannipieri, P., Rasse, D.P., Weiner, S., Trumbore, S.E., 2011. Persistence of soil organic matter as an ecosystem property. Nature 478, 49-56. doi:10.1038/nature10386

Shahbaz, M., Kumar, A., Kuzyakov, Y., Börjesson, G., Blagodatskaya, E., 2018. Interactive priming effect of labile carbon and crop residues on SOM depends on residue 
decomposition stage: Three-source partitioning to evaluate mechanisms. Soil Biology and Biochemistry. doi:10.1016/j.soilbio.2018.08.023

Shahzad, T., Chenu, C., Genet, P., Barot, S., Perveen, N., Mougin, C., Fontaine, S., 2014. Contribution of exudates, arbuscular mycorrhizal fungi and litter depositions to the rhizosphere priming effect induced by grassland species. Soil Biology and Biochemistry 80, 146-155. doi:10.1016/j.soilbio.2014.09.023

Shen, J., Bartha, R., 1997. Priming effect of glucose polymers in soil-based biodegradation tests. Soil Biology and Biochemistry 29, 1195-1198. doi:10.1016/S00380717(97)00031-X

Simpson, A.J., Simpson, M.J., Smith, E., Kelleher, B.P., 2007. Microbially Derived Inputs to Soil Organic Matter: Are Current Estimates Too Low? Environmental Science \& Technology 41, 8070-8076. doi:10.1021/es071217x

Sinsabaugh, R.L., Gallo, M.E., Lauber, C., Waldrop, M.P., Zak, D.R., 2005. Extracellular Enzyme Activities and Soil Organic Matter Dynamics for Northern Hardwood Forests receiving Simulated Nitrogen Deposition. Biogeochemistry 75, 201-215. doi:10.1007/s10533-004-7112-1

Sinsabaugh, R.L., Manzoni, S., Moorhead, D.L., Richter, A., 2013. Carbon use efficiency of microbial communities: stoichiometry, methodology and modelling. Ecology Letters 16, 930-939. doi:10.1111/ele.12113

Smilauer, P., Lepš, J., 2014. Multivariate Analysis of Ecological Data using CANOCO 5, Multivariate Analysis of Ecological Data Using CANOCO 5. Cambridge University Press, Cambridge. doi:10.1017/CBO9781139627061

Song, Z., Vail, A., Sadowsky, M.J., Schilling, J.S., 2012. Competition between two wood-degrading fungi with distinct influences on residues. FEMS Microbiology Ecology 79, 109-117. doi:10.1111/j.1574-6941.2011.01201.x

Steffen, W., Richardson, K., Rockstrom, J., Cornell, S.E., Fetzer, I., Bennett, E.M., Biggs, R., Carpenter, S.R., de Vries, W., de Wit, C.A., Folke, C., Gerten, D., Heinke, J., Mace, G.M., Persson, L.M., Ramanathan, V., Reyers, B., Sorlin, S., 2015. Planetary boundaries: Guiding human development on a changing planet. Science 347, 12598551259855. doi:10.1126/science.1259855

Sterner, R.W., Elser, J.J., 2002. Ecological stoichiometry : the biology of elements from molecules to the biosphere. Princeton University Press.

Strickland, M.S., Wickings, K., Bradford, M.A., 2012. The fate of glucose, a low molecular weight compound of root exudates, in the belowground foodweb of forests and pastures. Soil Biology and Biochemistry 49, 23-29. doi:10.1016/j.soilbio.2012.02.001 
Subke, J.-A., Hahn, V., Battipaglia, G., Linder, S., Buchmann, N., Cotrufo, M.F., 2004. Feedback interactions between needle litter decomposition and rhizosphere activity. Oecologia 139, 551-9. doi:10.1007/s00442-004-1540-4

Sullivan, B.W., Hart, S.C., 2013. Evaluation of mechanisms controlling the priming of soil carbon along a substrate age gradient. Soil Biology and Biochemistry 58, 293-301. doi:10.1016/j.soilbio.2012.12.007

Swift, M.J. (Michael J., Heal, O.W., Anderson, J.M. (Jonathan M., 1979. Decomposition in terrestrial ecosystems. University of California Press.

Talhelm, A.F., Pregitzer, K.S., Zak, D.R., 2009. Species-specific responses to atmospheric carbon dioxide and tropospheric ozone mediate changes in soil carbon. Ecology Letters 12, 1219-1228. doi:10.1111/j.1461-0248.2009.01380.x

Terrer, C., Vicca, S., Hungate, B.A., Phillips, R.P., Prentice, I.C., 2016. Mycorrhizal association as a primary control of the CO2 fertilization effect. Science 353, 72-74. doi:10.1126/science.aaf4610

Tian, Q., Yang, X., Wang, X., Liao, C., Li, Q., Wang, M., Wu, Y., Liu, F., 2016. Microbial community mediated response of organic carbon mineralization to labile carbon and nitrogen addition in topsoil and subsoil. Biogeochemistry 128, 125-139. doi:10.1007/s10533-016-0198-4

Tiunov, A. V., Scheu, S., 2005. Facilitative interactions rather than resource partitioning drive diversity-functioning relationships in laboratory fungal communities. Ecology Letters 8, 618-625. doi:10.1111/j.1461-0248.2005.00757.x

Ushio, M., Wagai, R., Balser, T.C., Kitayama, K., 2008. Variations in the soil microbial community composition of a tropical montane forest ecosystem: Does tree species matter? Soil Biology and Biochemistry 40, 2699-2702. doi:10.1016/j.soilbio.2008.06.023

Uyttebroek, M., Ortega-Calvo, J.-J., Breugelmans, P., Springael, D., 2006. Comparison of mineralization of solid-sorbed phenanthrene by polycyclic aromatic hydrocarbon (PAH)-degrading Mycobacterium spp. and Sphingomonas spp. Applied Microbiology and Biotechnology 72, 829-836. doi:10.1007/s00253-006-0337-2

Vainio, E.J., Hantula, J., 2000. Direct analysis of wood-inhabiting fungi using denaturing gradient gel electrophoresis of amplified ribosomal DNA. Mycological Research 104, 927-936. doi:10.1017/S0953756200002471

van Der Heijden, M.G.A., Bardgett, R.D., van Straalen, N.M., 2008. The unseen majority: Soil microbes as drivers of plant diversity and productivity in terrestrial ecosystems. Ecology Letters 11, 296-310. doi:10.1111/j.1461-0248.2007.01139.x 
van der Putten, W.H., 2012. Climate Change, Aboveground-Belowground Interactions, and Species' Range Shifts. Annual Review of Ecology, Evolution, and Systematics 43, 365-383. doi:10.1146/annurev-ecolsys-110411-160423

van der Wal, A., de Boer, W., 2017. Dinner in the dark: Illuminating drivers of soil organic matter decomposition. Soil Biology and Biochemistry 105, 45-48. doi:10.1016/j.soilbio.2016.11.006

van der Wal, A., de Boer, W., Smant, W., van Veen, J. a., 2007. Initial decay of woody fragments in soil is influenced by size, vertical position, nitrogen availability and soil origin. Plant and Soil 301, 189-201. doi:10.1007/s11104-007-9437-8

van der Wal, A., Geydan, T.D., Kuyper, T.W., de Boer, W., 2013. A thready affair: linking fungal diversity and community dynamics to terrestrial decomposition processes. FEMS Microbiology Reviews 37, 477-494. doi:10.1111/1574-6976.12001

van der Wal, A., Ottosson, E., de Boer, W., 2015. Neglected role of fungal community composition in explaining variation in wood decay rates. Ecology 96, 124-133. doi:10.1890/14-0242.1

van der Wal, A., van Veen, J. a., Smant, W., Boschker, H.T.S., Bloem, J., Kardol, P., van der Putten, W.H., de Boer, W., 2006. Fungal biomass development in a chronosequence of land abandonment. Soil Biology and Biochemistry 38, 51-60. doi:10.1016/j.soilbio.2005.04.017

van Gestel, N., Shi, Z., van Groenigen, K.J., Osenberg, C.W., Andresen, L.C., Dukes, J.S., Hovenden, M.J., Luo, Y., Michelsen, A., Pendall, E., Reich, P.B., Schuur, E.A.G., Hungate, B.A., 2018. Predicting soil carbon loss with warming. Nature 554, E4E5. doi:10.1038/nature25745

Veen, G.F.C., Freschet, G.T., Ordonez, A., Wardle, D.A., 2015. Litter quality and environmental controls of home-field advantage effects on litter decomposition. Oikos 124, 187-195. doi:10.1111/oik.01374

Veen, G.F.C., Keiser, A.D., van der Putten, W.H., Wardle, D.A., 2018. Variation in home-field advantage and ability in leaf litter decomposition across successional gradients. Functional Ecology 32, 1563-1574. doi:10.1111/1365-2435.13107

Veen, G.F.C., Sundqvist, M.K., Wardle, D.A., 2015. Environmental factors and traits that drive plant litter decomposition do not determine home-field advantage effects. Functional Ecology 29, 981-991. doi:10.1111/1365-2435.12421

Verhagen, F.J.M., Hageman, P.E.J., Woldendorp, J.W., Laanbroek, H.J., 1994. Competition for ammonium between nitrifying bacteria and plant roots in soil in pots; effects of grazing by flagellates and fertilization. Soil Biology and Biochemistry 26, 89-96. doi:10.1016/0038-0717(94)90199-6 
Vinale, F., Sivasithamparam, K., Ghisalberti, E.L., Marra, R., Woo, S.L., Lorito, M., 2008. Trichoderma-plant-pathogen interactions. Soil Biology and Biochemistry 40, 1-10. doi:10.1016/j.soilbio.2007.07.002

Vos, M., Quince, C., Pijl, A.S., et al., 2012. A Comparison of rpoB and 16S rRNA as Markers in Pyrosequencing Studies of Bacterial Diversity. PLoS ONE 7, e30600. doi:10.1371/journal.pone.0030600

Waldrop, M.P., Zak, D.R., Sinsabaugh, R.L., 2004. Microbial community response to nitrogen deposition in northern forest ecosystems. Soil Biology and Biochemistry 36, 1443-1451. doi:10.1016/j.soilbio.2004.04.023

Wallenstein, M.D., Haddix, M.L., Ayres, E., Steltzer, H., Magrini-Bair, K.A., Paul, E.A., 2013. Litter chemistry changes more rapidly when decomposed at home but converges during decomposition-transformation. Soil Biology and Biochemistry 57, 311319. doi:10.1016/j.soilbio.2012.09.027

Wang, H., Boutton, T.W., Xu, W., Hu, G., Jiang, P., Bai, E., 2015. Quality of fresh organic matter affects priming of soil organic matter and substrate utilization patterns of microbes. Scientific Reports 5, 10102. doi:10.1038/srep10102

Wardle, D. A., Bardgett, R.D., Klironomos, J.N., Setälä, H., van der Putten, W.H., Wall, D.H., 2004. Ecological linkages between aboveground and belowground biota. Science (New York, N.Y.) 304, 1629-33. doi:10.1126/science.1094875

Whitaker, J., Ostle, N., McNamara, N.P., Nottingham, A.T., Stott, A.W., Bardgett, R.D., Salinas, N., Ccahuana, A.J.Q., Meir, P., 2014. Microbial carbon mineralization in tropical lowland and montane forest soils of Peru. Frontiers in Microbiology 5, 1-13. doi:10.3389/fmicb.2014.00720

White, T.J., Bruns, S., Lee, S., Taylor, J., 1990. Amplification and direct sequencing of fungal ribosomal RNA genes for phylogenetics. PCR Protocols: A Guide to Methods and Applications. doi:citeulike-article-id:671166

Wicklow, D., 2006. The Fungal Community. Its Organization and Role in the Ecosystem. 3rd Edition Edited by John Dighton, James F. White, and Peter Oudemans (Rutgers University). Taylor \&amp; Francis Group, CRC Press, Boca Raton, FL. 2005. xx + 936 pp. $18.5 \times 26$ cm. \$139.95. Journal of Natural Products, Mycology 69, 859-859. doi:10.1021/np0682244

Wieder, W.R., Bonan, G.B., Allison, S.D., 2013. Global soil carbon projections are improved by modelling microbial processes. Nature Climate Change 3, 909-912. doi:10.1038/nclimate1951

Wild, B., Alaei, S., Bengtson, P., Bodé, S., Boeckx, P., Schnecker, J., Mayerhofer, W., Rütting, T., 2017. Short-term carbon input increases microbial nitrogen demand, but 
not microbial nitrogen mining, in a set of boreal forest soils. Biogeochemistry 136, $261-$ 278. doi:10.1007/s10533-017-0391-0

Wild, B., Schnecker, J., Alves, R.J.E., Barsukov, P., Bárta, J., Čapek, P., Gentsch, N., Gittel, A., Guggenberger, G., Lashchinskiy, N., Mikutta, R., Rusalimova, O., Šantrůčková, H., Shibistova, O., Urich, T., Watzka, M., Zrazhevskaya, G., Richter, A., 2014. Input of easily available organic $C$ and $N$ stimulates microbial decomposition of soil organic matter in arctic permafrost soil. Soil Biology and Biochemistry 75, 143-151. doi:10.1016/j.soilbio.2014.04.014

Willis, A., Rodrigues, B.F., Harris, P.J.C., 2013. The Ecology of Arbuscular Mycorrhizal Fungi. Critical Reviews in Plant Sciences 32, 1-20. doi:10.1080/07352689.2012.683375

Wilson, G.W.T., Rice, C.W., Rillig, M.C., Springer, A., Hartnett, D.C., 2009. Soil aggregation and carbon sequestration are tightly correlated with the abundance of arbuscular mycorrhizal fungi: results from long-term field experiments. Ecology Letters 12, 452-461. doi:10.1111/j.1461-0248.2009.01303.x

Wu, J., Brookes, P.C., Jenkinson, D.S., 1993. Formation and destruction of microbial biomass during the decomposition of glucose and ryegrass in soil. Soil Biology and Biochemistry 25, 1435-1441. doi:10.1016/0038-0717(93)90058-J

Xiao, C., Guenet, B., Zhou, Y., Su, J., Janssens, I. a., 2015. Priming of soil organic matter decomposition scales linearly with microbial biomass response to litter input in steppe vegetation. Oikos 124, 649-657. doi:10.1111/oik.01728

Youssef, N.H., Elshahed, M.S., 2009. Diversity rankings among bacterial lineages in soil. The ISME Journal 3, 305-313. doi:10.1038/ismej.2008.106

Yu, Z., Huang, Z., Wang, M., Liu, R., Zheng, L., Wan, X., Hu, Z., Davis, M.R., Lin, T.C., 2015. Nitrogen addition enhances home-field advantage during litter decomposition in subtropical forest plantations. Soil Biology and Biochemistry 90, 188-196. doi:10.1016/j.soilbio.2015.07.026

Zhu, B., Gutknecht, J.L.M., Herman, D.J., Keck, D.C., Firestone, M.K., Cheng, W., 2014. Rhizosphere priming effects on soil carbon and nitrogen mineralization. Soil Biology and Biochemistry 76, 183-192. doi:10.1016/j.soilbio.2014.04.033 


\section{Summary}

Priming effects (PEs) are defined as short-term changes in the turnover of soil organic matter (SOM) caused by the addition of easily degradable organic carbon. PEs can be positive (acceleration of SOM decomposition) but also negative (retardation of SOM decomposition). Furthermore, PEs can be classified as real or apparent, and the distinction is based on the origin of the extra $\mathrm{CO}_{2}$ released from the soil. In apparent PEs the increased $\mathrm{CO}_{2}$ originates from the turnover of microbial compounds such as reserve materials, whereas in real PEs it is due to the decomposition of SOM. The direction (acceleration or retardation of SOM decomposition) and magnitude of priming in response to organic carbon additions are not easy to predict. Several environmental factors are involved, such as the amount and quality of added substrates, the inorganic nutrient availability, soil microbial biomass and soil microbial community composition. Although PEs are recognized to be large enough to be taken into account into the ecosystem carbon balance, the exact mechanisms are still unknown. The main aim of this thesis was to increase the understanding of the mechanisms involved in soil priming effects.

The effects of two characteristics of added compounds on PEs were examined in chapter 2, namely the metabolic usable energy for microbes and the resemblance to recalcitrant fractions of SOM. For this purpose, glucose, cellobiose (energy rich compounds, low resemblance with recalcitrant SOM) and vanillic acid (energy-poor compound, higher resemblance with recalcitrant $\mathrm{SOM}$ ) were selected. In addition, the effect of mineral nitrogen $(\mathrm{N})$ on PEs was tested. ${ }^{13} \mathrm{C}$ labelled compounds were mixed with sandy soil from an ex-arable site. To separate the effect of energy content from that of chemical composition, the amount of carbon and the amount of energy content of added compounds was kept constant in treatments, respectively. When corrected for energy content, vanillic acid induced the highest $\mathrm{CO}_{2}$ respiration and PEs. The analysis of the microbial community revealed that the contribution of fungi to PEs was minor, reflecting the low $\mathrm{F}: \mathrm{B}$ ratio of the ex-arable soil. Although different substrates resulted in different PEs, they stimulated the growth of similar bacterial groups. This suggests that the added compounds induced different enzyme systems within similar bacterial taxa. Finally, combined addition of mineral nitrogen and organic C-compounds caused a slightly extra increase in PEs in most treatments. Overall these results indicate that the effect of chemical structure of added compounds on PEs is much larger than the effect of energycontent.

Chapter 3 describes another approach to study the role of physicochemical similarity between added organic compounds to SOM fractions in PEs. More specifically, the relationship between home-field advantage of litter decomposition (acceleration of plant litter decomposition in soils that receive their indigenous litter) and PEs was investigated. 
To study this, three ${ }^{13} \mathrm{C}$ labelled litter types (maize, bent and beech) were reciprocally incubated in soils from ecosystems where these litters are abundantly produced (e.g., arable sites, grasslands and forests), with and without the addition of mineral N. Generally, respiration of both litter-derived and SOM-derived $\mathrm{C}$ were lowest when beech litter was added and were lower in forest soils than in arable or grassland soils. Nitrogen addition slightly increased the respiration of litter-derived $\mathrm{C}$, but had no effect on SOM-derived C. All litter types induced a positive PE in all soils. A positive relationship between litter and priming HFA was found, indicating that the rates of both litter decomposition and PE may be affected in the same manner by home combinations of plant and litter versus away combinations. This positive relationship disappeared when $\mathrm{N}$ was added. These results provide a first indication that the extent to which indigenous soil microbes are specialized to breakdown home litter, not only accelerates or decelerates the decomposition of litter, but also affects the breakdown of SOM in the same way.

Chapter 4 deals with another factor influencing PEs, namely the ratio between the amount of added labile organic compounds to the size of initial soil microbial biomass. To test this, three different amounts of ${ }^{13} \mathrm{C}$-glucose with or without addition of mineral $\mathrm{N}$ were added to soils collected from arable lands, grasslands and forests that differ in terms of amount of soil microbial biomass, soil microbial community composition and soil organic matter quality. The addition of ${ }^{13} \mathrm{C}$-glucose was equivalent to $15 \%, 50 \%$ and $200 \%$ of microbial biomass $\mathrm{C}$. After one month of incubation, glucose had induced positive PEs for the majority of soils, with differences in magnitude related to the soil origin and the amount of glucose added. For arable and forest soils, the primed $\mathrm{C}$ increased with increasing amount of glucose added, whereas for grassland soils this relationship was negative. We found positive correlations between glucose-derived $\mathrm{C}$ and primed $\mathrm{C}$ and the strength of these correlations was different among the three ecosystems considered. Generally, the addition of $\mathrm{N}$ to our soil mesocosms had little effect on the flux of substrate-derived $\mathrm{C}$ and primed C. Overall, this research study does not support the hypothesis that the triggersubstrate to microbial biomass ratio can be an important predictor of PEs. Rather the results indicate that the degree of microbial activity induced by the trigger substrate (glucose-derived C) is an important factor for the magnitude of PEs.

Chapter 5 reports on the influence of different concentrations of mineral $\mathrm{N}$ on the growth efficiency of two common soil fungi, Trichoderma harzanium and Mucor hiemalis in a soillike environment. The contribution of fungi to $\mathrm{C}$ and $\mathrm{N}$ cycling is related to their growth efficiency. Growth efficiency is defined as the amount of biomass produced per unit of substrate utilized. Several environmental factors, such as the concentration and availability of $\mathrm{N}$, influence the activity and growth efficiency of saprotrophic fungi. Hence to test the role of $\mathrm{N}$, we measured fungal biomass production as well as the respiration fluxes in sand microcosms amended with cellobiose and mineral $\mathrm{N}$ at different $\mathrm{C}: \mathrm{N}$ ratios. For both fungal species, lower $\mathrm{C}: \mathrm{N}$ ratios resulted in the highest biomass production as 
well as the highest growth efficiency. This may imply that when $\mathrm{N}$ is applied concurrently with a degradable $\mathrm{C}$ source, a higher amount of $\mathrm{N}$ will be temporarily immobilized into fungal biomass. Therefore, these results might suggest that the $\mathrm{C}$ and $\mathrm{N}$ contents of fertilizers applied to agricultural soils can be adapted in such a way that fungal biomass response is optimal, thereby reducing $\mathrm{N}$ losses.

Taken together, the results of this thesis gave new insights into different aspects of soil priming effects. I integrated this in a conceptual model on PEs, mainly indicating that 1) increasing the resemblance of the chemical structure of the added substrates to SOM fractions and 2) providing conditions for the optimal use of energy of the added substrates by soil microorganisms will stimulate the growth and activity of SOM degrading microbes, resulting in positive priming effects. Moreover, simultaneous addition of mineral $\mathrm{N}$ with organic $C$ had generally little or no impact on PEs. Soil priming effects in the context of global change and future research directions are discussed in chapter 6 . 


\section{Acknowledgements}

As many said before me, a PhD is not only the highest level of education someone can get, but it is an intense, challenging and exciting life journey. The many people I encountered in the past years made this journey funnier, safer and a wonderful experience. All of you supported me during the toughest moments and helped me looking always at the bright side, encouraging me to not give up.

Wietse, Annemieke, Julie, Marta, Antonella, Kim, Cam, Thijs, Antica, Natalia, Amaya, Daniela, Panam, Sander, Mia, Jelke, Jeroen, Cata, Marcela, Peter, Jeroen vL, Annelien, Kadri, Ruth S., Marta A., Maaike vA, Sarash, Adrian, Tianqi, Anna Maria, Flavia, Veronica, Oriana, Annelies, Thomas, de Zaaier, Alexandra, Leonardo, Bart, Carlos, Caro, Helen, Julia, Chunxu, Viviane, Ruth G., Yiying, Victor, Davide, Dedmer, Marika, Alena, Karen, Tania, Eke, Elisabet, Mandy, Sven, Gabriele, Simona, Elisabetta, Emilia, Jan Geert, Jonas, Janna, Claudius, Lennart, Mark, Natalie, Maria P., Joost, Lukas, Ina, Kelly, Lucia, Santos, Lucille, Rutger, Sigrid, Maaike dJ, Agaat, Steven, Jing, Gustavo, Luuk, Bart G., Michiel, Vero, Peiyu, Libin, Wei, Laura, Jan, Annette, Jos, Paul, Paolina, Mattias, Eiko, Hans, Juan, Irene, Lara, Desalegn, Ben, Afnan, Késia, Thiago, Ohana, Manoeli, Anna, Je Seung, Sytske, Kay, Adam, Femke, Iris, Maria, Saskia, Ciska R., Roos, Paulien, Marion, Paula, Nurmi, Ciska V., Koen, Gerard, Elly M., Robin, Tanja, Elly N., Ninke, Gerry, Gerda, Dick, Ed, Els, Lisbeth, Froukje, Nico, Nori, Olaf, Sang Yoon, Sam, Stijn, Yu, Yuan, Peter vE, Lisa, Marieke, Aad, Thomas TU, Sam S., Mila, David, Herman, Maria Chiara, Andrea, Lucia, Mamma, Papà and Sui.

To all of you from the bottom of my heart

Thank you! Dank je wel! Merci! Gracias! Obrigado! Aitäh! Danke! Kiitos! Grazie! 谢谢 !

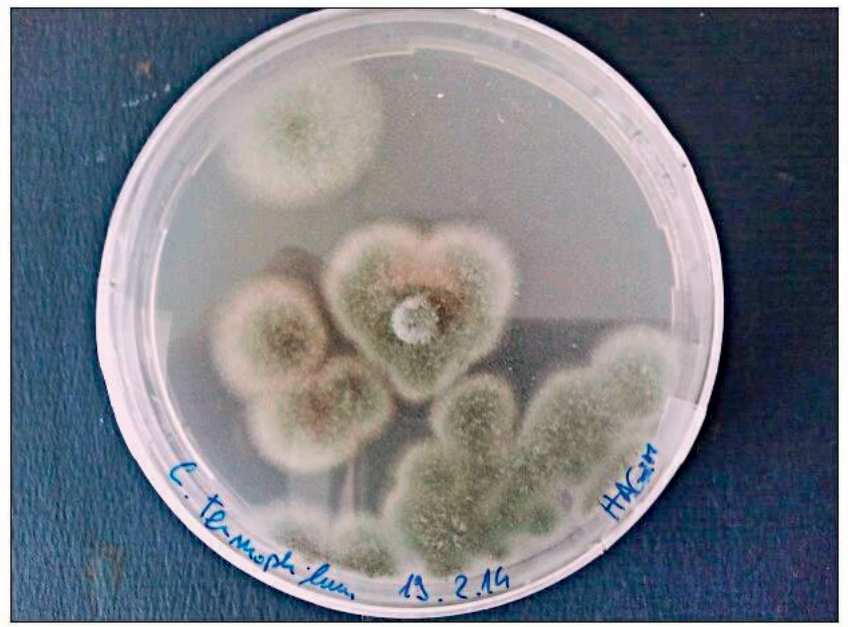




\section{About the author}

Domenico Paolo Di Lonardo was born in Rome on November $9^{\text {th }}, 1984$. He grew up in Frosinone, a small city in the central part of Italy. Fascinated by the natural world, after graduating from Liceo Scientifico F. Severi in 2003, he moved to Rome to study environmental sciences. He specialized in biological monitoring and for both his BSc and MSc theses he worked on the ecology of soil saprotrophic fungi. In 2009 he obtained a master's

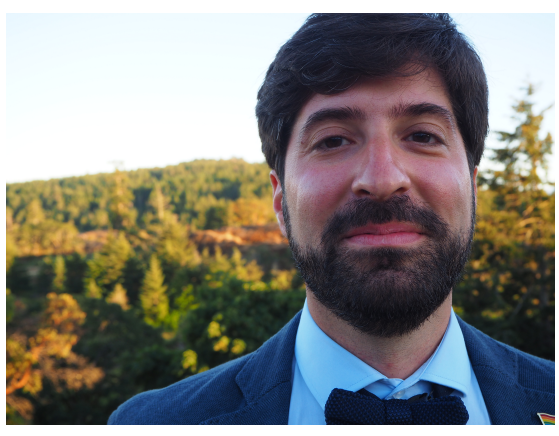
degree cum laude at Sapienza University of Rome in Environmental Monitoring and Recovery. Early 2010 he moved to Trento, in the heart of the Italian Alps, where he worked for more than two years for the Environmental Protection Agency (APPA). He was involved in projects related the ecological monitoring of freshwater ecosystem quality. After the experience in Trento he decided to move abroad and in 2012 he got the opportunity to work as a junior researcher at the University of Copenhagen for six months. There he worked on the effect of nitrogen depositions on soil fungal community and on soil organic matter turnover. The great experience in Denmark prompted him to pursue a PhD and that's what led him to Wageningen. At the beginning of 2013 he started a PhD on soil microbial ecology and carbon dynamics at the Netherlands Institute of Ecology (NIOOKNAW) under the supervision of Wietse de Boer and Annemieke van der Wal. Results of the $\mathrm{PhD}$ research project are presented in this thesis. Since September 2017 Paolo works in Wageningen as a researcher at AgroCares, investigating the possible link between soil spectroscopy data and the status and functions of the soil microbial community in agricultural soils. Besides his work, Paolo is an enthusiastic scuba diver. Moreover, he likes to hike and travel around the world. Meeting new people, trying different kind of cuisines and experiencing local life exert great fascination on him. 


\section{Peer reviewed publications}

Di Lonardo DP, Manrubia M, de Boer W, Zweers H, Veen GF, van der Wal A (2018) Relationship between home-field advantage of litter decomposition and priming of soil organic matter. Soil Biology and Biochemistry 126: 49-56. doi: 10.1016/j.soilbio.2018.07.025

Pinzari F, Maggi O, Lunghini D, Di Lonardo DP, Persiani AM (2017) - A simple method for measuring fungal metabolic quotient and comparing carbon use efficiency of different isolates: application to Mediterranean leaf litter fungi. Plant Biosystems 151(2): 371-376. doi: 10.1080/11263504.2017.1284166

Ho A, Di Lonardo DP, Bodelier PLE (2017) - Revisiting life strategy concepts in environmental microbial ecology. FEMS Microbiology Ecology 93 (3). doi: 10.1093/femsec/fix00

Di Lonardo DP, de Boer W, Klein Gunnewiek PJA, Hannula SE, van der Wal A (2017) - Priming of soil organic matter: chemical structure of added compounds is more important than the energy content. Soil Biology and Biochemistry 108: 47-54.

Lunghini D, Granito VM, Di Lonardo DP, Maggi O, Persiani AM (2013) - Fungal diversity of saprotrophic litter fungi in a Mediterranean maquis environment. Mycologia 105: 1499-1515.

Di Lonardo DP, Pinzari F, Lunghini D, Maggi O, Granito VM, Persiani AM (2013) - Metabolic profiling reveals a functional succession of active fungi during the decay of Mediterranean plant litter. Soil Biology and Biochemistry 60: 210-219.

\section{Submitted for publication}

Di Lonardo DP, van der Wal A, Harkes P, de Boer W - Effect of nitrogen on fungal growth efficiency. In revision.

Di Lonardo DP, de Boer W, Zweers H, van der Wal A - Effect of the amount of organic trigger compounds, nitrogen and soil microbial biomass on the magnitude of priming of soil organic matter. In revision. 


\section{PE\&RC Training and Education Statement}

With the training and education activities listed below the PhD candidate has complied with the requirements set by the C.T. de Wit Graduate School for Production Ecology and Resource Conservation (PE\&RC) which comprises of a minimum total of 32 ECTS (= 22 weeks of activities)

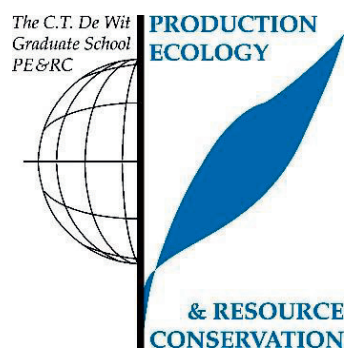

\section{Review of literature (4.5 ECTS)}

- Fungal life strategies and mechanisms of priming effects

\section{Writing of project proposal (4.5 ECTS)}

- The role of fungal ecology in the priming effects of soil organic matter

\section{Post-graduate courses (5 ECTS)}

- New Frontiers in Microbial Ecology; PE\&RC (2013)

- Multivariate Analysis; PE\&RC (2015)

- Soil ecology and \& the Planetary Boundaries; PE\&RC (2016)

Invited review of (unpublished) journal manuscript (3 ECTS)

- FEMS Microbiology Letters: soil microbial ecology (2014)

- Frontiers in Microbiology: soil microbial ecology (2014)

- European Journal of Soil Biology: soil microbial ecology (2015)

Deficiency, refresh, brush-up courses (1.5 ECTS)

- Basic statistics; PE\&RC (2013)

\section{Competence strengthening / skills courses (1.9 ECTS)}

- WGS PhD Workshop carousel; WGS (2016)

- Career perspectives; WGS (2016)

PE\&RC Annual meetings, seminars and the PE\&RC weekend (2.7 ECTS)

- PE\&RC First year weekend (2013)

- PE\&RC Day $(2013,2014,2015,2016)$

- PE\&RC Last year weekend (2016)

Discussion groups / local seminars / other scientific meetings (9.9 ECTS)

- $\quad$ NIOO Science days $(2013,2015)$

- NIOO-ME literature discussion meeting (2014-2016)

- NIOO-ME PhD discussion group (2014-2016) 
International symposia, workshops and conferences (7.5 ECTS)

- Workshop: priming of soil organic matter carbon; poster presentation; Copenhagen, Denmark (2013)

- The $10^{\text {th }}$ international mycological congress; poster presentation; Bangkok, Thailand (2014)

- Vegetation-soil interactions: from rhizosphere to ecosystem (2014)

- Environmental metagenomics symposium (2014)

- CSE Annual science meeting: managing soil life (2015)

- $5^{\text {th }}$ International symposium on soil organic matter; oral presentation; Göttingen, Germany) (2015)

\section{Lecturing / Supervision of practicals / tutorials (7 ECTS)}

- Practical student course EABI; WUR (2014)

- Internship student (HBO) (2015) 


\section{Colophon}

The research presented in this thesis was conducted at the Department of Microbial Ecology of the Netherlands Institute of Ecology (NIOO-KNAW) in Wageningen. The research described in this thesis was financially supported by a grant of the KNAW for establishing the Center for Soil Ecology (https://www.soilecology.eu/).

This is NIOO thesis 168

Layout: Paolo Di Lonardo

Cover and cover design: Paolo Di Lonardo and Dennis Hendriks (Proefschriftmaken)

Printed by: Digiforce | Proefschriftmaken.nl 